\title{
Leitlinie der Deutschen Gesellschaft für Pneumologie zur Diagnostik und Therapie von Patienten mit akutem und chronischem Husten
}

\section{Guideline of the German Respiratory Society for Diagnosis and Treatment of Patients Suffering from Acute or Chronic Cough}

\begin{tabular}{|c|c|}
\hline Inhalt & Seite \\
\hline 1 Struktur der Leitlinie & 571 \\
\hline Präambel & 571 \\
\hline 1.1 Schema der Leitlinienentwicklung & 571 \\
\hline 1.2 Klinische Evidenz der Leitlinie & 572 \\
\hline 1.3 Klinische Algorithmen & 572 \\
\hline 1.4 Teilnahme von Industrievertretern & 573 \\
\hline 1.5 Veröffentlichung, Verbreitung und Aktualisierung der Leitlinie & 573 \\
\hline 1.6 Sponsoring & 573 \\
\hline 2 Epidemiologie & 573 \\
\hline 3 Anmerkungen zur Physiologie des Hustens & 573 \\
\hline 3.1 Der Hustenreflex & 573 \\
\hline 3.2 Husten und Bronchospasmus & 574 \\
\hline 3.3 Produktiver und nicht-produktiver Husten & 574 \\
\hline 3.4 Eigenschaften des Auswurfs & 574 \\
\hline 4 Ursachen und Klassifizierung des Hustens & 575 \\
\hline 5 Akuter Husten: die wichtigsten Krankheitsbilder & 576 \\
\hline 5.1 Infektiöse Erkrankungen der oberen Atemwege & 576 \\
\hline 5.2 Allergische Erkrankungen der oberen Atemwege & 576 \\
\hline 5.3 Asthma & 576 \\
\hline
\end{tabular}

\begin{tabular}{|c|c|c|}
\hline \multicolumn{2}{|c|}{ Inhalt } & \multirow{2}{*}{$\begin{array}{c}\text { Seite } \\
576\end{array}$} \\
\hline 5.4 & Aspiration & \\
\hline 5.5 & $\begin{array}{l}\text { Akute inhalative Intoxikationen (Unfälle am Arbeitsplatz, } \\
\text { Rauchgasvergiftungen) }\end{array}$ & 576 \\
\hline 5.6 & Postinfektiöser Husten & 576 \\
\hline 5.7 & Pneumonie & 577 \\
\hline & Pleuritis & 577 \\
\hline & Lungenembolie & 577 \\
\hline 5.10 & Pneumothorax & 577 \\
\hline 5.11 & Akute Linksherzinsuffizienz & 577 \\
\hline 5.12 & AV Block II. und III. Grades & 577 \\
\hline $6 \mathrm{Ch}$ & Ironischer Husten: die wichtigsten Krankheitsbilder & 577 \\
\hline 6.1 & Asthma & 577 \\
\hline 6.2 & COPD & 577 \\
\hline 6.3 & Bronchialtumoren & 578 \\
\hline 6.4 & Aspiration & 578 \\
\hline 6.5 & $\begin{array}{l}\text { Diffuse Lungenparenchymerkrankungen - Systemerkrankungen } \\
\text { mit Lungenbeteiligung }\end{array}$ & 579 \\
\hline 6.6 & Seltene isolierte Erkrankungen des Tracheobronchialsystems & 579 \\
\hline 6.6. & 1 Tracheo-Bronchomegalie (M. Mounier-Kuhn) & 579 \\
\hline 6.6 .2 & 2 Tracheobronchiale Amyloidose & 579 \\
\hline
\end{tabular}

Institutsangaben

${ }^{1}$ Gemeinschaftspraxis und Pneumologisches-Allergologisches Zentrum Maingau Krankenhaus Frankfurt am Main. Dres. T. Gebhardt, A. Iwantscheff und P. Kardos

${ }^{2}$ Zentrum für Pneumologie, Allergologie und Schlafmedizin am Herz Jesu Krankenhaus Dernbach

${ }^{3}$ Robert-Koch-Klinik, Leipzig

${ }^{4}$ Krankenhaus Großhansdorf, Zentrum für Pneumologie und Thoraxchirurgie

${ }^{5}$ Gemeinschaftspraxis für Pneumologie, Allergologie, Umweltmedizin und Schlafmedizin am Krankenhaus Wermelskirchen, Remscheid

${ }^{6}$ Pneumologische Klinik Waldhof Elgershausen, Greifenstein

${ }^{7}$ Berufsgenossenschaftliche Kliniken Bergmannsheil Klinikum der Ruhr-Universität Bochum

${ }^{8}$ Institut für Theoretische Chirurgie, Philipps-Universität, Marburg

${ }^{9}$ Klinik für Innere Medizin - Schwerpunkt Pneumologie Philipps Universität, Marburg

${ }^{10}$ Medizinische Klinik III Schwerpunkt Pneumologie, Allergologie, Zentrum für Schlafmedizin

und Heimbeatmung, Krankenhaus Bethanien, Moers

${ }^{11}$ Medizinische Klinik I, Klinikum Fürth

${ }^{12}$ Deutsche Klinik für Diagnostik Gastroenterologie II, Wiesbaden

${ }^{13}$ Zentrum für Rhinologie und Allergologie, Wiesbaden

Korrespondenzadresse

Dr. med. Peter Kardos · Scheffelstraße 33 - 60318 Frankfurt am Main

E-mail: Kardos@lungenpraxis-maingau.de

Bibliografie

Pneumologie 2004; 58: 570-602 @ Georg Thieme Verlag Stuttgart · New York .

ISSN 0934-8387 · DOI 10.1055/s-2004-818356 


\begin{tabular}{|c|c|}
\hline Inhalt & Seite \\
\hline 6.6.3 Rezidivierende Polychondritis & 579 \\
\hline 6.6.4 Tracheobronchopathia osteoplastica & 580 \\
\hline 6.6.5 Juvenile laryngotracheale Amyloidose & 580 \\
\hline 6.7 RADS (Reactive airways dysfunction syndrome) & 580 \\
\hline 6.8 VCD (Vocal cord dysfunction) & 580 \\
\hline 6.9 Tuberkulose & 580 \\
\hline 6.10 Keuchhusten & 581 \\
\hline 6.11 Linksherzinsuffizienz & 581 \\
\hline 6.12 Endokarditis & 581 \\
\hline $\begin{array}{l}\text { 6.13 Husten als Nebenwirkung einer medikamentösen kardialen } \\
\text { Therapie }\end{array}$ & 581 \\
\hline 7 Chronisch persistierender Husten (CPH) & 581 \\
\hline 7.1 Erkrankungen im Bereich von Nase und Nebenhöhlen & 582 \\
\hline 7.2 Erkrankungen im Bereich von Pharynx und Larynx & 582 \\
\hline 7.3 Husten als Asthmaäquivalent & 582 \\
\hline 7.4 Gastroösophageale Refluxkrankheit & 583 \\
\hline 7.5 Chronische, nicht obstruktive Bronchitis & 584 \\
\hline 7.6 Bronchiektasen & 584 \\
\hline 7.7 Chronischer Husten unklarer Ursache & 585 \\
\hline 7.8 Psychogener Husten & 585 \\
\hline 7.9 Husten als Nebenwirkung von Medikamenten & 585 \\
\hline 7.10 Bronchomalazie & 586 \\
\hline 7.11 Eosinophile Bronchitis & 586 \\
\hline 7.12 Zystische Fibrose & 586 \\
\hline 8 Diagnostik & 586 \\
\hline 8.1 Akuter Husten & 587 \\
\hline
\end{tabular}

\section{Struktur der Leitlinie}

\section{Präambel}

Die vorliegende Leitlinie Husten (ICD 10 Klassifikation R 05) beinhaltet Empfehlungen für Ärzte, die erwachsene Patienten mit Husten, einem sehr häufigen Symptom oder Beschwerde behandeln. Solche Patienten werden in erster Linie ambulant beim Allgemeinarzt, Hals-Nasen-Ohrenarzt, Internisten, Kinderarzt oder Pneumologen versorgt. Neurologen, Psychiater, Gastroenterologen und Kardiologen werden ebenfalls oft mit dem Problem Husten konfrontiert. In seltenen Fällen ist eine stationäre Abklärung auf einer pneumologischen Abteilung erforderlich.

Die notwendigen diagnostischen und therapeutischen Schritte werden in der Leitlinie evaluiert und festgelegt. Ziel der Leitlinie ist es zu helfen, die Ursachen des Hustens aufzudecken, die Beeinträchtigungen der Gesundheit so weit als möglich zu beseitigen oder zu reduzieren.

Derzeit existiert keine umfassende deutschsprachige Leitlinie zur Diagnostik und Therapie des Hustens. Die Deutsche Gesellschaft für pädiatrische Pneumologie [1] und die Deutsche Gesellschaft für Hals-Nasen-Ohren-Heilkunde, Kopf- und Hals-Chirurgie [2] publizierten S1-Leitlinien bzw. einen klinischen Algorithmus zur Diagnostik von Reizhusten und Räusperzwang. In vergleichbarem Umfang liegt nur ein englischsprachiger „Consensus Panel Report" vom American College of Chest Physicians vor [3].

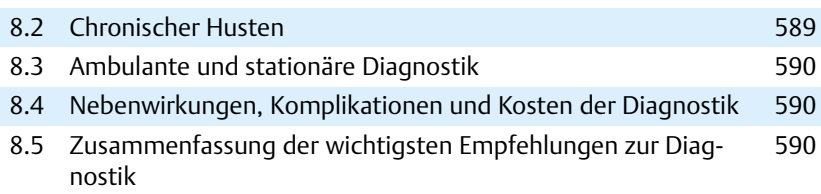

9 Häufige Fehler bei der Stufendiagnostik des Hustens 590

10 Therapie $\quad 591$

10.1.1 Physiotherapie bei produktivem Husten 591

10.1.2 Physiotherapie bei unproduktivem Husten 592

10.1.3 Atemphysiotherapie unter Zuhilfenahme von Geräten 592

10.2 Hustentherapeutika mit Wirkung am Hustenrezeptor 592

10.2.1 Expektorantien 593

10.2.2 Medikamente, die die Schleimproduktion verringern 593

10.2.3 Medikamente zur Steigerung der mukoziliären Clearance 593

10.2.4. Medikamente zur Reduktion der Reizung der Hustenrezepto- 594 ren

10.2.5 Schleimhautabschwellende Substanzen 594

10.2.6 Antibiotika $\quad 594$

10.2.7 Entzündungshemmende Substanzen 595

10.3 Hustentherapeutika mit Wirkung am Hustenreflexbogen: 595 Lokalanästhetika

10.4 Zentral wirksame Antitussiva 595

10.5 Hustentherapeutika mit Wirkung am Effektororgan 595

11 Komplikationen des Hustens $\quad 595$

Anhang 1 Teilnehmerliste der Konsensustreffen 596

Anhang 2 Ableitung von Qualitätsindikatoren aus der Leitlinie Husten 596

Anhang 3 Zusammenfassung der Leitlinie

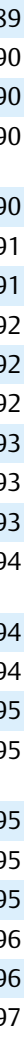

Diese Leitlinie soll ein wissenschaftlich begründetes - evidenzbasiertes - und hinsichtlich der Wirtschaftlichkeit optimiertes Stufenschema für die diagnostische Abklärung und Therapie des Hustens sein. Jeder Patient behält seinen Anspruch auf eine individuelle Diagnostik und Therapie, in einem konkreten Fall kann es sinnvoll sein, von der Leitlinie abzuweichen.

Verantwortlich für die Leitlinienerstellung ist die Deutsche Gesellschaft für Pneumologie (Federführer: Dr. P. Kardos, Frankfurt am Main). Die Erarbeitung der Leitlinie erfolgte in Zusammenarbeit mit verschiedenen medizinischen Fachgesellschaften und Organisationen (vgl. Anhang, Teilnehmerliste Konsensusprozesse).

\subsection{Schema der Leitlinienentwicklung (Tab. 1)}

Die Literaturrecherche wurde vom federführenden Autor in Medline und PubMed durchgeführt. Folgende Suchbegriffe wurden primär verwendet: „chronic cough“, „,cough“ and „amiodarone“, ,cough“ and „antitussive“, „cough“ and „asthma“ „cough“ and „bronchitis“, „cough“ and „cold“, „cough“ and „Crohn“, „cough" and „enzyme“, „cough“ and „exposure“, „cough“ and „,heart“, „cough“ and „inflammation“, „cough“ and „laryngitis“, „cough“ and „Parkinson“, „cough“ and „provocation“, „cough“ and „reflex“, „,ough“ and „reflux“, „cough“ and „rhinitis“, „cough“ and „rib“, „cough“ and sarcoid“, ,cough“ and „sinusitis“, „cough" and „smoking“, „cough" and „syncope“, „cough" and „therapy“, „cough and treatment“, „cough type asthma“, ,cough variant asthma“, „cough“ and „vocal“, „,ough“ and „wheeze“, „postnasal drip“, „relapsing polychondritis“. Weitere Literatur 
Tab. 1 Drei-Stufen-Konzept der Leitlinienentwicklung der AWMF (Arbeitsgemeinschaft der wissenschaftlichen medizinischen Fachgesellschaften)

\section{Stufe (S1): \\ Expertengruppe}

2. Stufe (S2):

Formale Konsensusfindung

3. Stufe (S3):

Leitlinie mit allen Elementen systestellung matischer Er- eine repräsentativ zusammengesetzte Expertengruppe der Wissenschaftlichen Medizinischen Fachgesellschaften erarbeitet im informellen Konsens eine Leitlinie, die vom Vorstand der Fachgesellschaft verabschiedet wird. vorhandene Leitlinien der Stufe 1 werden in einem der bewährten formalen Konsensusverfahren beraten und als Leitlinien der Stufe 2 verabschiedet. Formale Konsensusfindungsmethoden sind nominaler Gruppenprozess, Delphimethode und Konsensuskonferenz.

Sie enthalten eine Diskussion der Evidenz für die verabschiedeten Statements. Für die Durchführung ist die Mitarbeit von Methodikern hilfreich.

Der formale Konsensusprozess wird durch weitere systematische Elemente erweitert:

- logische Analyse (klinischer Algorithmus),

- evidenz-basierte Medizin,

- Entscheidungsanalyse,

- Outcomeanalyse. wurde aus dem Literaturverzeichnis der gefundenen Publikationen verwendet.

Konsens für diese Leitlinie wurde durch eine Kombination von nominalem Gruppenprozess und Delphitechnik erreicht. Das Vorbereitungskomitee bestand aus Dr. P. Kardos und Dr. H. Sitter. Nach erfolgter Auswahl der Teilnehmer bzw. der Organisationen durch die Leitlinienkommission der Deutschen Gesellschaft für Pneumologie wurden diese um ihre Mitarbeit gebeten. Husten wird nicht nur durch pneumologische Erkrankungen, sondern häufig durch Erkrankungen im Bereich der oberen Atemwege oder der Speiseröhre verursacht. Bei der Erstellung dieser Leitlinie wirkten daher neben Pneumologen aus Forschung, Klink und Praxis Vertreter der Fächer Hals-Nasen-Ohrenheilkunde und Gastroenterologie mit ausgewiesener Erfahrung auf dem jeweiligen Fachgebiet betreffend die Erkrankungen, die Husten verursachen, beratend mit.

Die Teilnehmerliste ist im Anhang aufgeführt. Außerdem wurden auch die Leitlinienkommission der Deutschen Gesellschaft für Allgemeinmedizin, der Ärztliche Dienst der Krankenkassen, der Leiter der Medizinischen Abteilung beim VdAK (Verband der Angestelltenkassen) eingeladen, sie hielten eine eigene Beteiligung nicht für erforderlich).

\section{Tab. 2 Nominaler Gruppenprozess}

\footnotetext{
1 Entwurf der Leitlinie

2 Kommentar jedes Gruppenmitgliedes

3 Leiter sammelt alle Kommentare

4 Zusammenfassung ähnlicher Kommentare

5 Abstimmung über Priorisierung der Diskussionspunkte

6 Diskussion (aller Kommentare)

7 Überarbeitung des Entwurfes

8 Revision der überarbeiteten Leitlinie und Neubeginn des Prozesses bei Punkt 1 bis zum Konsens
}

Tab. 3 Empfehlungsgrad und Nachweisstärke der Effektivität einer Leitlinie oder Teilen davon (nach Centre of Evidence Based Medicine, Oxford 1999)

\begin{tabular}{|ccl}
$\begin{array}{l}\text { Empfeh- } \\
\text { lungsgrad }\end{array}$ & $\begin{array}{l}\text { Evidenz- } \\
\text { grad }\end{array}$ & \\
\hline A & $1 \mathrm{a}$ & $\begin{array}{l}\text { Evidenz durch systemisches Review randomisierter } \\
\text { kontrollierter Studien (RCT) }\end{array}$ \\
\hline Evidenz durch eine geeignete geplante randomisierte \\
\end{tabular}

*Überwältigende Evidenz, die keine vernünftigen Zweifel an der Wirksamkeit aufkommen lässt: z. B. die antimikrobielle Wirkung von Penicillin nach dessen Einführung, Appendektomie bei eitriger Appendizitis. Es wäre unethisch gegen Plazebo zu testen.

Es fanden zwei 1-tägige Sitzungen nach dem Verfahren „Nominaler Gruppenprozess“ in Frankfurt am Main statt (Teilnehmerliste siehe Anhang I), zusätzlich dazu mehrere schriftliche Konsensusrunden nach der Delphitechnik, einem analogen Verfahren, das jedoch nur auf schriftlichem Wege, ohne Treffen der Teilnehmer, abläuft. Nach der Verabschiedung wurde die Leitlinie durch unabhängige, von der Deutschen Gesellschaft für Pneumologie beauftragte Experten begutachtet. Als Konsequenz dieser Begutachtung wurden die Kapitel Epidemiologie und Physiologie des Hustens gekürzt, die Abhandlung über Tuberkulose ergänzt.

\subsection{Klinische Evidenz der Leitlinie}

Die Studien wurden nach Qualität kategorisiert und mit einem entsprechenden Evidenzgrad gekennzeichnet (Tab. 3).

Von dieser starren Zuordnung von Evidenzgrad zu Empfehlungsgrad konnte durch Expertenmeinung im Konsensusprozess abgewichen werden.

\subsection{Klinische Algorithmen}

Ein klinischer Algorithmus ist ein in endlich vielen Schritten formuliertes Verfahren zur Lösung eines klinischen Problems unter Benutzung von bedingten logischen Anweisungen (Wenn-dannLogik). Die Darstellung erfolgt in graphischem Format mit einer von der Society for Medical Decision Making [4] empfohlenen Standardnomenklatur (Abb.1). Dabei unterscheidet man Zustands-, Aktions- und Entscheidungsknoten. Zustands- und Aktionsknoten haben je einen Ausgang, Entscheidungsknoten haben 2 Ausgänge: ja und nein. 


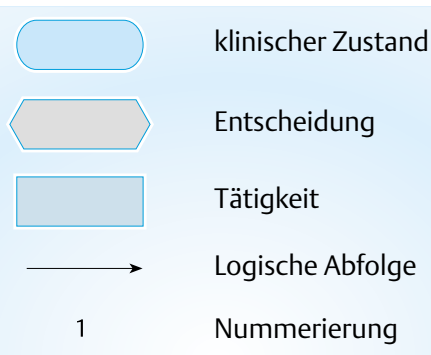

Abb. 1 Standardisierte Terminologie für klinische Algorithmen

\subsection{Teilnahme von Industrievertretern}

Der Industrievertreter hatte genau wie jeder andere Teilnehmer des nominalen Gruppenprozesses eine Stimme bei den Abstimmungen. Darüber hinaus hatten Industrievertreter keinen Einfluss auf Inhalt, Form und Erstellung der Leitlinie.

\subsection{Veröffentlichung, Verbreitung und Aktualisierung der Leitlinie}

Angesichts wachsender medizinisch-wissenschaftlicher und ökonomischer Notwendigkeiten ist die Implementierung von Leitlinien für häufige Krankheitsbilder erforderlich. Es wird auch erwartet, dass ihre Akzeptanz durch die Ärzteschaft - nicht als bürokratische Vorschrift, sondern als Entscheidungshilfe wachsen wird.

Die Leitlinie Husten wird in Fachzeitschriften publiziert, welche alle Ärzte erreichen, die Patienten mit Husten behandeln. Sie wird in 3 Versionen vorgelegt: eine vollständige Version für den Spezialisten, ein Auszug und Zusammenfassung für den praktisch tätigen Arzt (Kurzversion) und schließlich eine Patientenversion. Alle Versionen werden im Internet auf den Seiten der AWMF (http://awmf.org/) einsehbar sein. Eine Verbreitung durch lokale Meinungsbildner in Form von Weiterbildungsvorträgen und durch noch zu erstellende Computerprogramme zu den Algorithmen wird angestrebt.

Verantwortlich für die Aktualisierung der Leitlinie ist die Deutsche Gesellschaft für Pneumologie. Eine Revision ist alle 3 Jahre geplant. Neue wesentliche Erkenntnisse werden jedoch zeitnah eingearbeitet. Die jeweils gültige Version kann auch auf der Internetseite der AWMF und der DGP eingesehen werden.

\subsection{Sponsoring}

Die erforderlichen Aufwendungen für Reisekosten, die Kosten für die 2 Sitzungen in Frankfurt und die Kosten für die Leitung der 2 Konsensustreffen wurden von der Deutschen Gesellschaft für Pneumologie übernommen. Darüber hinaus wurden weder Kosten noch Honorare oder Entschädigungen gezahlt.

\section{Epidemiologie des Hustens}

Husten ist ein wichtiger physiologischer Schutzreflex der Atemwege, aber auch das gemeinsame Symptom beinahe aller pulmonaler und einiger extrapulmonaler Erkrankungen. Husten kann zur Ausbreitung von Infektionskrankheiten beitragen. Husten ist eine außerordentlich häufige Beschwerde. Da er auch im Rah- men der banalen akuten, meist viralen Bronchitis auftritt, ist er für einen wesentlichen Teil der Arztbesuche verantwortlich. In den USA war Husten der häufigste Grund einen Allgemeinarzt [5] und der dritthäufigste Grund einen niedergelassenen Internisten aufzusuchen [6]. In Frankreich sind 10-38\% der Konsultationen von Pneumologen auf das Symptom Husten zurückzuführen [7]. In Deutschland ist der chronische Husten der dritthäufigste Grund für die Konsultation eines niedergelassenen Pneumologen [8]. 10-40\% aller Überweisungen zum Pneumologen erfolgen wegen eines chronischen Hustens [9]. Sowohl die Diagnostik als auch die Therapie des Hustens (unter Einschluss verschreibungspflichtiger und frei verkäuflicher Medikamente) beanspruchen einen bedeutsamen Anteil der Gesundheitsausgaben. Der medizinische Fortschritt und ein wachsender ökonomischer und politischer Druck erfordern standardisierte Empfehlungen zur Diagnostik und Therapie auf dem Boden der besten vorhandenen wissenschaftlichen Evidenz zu erstellen.

\section{Anmerkungen zur Physiologie des Hustens}

\subsection{Husten als Reflex}

Der Reflexbogen besteht aus 5 Abschnitten:

1. Hustenrezeptoren

2. Afferenter Schenkel des Reflexbogens

3. Hustenzentrum

4. Efferenter Schenkel des Reflexbogens

5. Effektororgan: (Kehlkopf-, Brust- und Bauchmuskulatur).

\section{Die Hustenrezeptoren}

Der Ablauf des Reflexes beginnt mit der Stimulation der Mechanorezeptoren (myelinisierte schnell adaptierende, sog. „irritant“ Rezeptoren). Der Hustenreflex kann überall dort initiiert werden, wo Hustenrezeptoren vorhanden sind: in dem gesamten Bereich der oberen und unteren Atemwege, im Lungenparenchym, aber auch in der Pleura, im Perikard, am Zwerchfell, im Ösophagus und im Magen. Die Verteilung der Rezeptoren ist jedoch nicht gleichmäßig: sie sind am dichtesten am Kehlkopf und in seiner Umgebung (Pharynx, Trachea, große Bronchien) lokalisiert [10].

\section{Der Reflexbogen des Hustens (afferenter Schenkel, Husten- zentrum, efferenter Schenkel)}

Afferenter Schenkel ist der N. vagus, im Bereich der oberen Atemwege fraglich auch der N. trigeminus und der N. glossopharyngeus.

Ein Hustenzentrum wird in der Medulla oblongata mit Verbindungen zum Kortex (willkürlicher Husten und willkürliches Unterdrücken des Hustens) postuliert. Der efferente Schenkel läuft zu den Effektororganen: dem Zwerchfell, den Bauch- und Thoraxmuskeln und der Glottismuskulatur [10].

\section{Der Hustenstoß (Tab. 4)}

Husten als nachgeschalteter Reinigungsmechanismus und damit Abwehrmechanismus des Bronchialsystems tritt dann in Erscheinung, wenn der primäre mukoziliäre Clearancemechanismus geschädigt ist (z.B. durch inhalatives Rauchen) oder das Bronchialsystem mit Fremdmaterial überflutet wird (bei Aspiration, Hypersekretion, Lungenödem, extreme Rauch- oder Staubentwicklung). 
Tab. 4 Die 4 Phasen des Hustenstoßes [11]

\begin{tabular}{|c|c|c|}
\hline Phase & Bezeichnung & Physiologie \\
\hline 1 & schnelle Inspiration & Glottis, Stimmritze geöffnet \\
\hline 2 & Kompression & $\begin{array}{l}\text { Verschluss der Glottis, Kontraktion der } \\
\text { Exspirationsmuskeln, Öffnung der Glottis }\end{array}$ \\
\hline 3 & Akzeleration & $\begin{array}{l}\text { Anstieg des transbronchialen Druckes, } \\
\text { dynamische Kompression des Bronchial- } \\
\text { baumes }\end{array}$ \\
\hline 4 & Exspiration - Expulsion & $\begin{array}{l}\text { schneller }(250 \mathrm{~m} / \mathrm{sec}) \text { exspiratorischer } \\
\text { Fluss }\end{array}$ \\
\hline
\end{tabular}

Je nach Bedarf können verschiedene Abschnitte der Atemwege durch einen effektiven Hustenstoß gereinigt werden. Die Alveolen, Bronchiolen und kleinen Bronchien verfügen allerdings nicht über Hustenrezeptoren, um den Hustenreflex zu initiieren. Das Sekret wird aus den peripheren Anteilen zunächst durch die mukoziliäre Clearance und die dynamische Kompression „ausgequetscht" - bis zu den mittleren und größeren Bronchien (in etwa bis zur 5.-6. Generation) gefördert. Hier finden sich bereits Hustenrezeptoren, die den Husten auslösen. Das Volumen des Atemzugs unmittelbar vor dem Husten bestimmt vorwiegend, welcher Abschnitt der Atemwege (zwischen Larynx und Bronchien der 5.-6. Generation) gereinigt wird.

Ein effektiver Hustenreflex setzt mehr oder minder intakte anatomische Verhältnisse (keine schwere Atemwegsobstruktion, kein Bronchialkollaps, normale Atemmuskel- und Kehlkopffunktion, normale statische Volumina, normale Viskosität des Bronchialsekrets) voraus [12]. Insbesondere bei Bronchialwandinstabilität (z. B. bei der chronischen Bronchitis) ändern sich die Verhältnisse. Falls die Kompression zum Kollaps führt, verhindert dieser die Sekreteliminierung, eine Kompression ohne totalen Kollaps ist für die Effektivität förderlich, denn im Bereich des komprimierten Abschnittes (beim Gesunden: die pars membranacea) tritt eine erhebliche Flussbeschleunigung auf. Der beschleunigte Fluss hilft das Fremdmaterial von der Bronchialwand abzulösen und zu entfernen. Einer dynamischen, sich von der Peripherie nach zentral hin fortpflanzenden Kompression ist es zu verdanken, dass ein produktiver Husten selbst bei intubierten oder tracheotomierten Patienten möglich ist [13]. Sie dürfte auch teilweise erklären, wie eine Reinigung bei geschädigtem oder fehlendem Flimmerepithel in den peripheren Bronchien funktioniert: durch „Ausquetschen“ mittels der dynamischen Kompression [14]. Eine effektive Hustenclearance kann eine gestörte mukoziliäre Funktion (Ziliendyskinesie) viel besser kompensieren als umgekehrt.

Die Kenntnis dieser Zusammenhänge ist wichtig für die Physiotherapie des Hustens und der Sekretretention (Kapitel 10.1.1).

\section{Welche Stimuli lösen Husten aus?}

Husten kann durch physikalische und chemische Stimuli ausgelöst werden. Tab. 5 zeigt eine Auswahl von Husten auslösenden Reizen.
Tab. 5 Einige Stimuli, die Husten auslösen können

\begin{tabular}{|c|c|}
\hline Physikalische Reize & \\
\hline Thermische Reize ( & Ite Luft) \\
\hline Mechanische Reize & remdpartikel) \\
\hline Chemische Reize & \\
\hline Pharmakologisch: & $\begin{array}{l}\text { Capsaicin } \\
\text { Zitronensäure } \\
\text { Destilliertes Wasser } \\
\text { Lobelin } \\
\text { Entzündungsmediatoren: } \\
\text { Bradykinin } \\
\text { Tachykinin } \\
\text { Prostaglandin E } 2\end{array}$ \\
\hline Toxische Gase & \\
\hline Zigarettenrauch & \\
\hline Bakterielle Mediatc & \\
\hline
\end{tabular}

\subsection{Husten und Bronchospasmus}

Die 40 Jahre alte „Bronchomotor-Theorie des Hustens“ [15] ging davon aus, dass derselbe Rezeptor für die parallele Auslösung von Husten und Bronchospasmus verantwortlich ist. Nach neueren experimentellen Ergebnissen handelt es sich um eng verbundene, jedoch getrennte Reflexbögen. So ist die Capsaicin- oder Metacholinsensitivität des Hustenreflexes bei Asthmapatienten nicht erhöht [16]. Durch destilliertes Wasser provozierbarer Husten ist mit Lokalanästhetika blockierbar, nicht jedoch die Bronchokonstriktion; Dinatrium Cromoglykat blockiert die Bronchokonstriktion, nicht aber den Husten [17]. Inhalative Kortikosteroide sind in der Regel gut wirksam beim Asthma und bei dem asthmatischen Husten. Manche Asthma-Patienten husten jedoch unter inhalativer Kortisontherapie weiter, unabhängig von der Besserung ihrer Lungenfunktion $[18,19]$.

\subsection{Produktiver und nicht-produktiver Husten}

Der Husten wird klinisch in produktiven und trockenen (Reiz-)Husten unterteilt, obwohl die Grenzen zwischen den beiden Kategorien fließend sind. Beim produktiven Husten wird eine Sekretproduktion von $30 \mathrm{ml}$ (entsprechend 2 Esslöffeln) in 24 Stunden angegeben. Die Einschätzung der Sputummenge ist schwierig, da sie vom Patienten häufig überschätzt wird. Die Abgrenzung des Bronchialsekrets gegenüber Speichel ist problematisch. Entgegen früheren Annahmen ergeben sich nur geringe differenzialdiagnostische Konsequenzen daraus, ob der Husten produktiv oder nicht produktiv ist [20]. Die symptomatische Therapie (s. Kapitel 10) unterscheidet sich hingegen.

\subsection{Eigenschaften des Auswurfs}

- Mukös: entsprechend dem Sekret bei einer chronischen Bronchitis.

- Serös-schaumig: bei hohem Flüssigkeitsgehalt des Sekrets, z.B. bei Lungenödem

- Purulent oder putrid (gelb oder grün): bei Infektionen, aber auch bei Asthma oder eosinophiler Bronchitis, Bronchiektasen

- Blutig (Hämoptoe): bei Infektionen, Nekrosen, Tumor, Bronchiektasen, Gerinnungsstörung, Systemerkrankung

- Bronchialausguss: allergische bronchopulmonale Aspergillose, Bronchiektasen. 
Tab. 6 Ursachen des Hustens und ihre Klassifizierung

\begin{tabular}{|c|c|}
\hline Akut (< 8 Wochen) & Chronisch (> 8 Wochen) \\
\hline $\begin{array}{l}\text { Erkrankungen der Atemwege: } \\
\text { akute Sinusitis } \\
\text { Rhino-Laryngo-Tracheobronchitis: } \\
\quad \text { meist virale Infektion oder } \\
\text { allergisch } \\
\text { Asthma } \\
\text { Aspiration: oft Kinder 1-3 Jahre } \\
\text { inhalative Intoxikation: Unfälle, } \\
\text { Brände } \\
\text { postinfektiöser Husten } \\
\text { Erkrankungen der Lungen/Pleura: } \\
\text { Pneumonie } \\
\text { Pleuritis } \\
\text { Lungenembolie } \\
\text { Pneumothorax } \\
\text { extrapulmonale Ursachen: } \\
\text { akute Linksherzinsuffizienz } \\
\text { Bradykardie mit AV Block II, III }\end{array}$ & $\begin{array}{l}\text { Erkrankungen der Atemwege/ } \\
\text { der Lungen: } \\
\text { Asthma } \\
\text { COPD:* häufige Ursache } \\
\text { Bronchialtumoren } \\
\text { akute oder chronische Aspiration } \\
\text { diffuse Lungenparenchymerkr. - } \\
\text { Systemerkr. mit Lungenbeteiligung } \\
\text { seltene lokalisierte Erkrankungen des } \\
\text { Tracheobronchialsystems } \\
\text { Reactive Airways Dysfunction } \\
\text { Syndrome (RADS) } \\
\text { Vocal Cord Dysfunction (VCD) } \\
\text { Infektionskrankheiten: } \\
\text { Tuberkulose } \\
\text { Pertussis } \\
\text { kardiale Erkrankungen: } \\
\text { Chr. Linksherzinsuffizienz } \\
\text { Endokarditis } \\
\text { chronisch persistierender Husten (CPH) }\end{array}$ \\
\hline
\end{tabular}

COPD: „chronic obstructive pulmonary disease“, chronisch obstruktive Lungenkrankheit

\section{Ursachen und Klassifizierung des Hustens}

Da Husten das gemeinsame und manchmal das einzige Symptom eines breiten Spektrums von Erkrankungen mit unterschiedlichem Therapieansatz und unterschiedlicher Prognose ist, sollte der diagnostischen Abklärung des Hustens größte Bedeutung beigemessen werden. Andererseits erfordert die häufigste Ursache des Hustens: eine akute virale Erkrankung der oberen und/oder der unteren Atemwege in der Regel nur die Erhebung der Anamnese und eine körperliche Untersuchung. Jede weitere Diagnostik bei diesen Patienten würde die Ressourcen im Gesundheitswesen unnötig mit erdrückenden Kosten belasten (Evidenzgrad 5).

Daher erscheint eine Klassifizierung des Hustens anhand eines anamnestisch leicht zu erhebenden Merkmals: akut und chronisch - als erster Schritt der Diagnostik angezeigt, wenngleich Überschneidungen zwischen den Gruppen nicht zu vermeiden sind (Tab. 6).

Die exakte Diagnose sollte vor Beginn der Therapie des Hustens gestellt werden um möglichst kausal therapieren zu können. Bei einigen Krankheitsbildern aus der Tab. 6 ist eine frühzeitige Diagnose wichtig:

- bei kontagiösen Erkrankungen wie der Tuberkulose

- bei malignen Erkrankungen wie dem Bronchialkarzinom

- bei akut lebensbedrohlichen Erkrankungen wie dem Pneumothorax, der akuten Linksherzinsuffizienz oder der Lungenembolie.

Die Diagnose wird immer dann schwierig zu stellen sein, wenn der Röntgenbefund der Thoraxorgane nicht weiterführt, die Lungenfunktion unauffällig ist und der Husten als einziges Symptom auftritt. Dies ist oft der Fall bei Bronchiektasen und anderen seltenen isolierten Erkrankungen des Tracheobronchialsystems, bei
Tab. 7 Begleitsymptome und Begleiterkrankungen, die eine sofortige Diagnostik begründen

\begin{tabular}{|l|l|}
\hline Symptom & Hämoptoe \\
\hline & Thoraxschmerz \\
\hline Atemnot \\
\hline Hegleiterkrankung & HIV-Positivität \\
\hline Besondere Umstände & Malignome \\
\hline Risikogruppen & Immundefizienz \\
\hline & Obdachlose \\
\hline & extrem starke Raucher \\
\hline
\end{tabular}

$\mathrm{CPH}$ und im Anfangsstadium einiger systemischen und Lungenparenchymerkrankungen.

\section{Akuter und chronischer Husten}

Der Spontanverlauf des Hustens bei der akuten Bronchitis beträgt bis zum völligen Abklingen durchschnittlich 4 Wochen [21]. Adenoviren und Mykoplasmen verursachen in der Regel 6-8 Wochen anhaltenden Husten, nach Infektion mit B. pertussis husten die Patienten noch länger. Deshalb ist es sinnvoll, 8 Wochen bis zum Beginn der Stufendiagnostik des Hustens abzuwarten, falls eine für einen akuten Infekt der Atemwege typische Anamnese und ein passender körperlicher Untersuchungsbefund vorliegen [12]. Diese willkürlich gezogene Grenze von 8 Wochen zur Differenzierung des akuten vom chronischen Husten, markiert den obligatorischen Start der Diagnostik. Wenn besondere Umstände vorliegen (Tab. 7), die mit einem akuten banalen Infekt der Atemwege nicht in Einklang stehen, ist die Diagnostik unverzüglich einzuleiten [22 - 24]. In den meisten Studien bei Patienten mit abzuklärendem chronischen Husten betrug die durchschnittliche Dauer des Hustens mehrere Monate bis Jahre [25 - 27]: Allerdings lag die Dauer des Hustens als Einschlusskriterium für die Aufnahme von Patienten in diese Studien meistens unter 4 Wochen $[20,28,29]$. In einer neueren Übersicht zur Diagnostik und Therapie des Hustens [30] wird empfohlen, Husten als akut, subakut und chronisch zu charakterisieren. Subakut wurde Husten mit einer Dauer von 3-8 Wochen bezeichnet, ein chronischer Husten liegt ab einer Dauer von 8 Wochen vor. In ihrer neuesten Arbeit empfiehlt die gleiche Arbeitsgruppe, den Husten erst nach 8 Wochen Dauer abzuklären [31].

In dieser Leitlinie wird der akute Husten mit einer Dauer bis zu 8 Wochen, der chronische Husten mit einer Dauer von mehr als 8 Wochen Dauer definiert.

\begin{tabular}{|lll}
\hline Nr. Empfehlung: Differenzierung akuter und & $\begin{array}{l}\text { Empfeh- } \\
\text { chronischer Husten }\end{array}$ & $\begin{array}{l}\text { Evidenz- } \\
\text { lungsgrad }\end{array}$ \\
\hline E1 Über 8 Wochen anhaltender Husten ist chronisch, & B & $3 a$ \\
\hline
\end{tabular}


Die Diagnostik beim akuten Husten erfordert sowohl ein stufenweises Vorgehen als auch in manchen Fällen die sofortige, volle Ausschöpfung aller diagnostischen Möglichkeiten.

\subsection{Akute infektiöse Erkrankungen im Bereich der oberen und unteren Atemwege}

Die Diagnose wird häufig vom erwachsenen Patienten oder ärztlich auf Basis der Anamnese und der körperlichen Untersuchung (zum Ausschluss einer Pneumonie und anderer Ursachen) gestellt. Der akute Virusinfekt des Atemtraktes ist eine alltägliche, spontan ausheilende Erkrankung, der in der Regel weder eine radiologische noch mikrobiologische oder Labordiagnostik erfordert [32,33]. Bei typischer Anamnese für einen solchen Infekt und ohne klinischen Hinweis auf eine Pneumonie oder eine schwere (Begleit-)Erkrankung kann mit der Einleitung der Diagnostik bis zu 8 Wochen abgewartet werden. Im typischen Fall sind keine weitergehenden diagnostischen Maßnahmen erforderlich. Akute virale Infekte („Erkältung“) gehen meist mit Schnupfen, Halsschmerzen, Husten, selten mit erhöhter Temperatur oder Fieber einher: Die möglichen pathologisch-anatomischen Lokalisationen sind: Rhinitis, Sinusitis, Pharyngitis, Laryngitis, Bronchitis. Häufigste Auslöser: Rhinoviren in 30-50\% der Fälle, weitere: Corona-, Parainfluenza-, Respiratory Syncytial-, Influenza-, Adeno-, Entero-, und die kürzlich entdeckten Metapneumoviren [34].

- Akute Infekte der Atemwege können im Rahmen einer Grippeepidemie auftreten (Myxovirus influenzae A oder B).

- Chlamydia pneumoniae kann als bakterieller Erreger für akute Infekte der oberen und unteren Atemwege verantwortlich sein.

- Junge Männer erkranken häufig an Mycoplasma pneumoniae oder Adenovirusinfekten, besonders in Gemeinschaftsunterkünften.

- Kinderkrankheiten wie Keuchhusten, Masern, Scharlach, das Pfeiffersche Drüsenfieber manifestieren sich oft als akute respiratorische Infekte.

- Die akute bakterielle Sinusitis (am häufigsten durch S. haemolyticus, H. influenzae, S. pneumoniae, S. aureus) ist im Vergleich zu den viralen Entzündungen seltener für den akuten Husten verantwortlich.

\begin{tabular}{|lll|}
\hline Nr. Empfehlung: Diagnostik beim akuten Husten & $\begin{array}{l}\text { Empfeh- } \\
\text { lungsgrad }\end{array}$ & $\begin{array}{l}\text { Evidenz- } \\
\text { grad }\end{array}$ \\
\hline E2 & $\begin{array}{l}\text { Im typischen unkomplizierten Fall: Anamnese und } \\
\text { körperliche Untersuchung ausreichend }\end{array}$ & $\mathbf{1 b}$ \\
\hline
\end{tabular}

\subsection{Allergische Erkrankungen im Bereich der oberen Atem- wege}

Die intermittierende allergische Rhinopathie (Heuschnupfen), oft vergesellschaftet mit Sinusitis, Konjunktivitis, Pharyngitis und Laryngitis kann ebenfalls zu akutem Husten führen. Die Differenzialdiagnose zu den viralen Infekten wird anhand der aktuellen Allergenexposition in Zusammenschau mit den Allergietestergebnissen und der von den viralen Infekten abweichenden
Symptomatik gestellt. Juckreiz im Bereich der Konjunktiven, Nase, des Rachens und längere Niesanfälle stehen oft im Vordergrund [35]. (Nichtallergische nicht-infektiöse oder persistierende allergische Rhinitiden verursachen in der Regel chronischen Husten, s. Kapitel 7.1).

\subsection{Asthma}

Intermittierendes allergisches Asthma kann akuten Husten verursachen. Bei gelegentlicher Allergenexposition (z. B. unerwarteter Tierkontakt bei entsprechender Sensibilisierung) oder im Rahmen des Heuschnupfens kann akuter trockener Husten mit und ohne Atemnot bzw. pfeifendem Atemgeräusch auftreten.

Diagnostik und Therapie: Es wird auf die aktuellen Asthma-Leitlinien hingewiesen [36] bzw. http://www.nih.gov/. Auch der Husten spricht in der Regel auf die antiasthmatische Therapie an.

\subsection{Aspiration}

Husten schützt vor den Konsequenzen der Aspiration. Die Aspiration von Fremdkörpern kann (besonders häufig bei 1-3 Jahre alten Kindern) zum akuten Husten führen. Fremdkörper geringer Strahlendichte entgehen der direkten Darstellung. Indirekte Röntgenzeichen der Aspiration: einseitige Überblähung oder Volumenminderung, Minderperfusion. Feuerschlucker aspirieren oft chronisch und erkranken gelegentlich an akuten Husten infolge einer abszedierenden Pneumonie. Eine einmalige oder chronische Aspiration kann auch die Ursache für chronischen Husten sein (s. Kapitel 6.4).

Anmerkungen zur Diagnostik: Bronchoskopie, Inhalationsszintigraphie

\subsection{Akute inhalative Intoxikationen (Unfälle am Arbeitsplatz, Brände, Schnüffeln von Lösemitteln)}

Sie verursachen meistens gleichzeitig Bronchitis, Konjunktivitis und Rhinitis. Hitzeschäden und Schädigung durch inhalierte Substanzen sind zu unterscheiden. Als chronischer Folgeschaden kann ein „reactive airway dysfunction syndrome“ RADS auftreten (s. Kapitel 6.7). Die Diagnose wird anhand der Anamnese und der körperlichen Untersuchung, Lungenfunktionsprüfung (Diffusionskapazität), Oxymetrie, CO-Hämoglobinbestimmung und Blutgasanalyse gestellt. Inhalative Intoxikationen können oft nach einem beschwerde- und hustenfreien Intervall von 6-24 Stunden - zu toxischem Lungenödem, zur akuten interstitiellen Pneumonie und Bronchiolitis mit erneutem Auftreten von Husten führen. Akute inhalative Intoxikationen benötigen meist stationäre Beobachtung und oft intensivmedizinische Behandlung. Die Vergiftungszentralen können zur inhalierten Substanz Auskunft geben.

\subsection{Postinfektiöser Husten}

Der postinfektiöse Husten überdauert zeitlich den auslösenden bronchialen Infekt um mehrere Wochen. Er wird anhand einer sorgfältigen Anamnese und durch Ausschluss anderer Ursachen diagnostiziert. Nach manchem akutem Virusinfekt kann es 8 Wochen dauern, bis der postinfektiöse Husten spontan abklingt. Deshalb wurde die Grenze zwischen akutem und chronischem Husten bei 8 Wochen gezogen (s. Kapitel 4) Evidenzgrad 3b. Der Pathomechanismus des postinfektiösen Hustens ist nicht einheitlich: wahrscheinlich handelt es sich in einem Teil der Fäl- 
le um einen Epithelschaden mit Offenlegung der „irritant“ Rezeptoren der Bronchialschleimhaut (z.B. B. pertussis-Infektion, s. Kapitel 6.10). Hier kann der Husten bei ausgedehnter Epithelschädigung länger als 8 Wochen persistieren, ebenso bei Infektion mit Mycoplasma pneumoniae.

Anderen Fällen liegt eine vorübergehende spontan abklingende Steigerung der bronchialen Reaktionsbereitschaft zugrunde. Die bronchiale Hyperreagibilität kann mit dem unspezifischen inhalativen Provokationstest (z.B. Metacholin) nachgewiesen werden. Dieser Husten spricht gut auf $\beta_{2}$-Agonisten oder inhalative Kortikosteroide an. Falls keine bronchiale Hyperreagibilität vorliegt, ist eine symptomatische Therapie mit Antitussiva möglich (s. Kapitel 10.4).

\begin{tabular}{llll} 
Nr. & $\begin{array}{l}\text { Empfehlung: Therapie des Hustens bei postinfek- } \\
\text { tiös gesteigerter bronchialer Reaktionsbereit- } \\
\text { schaft }\end{array}$ & $\begin{array}{l}\text { Empfeh- } \\
\text { lungsgrad }\end{array}$ & $\begin{array}{l}\text { Evidenz- } \\
\text { grad }\end{array}$ \\
\hline E3 & $\begin{array}{l}\beta_{2} \text {-Agonisten oder inhalatives Kortison für 2-4 } \\
\text { Wochen }\end{array}$ & A & 1 1a \\
\hline
\end{tabular}

\subsection{Pneumonie}

(Meist trockener) Husten ist ein klassisches Symptom der ambulant erworbenen Pneumonie. Andererseits treten bei gestörtem Hustenreflex häufig rezidivierende Pneumonien auf [37].

Diagnostik und Therapie: Es wird auf die aktuellen Leitlinien der Paul Ehrlich Gesellschaft und der Deutschen Atemwegsliga hingewiesen [38]. Auch nosokomiale Pneumonien gehen mit Husten einher.

\subsection{Pleuritis}

Die akute Pleuritis sicca geht mit atemabhängigen Thoraxschmerzen, meist mit Fieber, trockenem Husten, auskultatorisch hörbarem Pleurareiben und erhöhten Entzündungslaborparametern einher.

\subsection{Lungenembolie}

$50 \%$ der Patienten mit akuter Lungenembolie haben neben anderen Symptomen Husten [39]. Insofern kann akut aufgetretener trockener Husten - meist zusammen mit Atemnot - ein wichtiger Hinweis auf eine Lungenembolie sein.

Diagnostik: Es wird auf die aktuellen Leitlinien Diagnostik der akuten Lungenembolie der Deutschen Gesellschaft für Pneumologie hingewiesen [40].

\subsection{Pneumothorax}

Alle Formen des Pneumothorax können mit trockenem Husten einhergehen.

\subsection{Akute Linksherzinsuffizienz}

Die akute Linksherzinsuffizienz mit pulmonaler Stauung (Lungenödem) kann zu bronchialer Hyperreagibilität [41,42], zur manifesten Bronchialobstruktion (früher Asthma cardiale genannt) und zum Husten führen. Der Hustenreiz wird bei Rückstau im kleinen Kreislauf (Mitralvitien) oder bei interstitiellem Lungen- ödem durch die intrapulmonalen Dehnungsrezeptoren vermittelt, bei „feuchtem“ Lungenödem durch Schleimhautschwellung und Reizung der „,irritant“ Rezeptoren der Bronchien.

\subsection{Bradykardie mit AV-Block II, III}

Sie führt durch Reduktion des Minutenvolumens zum konsekutiven Rückstau und Husten. Husten kann selber - vermutlich durch starke Vagotonie einen AV-Block II. oder III. Grades auslösen, es liegen hierüber Fallberichte vor. Der komplette AV-Block wird als ein möglicher Pathomechanismus der Hustensynkope (Kapitel 11) diskutiert [43-46]. Andererseits kann durch willkürlichen Husten am Beginn eines Herzstillstands der Kreislauf und das Bewusstsein aufrechterhalten werden [47]. Für den Zusammenhang zwischen Husten und assoziiertem AV-Block gibt es den Evidenzgrad 3b.

\section{Der chronische Husten}

\subsection{Asthma}

Husten ist ein klinisches Kardinalsymptom des Asthmas. Asthma ist häufig für den chronischen Husten verantwortlich. Ein hartnäckiger Reizhusten kann zu einer akuten Verschlechterung des Asthmas führen (der Patient „hustet sich in einen Asthmaanfall hinein“). Chronischer Husten bei bronchialer Hyperreagibilität, ohne andere Ursache und ohne eine in der Lungenfunktion nachgewiesene oder klinisch evidente Bronchialobstruktion wird im Kapitel 7.3 „Husten als Asthmaäquivalent“ abgehandelt.

Diagnostik und Therapie: Es wird auf die Leitlinien der Deutschen Atemwegsliga [36] bzw. http://www.nih.gov/ hingewiesen. Der asthmatische Husten bessert sich in der Regel auf die antiasthmatische Therapie ebenso wie die Lungenfunktion. Falls der Husten bei einigen Asthma-Patienten auf diese Behandlung nicht oder nur unzureichend anspricht, obwohl die Lungenfunktion und die übrige Symptomatik sich gebessert oder gar normalisiert hat und andere Ursachen ausgeschlossen worden sind, können zusätzlich Antitussiva verordnet werden.

\begin{tabular}{|lll}
\hline Nr. Empfehlung: Therapie des Hustens bei Asthma & $\begin{array}{l}\text { Empfeh- } \\
\text { lungsgrad }\end{array}$ & $\begin{array}{l}\text { Evidenz- } \\
\text { grad }\end{array}$ \\
\hline E4 $\begin{array}{l}\text { Persistierender Husten trotz optimaler Asthma- } \\
\text { therapie kann mit Antitussiva behandelt werden }\end{array}$ & D & $\mathbf{5}$ \\
\hline
\end{tabular}

\subsection{COPD}

Die Bezeichnung COPD (chronic obstructive pulmonary disease, chronisch obstruktive Lungenerkrankung) steht für die klinisch meist koinzidente chronisch obstruktive Bronchitis und das Lungenemphysem. Die chronische Bronchitis geht definitionsgemäß mit Husten einher. Bei COPD kann sowohl ein meist morgendlicher, produktiver, als auch ein trockener Husten (häufig im Rahmen von Exazerbationen) auftreten. Verantwortlich für den Husten ist vorwiegend die Hyperkrinie in Kombination mit der Verschlechterung der mukoziliären Clearance. Die chronische, nicht obstruktive Bronchitis (nach den GOLD Leitlinien http://www.goldcopd.com/ - als Schweregrad 0 der COPD definiert) ist die häufigste Ursache des chronischen Hustens. Sie 
wird im Kapitel 7.5 unter chronisch persistierendem Husten abgehandelt, da sie nicht mit einer Bronchialobstruktion einhergeht.

Diagnostik und Therapie: Es wird auf die aktuellen Leitlinien der Deutschen Atemwegsliga und der Deutschen Gesellschaft für Pneumologie [48] bzw. auf die GOLD Leitlinie http://www.goldcopd.com/ hingewiesen.

\subsection{Bronchialtumoren}

Seltene intrabronchiale Tumoren sind das Zylindrom (auf das Bronchialsystem beschränkt) oder der Carcinoidtumor (kann auch peribronchial wachsen). Sie verursachen Husten als Hauptsymptom. Auf dem Thorax-Übersichtsbild sind sie oft nicht zu erkennen, die Diagnose wird bronchoskopisch gestellt.

Der häufigste Bronchialtumor ist das Bronchialkarzinom.

Husten gilt als ein relativ frühes Symptom des Bronchialkarzinoms. Mit einer Häufigkeit von 69\% war Husten das häufigste Symptom bei der Erstdiagnose eines Bronchialkarzinoms [49]; im Laufe der Krankheit leiden bis zu 90\% der Patienten an Husten [50]. Da das Rauchen die gemeinsame Noxe sowohl für eine chronische Bronchitis als auch für das Bronchialkarzinom ist, kann es schwierig sein, den Husten der Bronchitis oder dem Karzinom zuzuordnen. Auf die Änderung der Charakteristik des Hustens - aus einem morgendlichen produktiven Husten, typisch für die chronische Bronchitis, wird ein Reizhusten - ist kein sicherer Verlass. Wenn ein ACE-Hemmer bedingter Husten (Kapitel 7.9) ausgeschlossen werden kann, sollte jeder Patient mit chronischem Husten zum Ausschluss eines Bronchialkarzinoms gleich bei seiner ersten ärztlichen Konsultation geröntgt werden. Falls die Röntgenaufnahme der Thoraxorgane in 2 Ebenen keinen Hinweis auf die Ursache des Hustens (z.B. auf ein Bronchialkarzinom) ergibt, sollten zunächst die häufigsten Ursachen des chronischen Hustens (Asthma, COPD, Rhinopathie, gastroösophageale Refluxkrankheit etc.) abgeklärt werden, bevor die weitere Diagnostik auf ein radiologisch okkultes Bronchialkarzinom fokussiert wird (Computertomographie, Bronchoskopie). Falls die Röntgenaufnahme und die Lungenfunktionsprüfung negativ ausfallen, bringt die Bronchoskopie nur in weniger als 5\% der Fälle eine diagnostische Klärung [22,26]. In einer Untersuchung der Symptomhäufigkeit bei radiologisch okkultem Bronchialkarzinom wurde Husten ohnehin nur in 23\% der Fälle gefunden [51]. Allerdings soll jeder Patient mit ungeklärtem chronischem Husten spätestens am Ende der diagnostischen Aufarbeitung bronchoskopiert werden.

\begin{tabular}{|c|c|c|c|}
\hline Nr. & $\begin{array}{l}\text { Empfehlung: Ausschlussdiagnostik des Bronchial- } \\
\text { karzinoms }\end{array}$ & $\begin{array}{l}\text { Empfeh- } \\
\text { lungsgrad }\end{array}$ & $\begin{array}{l}\text { Evidenz- } \\
\text { grad }\end{array}$ \\
\hline E5 & $\begin{array}{l}\text { Patienten mit chronischem Husten, die keinen } \\
\text { ACE-Hemmer einnehmen, sollten zum Ausschluss } \\
\text { eines Bronchialkarzinoms gleich geröntgt werden }\end{array}$ & D & 5 \\
\hline E6 & $\begin{array}{l}\text { Falls die Röntgenuntersuchung negativ ausfällt, } \\
\text { Asthma, COPD, Rhinopathie, Reflux abklären }\end{array}$ & A & $1 a$ \\
\hline E7 & $\begin{array}{l}\text { Am Ende des diagnostischen Algorithmus sollte } \\
\text { jeder Patient mit unklar gebliebenem Husten } \\
\text { bronchoskopiert werden. }\end{array}$ & A & kein \\
\hline
\end{tabular}

Diagnostik und Therapie des Bronchialkarzinoms: Es wird auf die aktuellen Leitlinien der Deutschen Gesellschaft für Pneumologie hingewiesen $[52,53]$.

Anmerkungen zur Therapie des Hustens beim Bronchialkarzinom: neben Antitussiva kommen interventionelle bronchologische Palliativmaßnahmen wie Afterloading (intrakavitäre Kleinraumbestrahlung) Lasertherapie, Stent oder systemische Chemotherapie und Bestrahlung zur Linderung des Hustens in Betracht.

\subsection{Aspiration}

Chronischer Husten kann durch eine einmalige Aspiration bei normalen anatomischen Verhältnissen vorkommen, wenn der aspirierte Fremdkörper im Bronchialsystem verbleibt oder wenn Folgeerkrankungen (Pneumonie nach Aspiration von Mageninhalt bei Bewusstlosigkeit bzw. eine Retentionspneumonie, eine poststenotische Überblähung und isolierte Bronchiektasen) entstehen. Im letzteren Fall tritt der Husten erst nach einem beschwerdefreien Intervall auf. Ein Teil der Patienten stellt sich sofort vor (zum akuten Husten nach einmaliger Aspiration s. Kapitel 5.4), die Aspiration kann bei der Vorstellung aber auch Wochen zurückliegen.

Chronischer Husten kann auch Folge chronisch rezidivierender Aspirationen sein. Eine chronische Aspiration als Ursache des Hustens ist häufig schwer zu identifizieren. Sie kommt bei Motilitätsstörungen des Ösophagus und Schluckstörungen im Rahmen neurologischer Grunderkrankungen vor. Die häufigste Ursache ist der apoplektische Insult (Tab. 8).

Tab. 8 Neurologische Erkrankungen mit Neigung zur chronischen Aspiration

\begin{tabular}{|c|c|}
\hline \multicolumn{2}{|l|}{ Syringobulbie } \\
\hline \multicolumn{2}{|l|}{ Tumoren der Medulla oblongata } \\
\hline $\begin{array}{l}\text { Bulbärparalyse ( = symmetrische } \\
\text { Degeneration der Kerne XII, VII, } \\
\text { bzw. X und V motorisch) }\end{array}$ & $\begin{array}{l}\text { Enzephalomyelitis disseminata } \\
\text { amyotrophe Lateralsklerose }\end{array}$ \\
\hline $\begin{array}{l}\text { Pseudobulbärparalyse (= bilaterale } \\
\text { Läsion der kortikobulbären Bahnen): }\end{array}$ & $\begin{array}{l}\text { apoplektischer Insult } \\
\text { vaskuläre Enzephalopathie } \\
\text { M. Alzheimer }\end{array}$ \\
\hline \multicolumn{2}{|l|}{$\begin{array}{l}\text { Bulbospinale Muskelatrophie } \\
\text { (Kennedy-Syndrom) }\end{array}$} \\
\hline \multicolumn{2}{|l|}{ Myasthenia gravis } \\
\hline Läsionen des N. glossopharyngeus: & $\begin{array}{l}\text { postdiphtherisch, chronische Alkohol-, } \\
\text { Bleiintoxikation, Lues }\end{array}$ \\
\hline $\begin{array}{l}\text { Parkinson-Syndrom (Aspiration, } \\
\text { Speichelfluss, Effektormuskelschwäche) }\end{array}$ & \\
\hline
\end{tabular}

\section{Weitere Ursachen:}

- Ösophagotracheale Fistel (angeboren oder erworben),

- Missbildungen im Bereich der oberen Atemwege,

- nach Tumoroperationen im Halsbereich, besonders mit neck dissection,

- Regurgitation von Mageninhalt bei massivem gastroösophagealem Reflux oder bei Sondenernährung. 
Die Folgen der chronischen Aspiration sind radiologisch als Infiltration, meist in den abhängigen Lungenanteilen (oft im rechten Unterlappen) zu erkennen. Es können ein Pleuraerguss, eine Bronchiolitis, eine organisierende chronische Pneumonie und Bronchiektasen entstehen.

Anmerkungen zur Diagnostik: Bronchoskopie mit bronchoalveolärer Lavage zum Nachweis von fettbeladenen Makrophagen.

(Für die Entfernung von Fremdkörpern kann die starre Bronchoskopie erforderlich sein).

Anmerkungen zur Therapie: Bei neurogenen Schluckstörungen, die kausal nicht gebessert werden können, kommt die Versorgung des Patienten mit einer PEG-Sonde (perkutane endoskopische Gastrotomie) in Betracht, bei Ösophagus-Motilitätsstörungen eine Ernährungssonde im Jejunum. Bei M. Parkinson tritt der Husten infolge von Schluckstörungen und Aspiration bei vermehrtem Speichelfluss und Nahrungsaufnahme auf. Hinzu kommt die herabgesetzte Effektivität des Hustenreflexes infolge Abschwächung und Verzögerung der exspiratorischen Muskelkontraktionen mit Verminderung der Clearance des Hustenreflexes $[54,55]$.

\subsection{Diffuse Lungenparenchymerkrankungen (DLPE) - Systemerkrankungen mit Lungenparenchymbeteiligung}

Trockener Husten ist neben der Dyspnoe das häufigste, oft das präsentierende Symptom diffuser Lungenparenchymerkrankungen [69 - 73]. Er kann den typischen radiologischen Veränderungen um Monate vorausgehen. Die Ursache für den Husten dürfte eine Steigerung der Empfindlichkeit des Hustenreflexes sein [56]. Die Klassifikation der diffusen Lungenparenchymerkrankungen ist nicht Gegenstand dieser Leitlinie. Einige diffuse Lungenparenchymerkrankungen (Tab. 9) werden aufgeführt, welche - belegt durch die Literatur - oft bereits in einem so frühen Stadium Husten auslösen, dass der Nachweis der diffusen Lungenparenchymerkrankung der konventionellen radiologischen Diagnostik entgehen kann. Eine scheinbar „normale“ Röntgen-Thoraxaufnahme und unauffällige Befunde in der Spirometrie schließen eine im HR (high resolution)-CT bereits nachweisbare Affektion der Lungen nicht aus. Typische diskontinuierliche Geräusche („Fibroserasseln“) können ein Frühzeichen sein. In den meisten Fällen erfolgt die weitere Abklärung durch Bronchoskopie mit histologischen Untersuchungen und BAL.

Systemerkrankungen (M. Sjögren, SLE, Rheumatoide Arthritis, systemische Sklerose) können mit Lungenbeteiligung einhergehen und Husten verursachen. Bei der Diagnostik des Hustens bei Systemerkrankungen ist jedoch zu beachten, dass auch die zur Therapie eingesetzten Medikamente als Nebenwirkung DLPE und somit einen unter der Therapie der Grunderkrankung sich verschlechternden Husten auslösen können [57].

\subsection{Seltene isolierte Erkrankungen des Tracheobronchial- systems}

Häufigkeitsmaximum dieser Krankheiten: 5. Lebensdekade und später. Alle der nachfolgenden Erkrankungen können zu Stridor, exspiratorischem Bronchialkollaps, zu zentraler irreversibler Atemwegsobstruktion führen. (Rezidivierende) Retentionspneumonien, Atelektasen und Bronchiektasen können die Folge sein;
Tab. 9 Diffuse Lungenparenchymerkrankungen mit Husten als Frühsymptom (Evidenzgrad 3b)

\begin{tabular}{|c|c|c|}
\hline DLPE & Anmerkung & Literatur \\
\hline Amiodaron induzierte DLPE & $\begin{array}{l}\text { Husten kann als einziges Früh- } \\
\text { symptom auftreten }\end{array}$ & [58] \\
\hline Methotrexat induzierte DLPE & $\begin{array}{l}\text { auch die behandelte Grunder- } \\
\text { krankung kann für den Husten } \\
\text { verantwortlich sein }\end{array}$ & [59] \\
\hline $\begin{array}{l}\text { M. Sjögren oder Sjögren (Sicca) } \\
\text { Syndrom }\end{array}$ & $\begin{array}{l}\text { selten monosymptomatisch als } \\
\text { Husten }\end{array}$ & {$[60-61]$} \\
\hline $\begin{array}{l}\text { Riesenzellarteriitis } \\
\text { M. Horton }\end{array}$ & $\begin{array}{l}\text { Husten ist als Hinweis auf die } \\
\text { seltene Lungenbeteiligung zu } \\
\text { werten }\end{array}$ & {$[63,64]$} \\
\hline M. Wegener & $\begin{array}{l}\text { Beteiligung der oberen Atem- } \\
\text { wege oder isoliert der Trachea } \\
\text { kann Husten bei unauffälligem } \\
\text { Thorax Röntgenbild auslösen }\end{array}$ & {$[65,66]$} \\
\hline $\begin{array}{l}\text { Colitis ulzerosa } \\
\text { M. Crohn }\end{array}$ & $\begin{array}{l}\text { Stenosen der Bronchien, Bron- } \\
\text { chiektasen, Bronchiolitis, COP, } \\
\text { oder die Therapie (Sulfasalazin) } \\
\text { kann für den Husten verant- } \\
\text { wortlich sein }\end{array}$ & {$[57,67,68]$} \\
\hline
\end{tabular}

häufig ist Husten das Leitsymptom (Evidenzgrad 3b). Ein Zylindrom oder ein Karzinoidtumor kann ebenfalls auf die Bronchien lokalisiert sein (s. unter 6.3).

\subsubsection{Tracheo-Bronchomegalie (M. Mounier-Kuhn)}

Die Erkrankung betrifft meist Männer; ihre Ursache ist unbekannt. Die Vergrößerung des Durchmessers des intrathorakalen Abschnittes der Trachea ( $>25 \mathrm{~mm}$ bei Männern und $>21 \mathrm{~mm}$ bei Frauen) und der großen Bronchien führt zu einer Chondromalazie $[74,75]$. Die Tracheo-Bronchomegalie kann mit einem Marfan-Syndrom assoziiert auftreten.

\subsubsection{Isolierte Tracheobronchiale Amyloidose}

Infolge einer ausschließlich lokalen monoklonalen Expansion von B-Lymphozyten wird AL-Amyloid vom Leichtkettentyp produziert und im Respirationstrakt, selten isoliert nur im Kehlkopf, meist in der Trachea und in den großen Bronchien abgelagert. Bronchoskopisch ist die so genannte „rock garden“ Erscheinung (weiße, unregelmäßige, prominente, leicht blutende submuköse Einlagerungen) typisch. Radiologisch (konventionell und im CT) zeigt sich eine charakteristische Verdickung, manchmal auch Verkalkung der Trachealwand [76]. Die Diagnose wird histologisch gesichert (Kongorot - positives Material).

Anmerkungen zur Therapie: endoskopische Lasertherapie, ggf. chirurgische Therapie.

\subsubsection{Rezidivierende Polychondritis}

Eine rezidivierende, in Schüben verlaufende entzündliche Erkrankung, die das tracheobronchiale Knorpelsystem (eventuell auch die Nase, die Ohrmuscheln und den Kehlkopf) angreift. Augen- (Konjunktivitis, Episkleritis, Keratitis) und Gelenkbeteiligungen sind möglich. Die Stellung dieser Diagnose ist schwierig. Bronchoskopisch sind die tracheobronchiale Entzündung, der inund exspiratorische Tracheobronchialkollaps und ggf. Stenosen 
zu sehen. Histologisch müssen tiefe Biopsien aus dem Knorpel gewonnen werden, meist mittels starrer Bronchoskopie, um die Diagnose zweifelsfrei zu stellen. Histologisch können degenerative Veränderungen, Lymphozyten- und Immunglobulinablagerungen an der Knorpel-Schleimhaut-Grenze gefunden werden [77]. Die Erkrankung kann mit Vaskulitiden oder Autoimmunerkrankungen assoziiert sein.

Anmerkungen zur Therapie: Die entzündungshemmende Therapie wird mit Kortikosteroiden (bei ungenügendem Ansprechen in Ergänzung mit Immunsuppressiva wie Azathioprin, Methotrexat oder Cyclosporin A) durchgeführt.

\subsubsection{Tracheobronchopathia osteochondroplastica}

Heterotope Ossifikation in der Trachea und in den großen Bronchien mit Atemwegsstenose [78]. Die Erkrankung ist lange symptomarm [79] und kann monosymptomatisch mit Husten in Erscheinung treten [80]. Die Bronchoskopie zeigt das Bild der „Tropfsteinhöhlentrachea“. Radiologisch finden sich Bronchialwandverkalkungen, histologisch ist Knorpel oder Knochen in der Trachealwand zu sehen.

Anmerkungen zur Therapie: Falls eine Therapie erforderlich ist, kann mittels Laser oder Argon-Beamer die Durchgängigkeit der Trachea oder der großen Bronchien verbessert werden.

\subsubsection{Juvenile laryngotracheale Papillomatose}

Sie tritt im Gegensatz zu den anderen lokalen Erkrankungen des Tracheobronchialsystems (6.6.1-6.6.4) bei Adoleszenten und jungen Erwachsenen auf. Es handelt sich um eine virale Erkrankung (Human Papilloma Virus). Multiple Papillome können die ganze Trachea auskleiden. Husten ist ein häufiges Symptom. Die Erkrankung ist benigne, neigt aber zu Rezidiven [81] und zur malignen Entartung [82]. Die Prognose ist in Hinblick auf die regelhaft auftretenden Rezidive ernst. Die Diagnose wird laryngoskopisch, bronchoskopisch und histologisch gestellt [83].

Anmerkungen zur Therapie: Kryotherapie, Laserbehandlung, mechanische Abtragung bei der Bronchoskopie.

\subsection{Reactive airways dysfunction syndrome (RADS)}

Es tritt nach kurzzeitiger, massiver Inhalation von Dämpfen, Rauch oder Gasen [84] (in der Regel als Arbeitsunfall) auf. Die Symptomatik besteht aus sofort einsetzendem (s. auch Kapitel 5.5) und über mindestens mehrere Monate anhaltendem Husten, Atemnot, bronchialer Hyperreagibilität und häufig im Verlauf schwerem, progredienten Asthma $[85,86]$. Die Symptomatik ist auf eine akute Schädigung des respiratorischen Epithels mit nachfolgender eosinophiler und neutrophiler Entzündung („remodeling“) zurückzuführen.

Anmerkungen zur Diagnostik: Sie stützt sich auf die Anamnese und den anamnestischen Ausschluss von früher bestehendem Asthma.

Anmerkungen zur Therapie: Neben der antiasthmatischen Therapie sind ggf. Antitussiva zur Linderung des Hustens angezeigt.

\subsection{Vocal cord dysfunction (VCD, Pseudoasthma)}

Ist charakterisiert durch eine intermittierend auftretende inspiratorische, ggf. auch exspiratorische Adduktion der Stimmbänder. Hierdurch werden Husten (trockenes Hüsteln), Pfeifen und Brummen sowie Atemnot ausgelöst [87]. Begleitet ist VCD von Heiserkeit und Angst. Auslöser sind häufig psychischer und physischer Stress sowie Husten. VCD tritt oft in Verbindung mit Asthma auf [88]. VCD reagiert nicht auf die antiasthmatische Therapie und wird häufig als schweres Asthma verkannt und fälschlicherweise mit hohen systemischen Kortikosteroiddosen behandelt [89]. Betroffen sind vor allem jüngere Frauen (Frauen : Männer $=4: 1)$.

Anmerkungen zur Diagnostik: Typischerweise gelingt es nicht, reproduzierbare Fluss-Volumenkurven zu registrieren, gelegentlich fällt eine Abflachung des inspiratorischen Teils der Fluss-Volumenkurve auf. Ganzkörperplethysmographisch findet sich eine wechselnde Erhöhung des Atemwegswiderstandes. Die Diagnose wird laryngoskopisch (ohne Sedierung oder Anästhesie) durch den Nachweis von paradoxen Stimmbandbewegungen, oft begleitet von einer kranialwärts gerichteten Bewegung des Kehlkopfes, gestellt. VCD mit paradoxen Stimmbandbewegungen kann meistens, aber nicht immer durch Bronchoskopie provoziert werden [90]. Unter Lokalanästhesie oder Sedierung verschwinden aber die paradoxen Stimmbandbewegungen.

Anmerkungen zur Therapie: Aufklärung, logopädische und psychotherapeutische Intervention. Bei gleichzeitigem Asthma ist eine antiasthmatische Therapie ebenfalls erforderlich.

\subsection{Tuberkulose}

Chronischer Husten ist ein typisches Symptom der Tuberkulose. Falls eine Lungentuberkulose vorliegt, wird die obligate Röntgendiagnostik des chronischen Hustens in den meisten Fällen einen pathologischen Befund ergeben. Daher sollte bei Patienten, die der Tuberkulose-Risikopopulation angehören stets an die Möglichkeit einer Tuberkulose gedacht und zügig die radiologische und ggf. die Sputumdiagnostik eingeleitet werden. Die wichtigsten Risikogruppen sind: Migranten aus Gebieten mit hoher Tuberkuloseinzidenz, aus Entwicklungsländern und der ehemaligen Sowjetunion; besonders wenn sie in Gemeinschaftsunterkünften wohnen; Alkoholiker, Obdachlose, geriatrische und immundefiziente Patienten. Eine isolierte Larynx- und Bronchustuberkulose kann in seltenen Fällen der Röntgen- oder CTDiagnostik entgehen [91-93]. Die Abklärung erfolgt bronchoskopisch, daher ist die Bronchoskopie als letzte diagnostische Maßnahme bei jedem Patienten mit unklar gebliebenen Husten erforderlich.

Therapie des Hustens bei Tuberkulose: s. Empfehlungen der Deutschen Gesellschaft für Pneumologie für die medikamentöse Behandlung der Tuberkulose bei Erwachsenen und Kindern [94]. Die antituberkulotische Therapie lindert auch den Husten. Antitussiva können jedoch zu Beginn der Chemotherapie nicht nur eine Linderung der Beschwerden bewirken, sondern auch zur Eindämmung der Kontagiosität beitragen. 
Empfeh- Evidenzlungsgrad grad

E8 Als symptomatische Zusatztherapie zu Beginn der D 5 Chemotherapie, die auch die Kontagiosität eindämmt.

\subsection{Keuchhusten}

Eine akute Infektion mit B. pertussis kann bei (nicht geimpften) Kindern eine akute fieberhafte Erkrankung mit akut auftretendem und charakteristischem „pertussiformem“ lang anhaltendem Stakkato-Husten verursachen. Die Schutzwirkung der Impfung kann bis zum Erwachsenenalter verloren gehen. Eine Infektion im Erwachsenenalter bei entsprechendem Kontakt ist daher möglich. Keuchhusten als Ursache eines chronischen Hustens im Erwachsenenalter ohne vorausgegangene akute Infektphase wurde beschrieben $[95,96]$. Auch abgelaufene respiratorische Mischinfektionen sind in Erwägung zu ziehen [97,98]. Der Goldstandard der Diagnose, der Direktnachweis von B. pertussis auf der Agarplatte gelingt zum Zeitpunkt der Erstuntersuchung von Erwachsenen nur selten. Die serologischen Methoden sind oft methodenabhängig und schwierig zu interpretieren (Schwellenwert der Positivität, alte oder frische Infektion, Titeranstieg). Therapie der Wahl sind Makrolid-Antibiotika, nach Abklingen der akuten exsudativen Phase der Infektion (Dauer: bis zu $10 \mathrm{Ta}-$ gen) haben sie aber keine Wirkung mehr auf die Heilung und auf den Husten. Der chronische Husten durch eine B. pertussis-Infektion ist beim Erwachsenen selten und klingt nach Monaten spontan ab. Antitussiva können Linderung verschaffen (Empfehlungsgrad D).

\subsection{Chronische Linksherzinsuffizienz}

Der Husten bei einer chronischen Linksherzinsuffizienz folgt dem gleichen Pathomechanismus, wie bei einer akuten Linksherzinsuffizienz. Der Husten tritt typischerweise bei körperlicher Anstrengung oder beim Hinlegen auf. Die häufigste Ursache der Linksherzinsuffizienz, die koronare Herzkrankheit, ist oft mit der COPD, einer häufigen Ursache des chronischen Hustens, vergesellschaftet. Beide Erkrankungen können einen chronischen Husten auslösen bzw. verschlimmern.

\subsection{Endokarditis}

Sie kann ebenfalls Husten verursachen [99].

\subsection{Husten als Nebenwirkung der kardialen Therapie}

ACE-(angiotensin converting enzyme)-Hemmer können Husten verursachen (s. Kapitel 7.9), ebenso $\beta$-Blocker, aber letztere nur bei Patienten, die auch an einer bronchialen Hyperreagibilität leiden. $\beta 1$-selektive $\beta$-Blocker könnten günstiger sein, als nichtselektive Blocker. Amiodaron kann zu einer diffusen Lungenparenchymerkrankung mit Husten führen (s. Kapitel 6.5).

\section{Chronisch persistierender Husten (CPH)}

Die diagnostische Abklärung eines Patienten mit chronischem Husten erweist sich als besonders schwierig, wenn die Lungenfunktionsdiagnostik und die Röntgenuntersuchung der Thorax- organe keinen richtungweisenden Befund ergeben. Der chronische Husten erscheint dann nicht als Symptom einer definierbaren Erkrankung (s. Kapitel 6.1-6.13), sondern sozusagen als eigenständiges Krankheitsbild. Ein solcher chronischer Husten ohne evidente Ursache wird in der angelsächsischen Literatur „chronic cough“ [100], deutsch CPH genannt [12]. CPH wurde definiert als über 8 Wochen anhaltender Husten (produktiv oder trocken), dessen Ursache bei der Anamnese, der körperlichen Untersuchung, der Röntgenaufnahme des Thorax und Lungenfunktion nicht ersichtlich ist (Tab. 10).

Tab. 10 Diagnostische Kriterien für den chronisch persistierenden Husten (CPH)

\section{Dauer: $\geq 8$ Wochen}

Anamnese, körperliche Untersuchung: nicht richtungweisend

Lungenfunktionsprüfung: nicht richtungweisend

Röntgen-Thoraxaufnahme in 2 Ebenen: nicht richtungweisend

Irwin u. Mitarb. schlugen 1977 vor, die Ursache eines solchen $\mathrm{CPH}$ entlang der bekannten anatomischen Lokalisation der Hustenrezeptoren zu suchen [100]. Auf der Grundlage eines anatomisch-diagnostischen Protokolls wurden weltweit mehrere Studien durchgeführt. Erwachsenenkollektive (43-329 Patienten mit CPH) $[23,25-27,29,100,101]$ sowie Kinder $[24,102]$ wurden untersucht. Als Ursache für den CPH fanden sich, abgesehen von Einzelfällen, in allen Studien - mit etwas unterschiedlicher Häufigkeit - folgende Erkrankungen, die es abzuklären und zu behandeln gilt, um den Husten zu bessern (Tab. 11).

\section{Tab. 11 Häufigste Ursachen des CPH}

chronische Erkrankungen der Nase und Nebenhöhlen

chronische Erkrankungen von Pharynx und Larynx

Husten als Asthmaäquivalent

medikamentös ausgelöster Husten (z. B. ACE-Hemmer)

gastroösophageale Refluxkrankheit

chronische, nicht obstruktive Bronchitis (Rauchen, Noxen am Arbeitsplatz)

Bronchiektasen, chronisch superinfiziert

postinfektiöser Husten nach B. pertussis und Mykoplasma pneumoniae

Bronchomalazie

eosinophile Bronchitis

\begin{tabular}{|c|c|c|c|}
\hline Nr. & $\begin{array}{l}\text { Empfehlung: Diagnostik des Hustens bei } \\
\text { normalem Röntgenbild und Lungenfunktions- } \\
\text { befund }\end{array}$ & $\begin{array}{l}\text { Empfeh- } \\
\text { lungsgrad }\end{array}$ & $\begin{array}{l}\text { Evidenz- } \\
\text { grad }\end{array}$ \\
\hline E9 & $\begin{array}{l}\text { Die drei häufigsten Ursachen in Erwägung ziehen: } \\
\text { Erkrankungen der oberen Atemwege } \\
\text { Husten als Asthmaäquivalent } \\
\text { Gastroösophagialer Reflux }\end{array}$ & A & 1a \\
\hline
\end{tabular}


7.1 Chronische Erkrankungen von Nase/Nebenhöhlen

Können Auslöser eines chronischen Hustens sein (Evidenzgrad 1a). Es handelt sich um die persistierende allergische Rhinitis, die nicht allergische Rhino/Sinusitis meist im Sinne von NENAR (non-eosinophilic, non-allergic rhinopathia) oder NARES (nonallergic rhinopathia eosinophilia syndrome), die Polyposis nasi, oft verbunden mit dem so genannten „postnasal drip“-Phänomen (Schleimstraße im Rachen, Irritationsgefühl im Hals, Globus, Hustenreiz, Räusperzwang). Eine chronische Sinusitis ist bei Erwachsenen selten, bei Kindern eine der häufigen Ursachen des chronischen Hustens. An den Allgemeinarzt, Kinderarzt, Internisten oder Pneumologen stellt die Diagnose einer Erkrankung der oberen Atemwege eine besondere Herausforderung, da für sie in der Regel die entsprechenden Untersuchungstechniken nicht zur Verfügung stehen. Folgende Symptome/klinische Zeichen lassen an eine Erkrankung der oberen Atemwege denken, die ursächlich für den chronischen Husten sein können (Tab.12).

Tab. 12 Häufigste Symptome und klinische Zeichen von Erkrankungen der oberen Atemwege mit chronischem Husten

herunterfließendes Sekret im Rachen (seltener: Sekretfluss aus der Nase)

Räusperzwang

chronisch oder intermittierend behinderte Nasenatmung

bei der Inspektion: pflastersteinartige Schleimhaut im Rachen

( = lymphofolliculäre Hyperplasie des Waldeyer'schen Ringes)

Schleimstraße

„Frosch im Hals“, Globusgefühl

Kopf-/Gesichtsschmerz

Riech- und Schmeckverlust

Heiserkeit

Anmerkungen zur Diagnostik: Meist ist die Überweisung des Patienten zum Hals-Nasen-Ohrenarzt erforderlich. Durch eine anteriore Rhinoskopie, besser durch eine Nasenendoskopie lassen sich Ödem, Hyperplasie, lividrote Verfärbung oder Polypen der Schleimhaut nachweisen. Die Sonographie und die Röntgenaufnahme der Nasennebenhöhlen sind hilfreich bei der Diagnose einer chronischen Sinusitis oder Polyposis nasi. Für eine Ausschlussdiagnostik eignet sich jedoch nur die Computertomographie, welche unerlässlich für die Diagnostik im Bereich der Sinus ethmoidales posteriores und der Sinus sphenoidales ist. Die Relevanz der erhobenen Befunde für den chronischen Husten ist in jedem Einzelfall kritisch zu prüfen, da diese Erkrankungen nur bei einer Minorität der Erkrankten zu CPH führen. Mögliche Ursachen dieser Erkrankungen sind eine Inhalationsallergie auf perenniale Allergene, anatomische Engstellen (Nasenendoskopie, CT), Zilienfunktionsstörungen, ASS-Intoleranz, Medikamenten/ Drogenabusus, bakterielle oder mykotische Stoffwechselprodukte (Enterotoxine/Superantigene), Autoimmunmukositis, selten: zystische Fibrose, M. Wegener, Tumor, spezifische granulomatöse Entzündungen u.a.

Anmerkungen zur Therapie: Therapieempfehlungen für die einzelnen Krankheitsbilder enthält die Tab.13.
Tab. 13 Therapieempfehlungen für die Erkrankungen der oberen Atemwege

\begin{tabular}{|c|c|c|}
\hline Diagnose & Therapie 1. Wahl & Weitere Therapieoptionen \\
\hline $\begin{array}{l}\text { nichtallergische Rhino- } \\
\text { pathie (NENAR) }\end{array}$ & nasales Kortikosteroid & $\begin{array}{l}\alpha \text {-Adrenergika nasal } \\
\text { (7 Tage) } \\
\text { Antihistaminika }\end{array}$ \\
\hline allergische Rhinopathie & Allergenkarenz & $\begin{array}{l}\text { wie nichtallergische } \\
\text { Rhinopathie } \\
\text { Leukotrienantagonist }\end{array}$ \\
\hline chronische Sinusitis & $\begin{array}{l}\text { Abfluss operativ } \\
\text { wiederherstellen }\end{array}$ & $\begin{array}{l}\text { Antibiotika: } \beta \text {-Lactam, } \\
\text { Makrolide, Ketolide, } \\
\text { Chinolone [103] }\end{array}$ \\
\hline Polyposis nasi (NARES) & nasales Kortikosteroid & Operation \\
\hline
\end{tabular}

\subsection{Chronische Erkrankungen von Pharynx und Larynx}

Im Bereich des Pharynx sind die Pharyngitis sicca und Malignome regelmäßig mit chronischem Husten verbunden. Auch an postoperative Defektzustände im Bereich von Zungengrund, Pharynx und Hypopharynx und an stenosierende Prozesse in Hypopharynx und oberem Ösophagus ist zu denken. Zu den seltenen Ursachen gehören erworbene ösophago-tracheale Fisteln.

Im Bereich des Larynx sind alle entzündlichen Erkrankungen und Tumore differenzialdiagnostisch in Erwägung zu ziehen. Häufig führen die Laryngitis sicca (L. atrophica) und die Laryngitis hyperplastica zu chronischem Husten [104], der meist mit einer Änderung des Stimmklanges (Heiserkeit, z.T. Aphonie) verbunden ist. Stimmbandpolypen, Kontaktgranulome und -ulzera, Stimmband- und Vallekulazysten und Papillome führen erst ab einer gewissen Größe zu Hustenreiz. Ebenfalls häufige Hustenursachen sind funktionelle Stimmstörungen, insbesondere die hyperfunktionelle Dysphonie.

Anmerkungen zur Diagnostik: Die Diagnose erfolgt im Regelfall durch Larynxendoskopie, ggf. in Kombination mit einer Stroboskopie und Elektromyographie des Larynx.

Anmerkungen zur Therapie: Abhängig vom Befund kommen topische Steroide, physikalische Maßnahmen (Inhalationen), mikrochirurgische und laserchirurgische Maßnahmen und/oder eine logopädische Therapie in Betracht.

Bei einem erheblichen Anteil der Patienten hat der Husten mehrere Ursachen, häufig kann neben einer Erkrankung der oberen Atemwege zusätzlich auch ein Asthmaäquivalent (s. nächstes Kapitel 7.3) vorliegen, dann handelt es sich um ein sog. Sinubronchiales Syndrom. Auch eine gastroösophageale Refluxkrankheit (Kapitel 7.4) kann vergesellschaftet sein. Beide müssen separat behandelt werden, um eine Linderung des Hustens zu erreichen. Die Annahme, dass eine Diagnose aus dem Bereich der oberen Atemwege für den Husten kausal ist, bedarf der Bestätigung durch die Therapie.

\subsection{Husten als Asthmaäquivalent}

Wenn Patienten mit einem trockenen Husten eine unspezifische bronchiale Hyperreagibilität aufweisen, kann letztere für den Husten verantwortlich sein [105-109] (Evidenzgrad 1a). Die 


\begin{tabular}{|llll|}
\hline Nr. Empfehlung: Abklärung multipler Ursachen & $\begin{array}{l}\text { Empfeh- } \\
\text { lungsgrad }\end{array}$ & $\begin{array}{l}\text { Evidenz- } \\
\text { grad }\end{array}$ \\
\hline E10 & $\begin{array}{l}\text { Der chronische Husten kann mehrere Ursachen } \\
\text { haben. Jede einzelne muss abgeklärt und separat } \\
\text { behandelt werden um den Husten zu lindern. }\end{array}$ & $\mathbf{1 a}$ \\
\hline
\end{tabular}

beiden anderen Symptome des Asthmas: Atemnot sowie Pfeifen und Brummen fehlen. Daher lässt sich dieser „Husten als Asthmaäquivalent“ („cough type asthma“, „cough variant asthma“) spirometrisch und ganzkörperplethysmographisch anhand einer asthmatypischen reversiblen Bronchialobstruktion nicht diagnostizieren. Erforderlich ist eine unspezifische inhalative Provokationstestung, die in der Regel der Pneumologe durchführt. Die nach viralen Infekten entstandene mit anhaltendem Husten einhergehende bronchiale Hyperreagibilität (s. auch akuter postinfektiöser Husten Kapitel 5.6) klingt in der Regel innerhalb von 6 Wochen spontan ab, kann aber auch jahrelang persistieren. Husten als Asthmaäquivalent ist die häufigste $[26,29]$ oder zweithäufigste $[23,101]$ Ursache des CPH. Wenn bei einem CPH eine bronchiale Hyperreagibilität im unspezifischen inhalativen Provokationstest nachgewiesen wird, kann nur dann die endgültige Diagnose „Husten als Asthmaäquivalent“ gestellt werden, wenn sie durch Ansprechen auf die antiasthmatische Therapie bestätigt wird, da bei 25\% [110] bis 30\% [111] der Bevölkerung eine asymptomatische bronchiale Hyperreagibilität besteht. Ein negativer inhalativer Provokationstest schließt hingegen mit großer Wahrscheinlichkeit Asthma als Ursache des Hustens aus.

Anmerkungen zur Therapie: Patienten mit Husten als Asthmaäquivalent sprechen sehr gut auf die klassische antiasthmatische Therapie, in der Regel auf inhalative Kortikosteroide, aber auch auf $\beta_{2}$-Agonisten oder Leukotrienantagonisten an [112]. Manche Patienten entwickeln im weiteren Verlauf ein klassisches Asthma [106]. Es gibt jetzt Evidenz dafür, dass die antiinflammatorische Therapie des Hustens als Asthmaäquivalent die Entstehung eines klassischen Asthmas günstig beeinflusst [113].

\begin{tabular}{llll}
\hline Nr. & $\begin{array}{l}\text { Empfehlung: Therapie des Hustens als Asthma- } \\
\text { äquivalent }\end{array}$ & $\begin{array}{l}\text { Empfeh- } \\
\text { lungsgrad }\end{array}$ & $\begin{array}{l}\text { Evidenz- } \\
\text { grad }\end{array}$ \\
\hline E11 & $\begin{array}{l}\text { Inhalative Kortisontherapie kann der Entstehung } \\
\text { eines klassischen Asthmas entgegenwirken. }\end{array}$ & B & 3b \\
\hline
\end{tabular}

\subsection{Gastroösophagealer Reflux (GÖR)}

Die Prävalenz des GÖR ist hoch und steigt weiter an: $51 \%$ einer nicht selektierten Population in einer deutschen Allgemeinpraxis hatten Symptome eines GÖR. An Husten litten 40\% der 82 Refluxpatienten, gegenüber von nur 16\% Husten unter den 80 Kontrollpersonen [114]. Allerdings ist diese Assoziation nicht automatisch mit Kausalität gleichzusetzen. Nach einem kürzlich publizierten Statement der American Gastroenterological Association [115] ist die Kausalität zwischen GÖR und pulmonalen Symptomen nach evidenzbasierten Kriterien nicht bewiesen (Evidenzgrad 4).
Für refluxbedingten Husten werden 2 Mechanismen diskutiert:

\section{A Reflextheorie:}

Der Husten kann auf reflektorischem Wege ausgelöst werden. (Im Laufe der Ontogenese entstehen sowohl das gastrointestinale als auch das respiratorische System aus dem Urdarm. Im distalen Ösophagus sind Hustenrezeptoren vorhanden. Der Reflexbogen läuft über sensible Vagusfasern zum Hustenzentrum).

\section{B Aspirationstheorie:}

Der pathologische GÖR kann auch den proximalen Ösophagus oder gar den Pharynx erreichen. Gerade der proximal nachgewiesene Reflux korreliert gut mit den respiratorischen Symptomen [116-118] und lässt auf einen weiteren bzw. alternativen Pathomechanismus, an Mikroaspirationen direkt in die Trachea schließen [118].

Die Aktivierung des Hustenreflexes durch einen GÖR erzeugt einen Circulus vitiosus: durch Erhöhung des transdiaphragmalen Druckes beim Hustenstoß wird die Öffnung des unteren Ösophagussphinkters und damit der weitere Reflux begünstigt [119].

Anmerkungen zur Diagnostik: Die klinische Diagnose des GÖRbedingten Hustens ist schwierig, da respiratorische Symptome in etwa bei der Hälfte der Patienten auch ohne Sodbrennen auftreten können [119-122]. Auch der endoskopische Befund kann negativ (Reflux ohne Refluxösophagitis) ausfallen. Daher lässt sich eine verlässliche Diagnose des GÖR nur mittels 24 Stunden pH-Metrie stellen. Es gibt keine allgemein anerkannten Auswertungskriterien für die pH-Metrie um beurteilen zu können, ob eine nachgewiesene Refluxepisode mit dem Husten nur assoziiert ist oder ihn auslöst. Eine pathologische 24 Stunden Säureexpositionszeit im unteren Ösophagus kann ein Hinweis auf einen kausalen Zusammenhang zwischen Husten und Reflux sein, ebenso bereits wenige proximale Refluxepisoden in 24 Stunden. Eine Assoziation der Hustenepisoden mit dem Reflux in 50\% der vom Patienten während der pH-Metrie durch eine Signaltaste markierten Hustens verdichtet die Wahrscheinlichkeit der Kausalität zwischen Reflux und Husten [123]. Es ist jedoch nicht klar, innerhalb welchen Zeitfensters der GÖR vor dem Husten zu erwarten ist. Es werden Intervalle von 2-10 Minuten genannt [124]. Obwohl durch die Druckschwankungen bei einem Hustenstoß Reflux ausgelöst werden kann, geht dem Husten in fast $50 \%$ eine Refluxepisode zeitlich voraus [123]. Es ist aber letztlich nicht ausgeschlossen, dass auch Refluxepisoden, die kurz nach dem Husten auftreten, für die Übererregbarkeit des Hustenreflexes verantwortlich sein könnten. Selbst bei normaler Säureexpositionszeit mit häufigen, mit dem Husten zeitlich assoziierten Refluxepisoden ist an refluxbedingten Husten zu denken [125].

Zusammenfassend beweist die bloße Assoziierung einer pathologischen Säureexpositionszeit mit dem Husten den kausalen Zusammenhang nicht. Für die Auswertung der pH-Metrie fehlen validierte und allgemein akzeptierte Kriterien in Hinblick darauf, wann der Husten als Folge des Refluxes angesehen werden kann. Diese Tatsache schränkt die Wertigkeit der pH-Metrie in der Routinediagnostik des $\mathrm{CPH}$ ein. Die pH-metrisch gestellte Verdachtsdiagnose eines Reflux bedingten Hustens bedarf der Bestätigung durch eine erfolgreiche Antirefluxtherapie mit Proto- 
nenpumpenhemmern. Die pH-Metrie hat einen positiven prädiktiven Wert von maximal 89\% [20] oder weniger [126].

Bei nachgewiesenem pathologischen Reflux ist nach gastroenterologischen Gesichtspunkten zu entscheiden ob eine Endoskopie indiziert ist, um eine anatomische Ursache des Refluxes oder eine Barett-Läsion des Ösophagus zu untersuchen.

Wegen der beschränkten Verfügbarkeit, Invasivität und der Limitationen der Interpretation der 24 Stunden pH-Metrie bezüglich der Auslösung von CPH wurden Protonenpumpeninhibitor (PPI) Therapieregimes zwischen $2[30,126,127]$ und $8-12$ Wochen $[121,128]$ vorgeschlagen, um den Reflux bedingten Husten ex iuvantibus zu diagnostizieren. Für den ex iuvantibus Ausschluss eines GÖR bedingten Hustens sind 3 Monate Therapie erforderlich [121,128 - 130]. Selbst ein 3-monatiger negativer Therapieversuch mit Standarddosen von Omeprazol schließt jedoch den GÖR als Ursache des Hustens nicht ganz aus:

- Ein Teil der Patienten benötigt zur Suppression des Refluxes mehr als $40 \mathrm{mg}$ Omeprazol/die [30,131-133].

- GÖR kann nur eine wesentliche Teilursache des Hustens bei Patienten mit dem häufigen multikausalen Husten $[134,121]$ sein

- Es wurde diskutiert, dass auch ein alkalischer Reflux mit Pankreasenzymen und Galle selbst dann Husten verursachen kann, wenn eine vollständige Suppression der Säurebildung erreicht wurde. Bei diesen Patienten war eine chirurgische Fundoplicatio hilfreich [135], welche auch als wirksam bei Patienten mit Husten und therapierefraktärem sauren GÖR beschrieben wird [136]. Die vorhandene Literatur reicht aber nicht aus, um eine Empfehlung zur Fundoplicatio bei Patienten ohne sauren Reflux auszusprechen.

Bei negativem Ausfall der 3-monatigen probatorischen Therapie (Therapieversager) ist daher eine 24 Stunden pH-Metrie indiziert. Sie kann auch zum Nachweis der ausreichenden Säuresuppression unter der PPI Therapie erforderlich werden [30].

\section{Nr. Empfehlung: Therapie des refluxbedingten Empfeh- Evidenz- Hustens bei Resistenz gegenüber Protonen- $\quad$ lungsgrad grad pumpenhemmer}

E12 Therapiedauer bis zu 3 Monaten erforderlich, um B eine Kausalität auszuschließen.

E13 Bei Misserfolg spätestens nach 3 Monaten 24 Stunden pH-Metrie unter Protonenpumpenhemmer-Therapie durchführen.

E14 Fundoplicatio zur Verhinderung von sauerem oder alkalischem Reflux gehört daher in das Spektrum des CPH. Sie kann aber nur dann als Ursache für den $\mathrm{CPH}$ akzeptiert werden, wenn der chronischen Bronchitis eine identifizierbare Ursache (Rauchen, starke Arbeitsplatz bezogene Schadstoffbelastung, z. B. Arbeit unter Tage) zugrunde liegt. Es ist nicht akzeptabel, die Diagnose der chronischen Bronchitis - definitionsgemäß - auf das Symptom Husten zu stützen und gleichzeitig als Ursache des chronischen Hustens eines Patienten die chronische Bronchitis zu diagnostizieren. Die chronisch obstruktive Bronchitis als Ursache eines chronischen Hustens wurde unter der COPD beschrieben (s. Kapitel 6.2). Obwohl die chronische nichtobstruktive Bronchitis eine der häufigsten Erkrankungen sein dürfte, die mit Husten einhergeht, war der Anteil der Raucher (falls nicht von vornherein ausgeschlossen [29] in allen CPH-Studien [20,23,26-28] gering, meist um 5\%. Offensichtlich verdrängen die Raucher den obligaten „Raucherhusten“ und suchen damit den Arzt gar nicht erst auf. Der Husten bei der chronischen Bronchitis wird durch eine neurogene Entzündung [137-139] der Bronchialschleimhaut verursacht. Die inflammatorischen Zytokine, insbesondere Substance P stimulieren die Hustenrezeptoren. Hinzu kommt die Hyperkrinie, ein physikalischer Stimulus des Hustenrezeptors.

Anmerkungen zur Diagnostik: Bei unauffälligem Auskultationsbefund kann der Anhusteversuch positiv ausfallen.

Anmerkungen zur Therapie: Der Raucherhusten bessert sich unter Nikotinkarenz bereits nach 4-6 Wochen [28,101,131,140-143], verschwindet aber in fortgeschrittenen Fällen nicht vollständig.

\begin{tabular}{|llll}
\hline Nr. Empfehlung: Therapie des Raucherhustens & $\begin{array}{l}\text { Empfeh- } \\
\text { lungsgrad }\end{array}$ & $\begin{array}{l}\text { Evidenz- } \\
\text { grad }\end{array}$ \\
\hline E15 & $\begin{array}{l}\text { Besserung unter Nikotinkarenz nach } 4-6 \\
\text { Wochen. }\end{array}$ & A & 2c \\
\hline
\end{tabular}

\subsection{Bronchiektasen}

Sind irreversibel dilatierte Bronchien mit entzündlicher Wandverdickung. Die Erweiterung kann zylindrisch, varikös oder zystisch sein. Bronchiektasen können auf der Übersichtsaufnahme des Thorax unentdeckt bleiben und so in die Kategorie des CPH fallen. Sie verursachen meist, aber nicht immer Husten mit voluminösem Auswurf (mindestens $30 \mathrm{ml}$, entsprechend zwei vollen Esslöffeln in 24 Stunden), oft mukopurulent oder purulent. Bronchiektasen sind auch eine häufige Ursache von Hämoptoe. Bei voluminösem Auswurf und diagnostisch nicht weiterführender Thoraxaufnahme kann die Diagnose durch eine hochauflösende Computertomographie (HR-CT) gestellt werden.

Anmerkungen zur Therapie: Antitussiva sind bei dem produktiven Husten bei Bronchiektasie kontraindiziert. In Ausnahmefällen kann jedoch eine bronchiectasis sicca mit quälendem Husten vorliegen, dann ist die vorübergehende Verordnung von Antitussiva akzeptabel. Die Basis der Behandlung sind: Physiotherapie (Kapitel 10.1.1) und Pharmakotherapie (Kapitel 10.2) zur Sekretelimination, Antibiotika (Kapitel 10.2.6) und in Einzelfällen chirurgische Resektion, falls die Bronchiektasen auf wenige Segmente beschränkt sind. In diesen Fällen können sie erfolgreich
Anmerkungen zur Diagnostik: Die nicht obstruktive chronische Bronchitis geht mit einer normalen Lungenfunktion einher und

\subsection{Chronische, nicht obstruktive Bronchitis}

Sie wird nach der WHO Definition als Husten und Auswurf an krankungen, die Husten hervorrufen können, ausgeschlossen worden sind. 
und risikoarm mit Segmentresektion oder Lobektomie behandelt werden. 46-68\% der resezierten Patienten waren nach mehreren Jahren beschwerdefrei. Der postoperative Erfolg war immer dann gut, wenn eine komplette Resektion bronchiektatischer Bezirke möglich war [144-147].

\begin{tabular}{|llll}
\hline Nr. & Empfehlung: Therapie bei Bronchiektasie & $\begin{array}{l}\text { Empfeh- } \\
\text { lungsgrad }\end{array}$ & $\begin{array}{l}\text { Evidenz- } \\
\text { grad }\end{array}$ \\
\hline E16 & $\begin{array}{l}\text { Antitussiva sind bei produktivem Husten } \\
\text { kontraindiziert. }\end{array}$ & D & $\mathbf{5}$ \\
\hline E17 & $\begin{array}{l}\text { Physiotherapie zur Sekretelimination indiziert. } \\
\text { Eei isolierter Bronchiektasie: chirurgische }\end{array}$ & C & 4 \\
\hline $\begin{array}{l}\text { Resektion. } \\
\text { B }\end{array}$ & $3 a$ \\
\hline
\end{tabular}

\subsection{Chronischer Husten unklarer Ursache}

Bei 0\% [27] bis 18\% [29] aller Patienten mit CPH bleibt - ungeachtet einer extensiven Diagnostik - die Ursache des Hustens unklar. Die Mehrzahl dieser Patienten - Verhältnis Frauen:Männer $=2: 1-$ lässt eine erhöhte Sensitivität des Hustenreflexes (s. im Kapitel 3.1) gegenüber Capsaicin erkennen. Sie husten bereits bei Inhalation einer Konzentration von $1-10 \mu \mathrm{mol} / \mathrm{ml}$ Capsaicin, Normalpersonen vertragen eine Konzentration bis zu $500 \mu \mathrm{mol} /$ $\mathrm{ml}$. Dieses Phänomen könnte den schon auf unterschwellige Reize einsetzenden Husten erklären. Es handelt sich in der Praxis um eine Ausschlussdiagnose. Bei chronischem Husten anderer Genese ist die Capsaicinschwelle ebenfalls herabgesetzt, kann sich aber nach Behebung der Ursache des Hustens bessern, zum Beispiel nach Behandlung des GÖR oder nach Absetzen eines ACE-Hemmers [148], der chronischen Husten verursacht hat. In unklaren Fällen von chronischem Husten kann die Provokationstestung mit Capsaicin - ein standardisiertes Provokationsprotokoll vorausgesetzt - zur Klärung der Diagnose vom Husten infolge Erhöhung der Sensitivität des Hustenreflexes beitragen [149] (Evidenzgrad 3b). Bei einigen dieser Patienten wurde eine Lymphozytose in der bronchoalveolären Lavage entdeckt und Husten im Rahmen einer noch nicht manifesten Autoimmunerkrankung vermutet [150].

\begin{tabular}{|c|c|c|c|}
\hline Nr. & $\begin{array}{l}\text { Empfehlung: Therapie bei chronischem Husten } \\
\text { unklarer Ursache }\end{array}$ & $\begin{array}{l}\text { Empfeh- } \\
\text { lungsgrad }\end{array}$ & $\begin{array}{l}\text { Evidenz- } \\
\text { grad }\end{array}$ \\
\hline E19 & Inhalation mit einem Lokalanästhetikum. & D & 4 \\
\hline
\end{tabular}

Anmerkungen zur Therapie: Nur eine symptomatische Therapie kommt in Betracht. Bei einigen Patienten hilft die Inhalation von Lokalanästhetika (s. Kapitel 10.3).

\subsection{Psychogener Husten}

Kommt selten bei Erwachsenen vor.

Anmerkungen zur Diagnostik: Sie ist meist schwierig und verleitet leicht zur falschen Diagnose. Falls die Capsaicin-Reizschwelle erniedrigt ist, handelt es sich definitionsgemäß nicht um einen psychogenen Husten. Allerdings ergibt die Bestimmung der Cap-
saicin-Reizschwelle gerade beim psychogenen Husten schlecht reproduzierbare Ergebnisse; Husten kann willkürlich sowohl unterdrückt als auch ausgelöst werden [151]. Die Diagnose des psychogenen Hustens ist dadurch erschwert, dass der chronische Husten organischer Ursache zur sozialen Isolation, Beeinträchtigung der Lebensqualität [152] und hierdurch zu einer psychischen Veränderung des Patienten führen kann. Andererseits besteht die Gefahr, einen multikausal verursachten, schwer abklärbaren organisch bedingten Husten als psychogen zu diagnostizieren.

\subsection{Husten durch Nebenwirkung von Medikamenten}

Eine Reihe von Medikamenten kann als Nebenwirkung zu einer Schädigung des respiratorischen Systems mit Husten führen (Zytostatika, Amiodaron, Nitrofurantoin, Mutterkornalkaloide und viele andere), die zumindest in Form von Kasuistiken dokumentiert sind. Folgende Internetadresse beinhaltet aktuelle Informationen und Literatur zu diesem Thema: http://www.pneumotox.com/. Tab. 14 zeigt die häufigsten Medikamente, die als Nebenwirkung Husten verursachen und häufig abgesetzt werden müssen, um den Husten zu bessern. Hierzu gehören potenziell auch sämtliche inhalativ zu verabreichende Medikamente. Die Schädigung der Thoraxorgane ist durch konventionelles Röntgen oft nicht nachweisbar.

Tab. 14 Medikamente, die Husten verursachen können

\begin{tabular}{|c|c|}
\hline Medikament & Anmerkung \\
\hline ACE-Hemmer & Klasseneffekt, Evidenzgrad s. Text \\
\hline Amiodaron & s. Kapitel 6.5 \\
\hline$\beta$-Blocker & $\begin{array}{l}\text { bei Husten als Asthmaäquivalent } \\
\text { Evidenzgrad 3b }\end{array}$ \\
\hline Methotrexat & s. Kapitel 6.5 \\
\hline Nizatidin & Evidenzgrad 3b \\
\hline $\begin{array}{l}\text { inhalatives Kortison } \\
\text { (aus Dosieraerosolen und Pulver- } \\
\text { oder elektrischen Inhalatoren ) }\end{array}$ & $\begin{array}{l}\text { nach Einsetzen der inhalativen } \\
\text { Kortisonwirkung bei Asthma kann } \\
\text { sich der durch Inhalation ausgelöste } \\
\text { Husten bessern. } \\
\text { Evidenzgrad 3b }\end{array}$ \\
\hline $\begin{array}{l}\text { weitere inhalative Medikamente: } \\
\beta_{2} \text {-Adrenergika, Ipratropium, } \\
\text { Tiotropium, Nedocromil, DNCG, } \\
\text { Pentamidin, Sekretolytika Zanamivir }\end{array}$ & Evidenzgrad 3b \\
\hline \multicolumn{2}{|l|}{ systemisch verabreichte Sekretolytika } \\
\hline Interferon $\alpha-2 b$ und $\alpha-2 a$ & \\
\hline
\end{tabular}

ACE-Hemmer sind die mit Abstand häufigste medikamentöse Ursache für den CPH. Sie blockieren den Abbau von Bradykinin und Substance P sowie Prostaglandinen in der Bronchialschleimhaut. Hierdurch nimmt die Sensitivität des Hustenreflexes zu [153]. Realistisch erscheint die Annahme, dass etwa 10\% aller Frauen und 5\% der Männer unter ACE-Hemmer-Medikation husten, in der Literatur werden Zahlen zwischen 0,2-33\% genannt [154]. Der trockene Husten kann bereits wenige Tage oder aber erst viele Monate nach Beginn der ACE-Hemmer-Therapie auftreten, und klingt innerhalb von 3 Wochen nach deren Absetzen ab [155]. Es handelt sich um einen Klasseneffekt aller ACE-Inhibitoren. Die (antihypertensive, kardiale oder nephroprotektive) 
Therapie kann auf einen Angiotensin-II-Rezeptor-Antagonisten umgesetzt werden, der wahrscheinlich nicht häufiger Husten verursacht als Plazebo [155].

Anmerkungen zur Diagnostik: Wenn ein Patient unter ACE-Hemmer Medikation hustet, sollte die Therapie ohne weitere Diagnostik selbst dann abgesetzt bzw. umgestellt werden, wenn für den chronischen Husten scheinbar andere Gründe, wie z.B. eine chronische Bronchitis, verantwortlich sein könnten. Falls der Husten nach spätestens 4 Wochen nicht sistiert, ist eine weiterführende Diagnostik einzuleiten. In Ausnahmefällen kann auch bei Angiotensin-II-Antagonisten ein Auslassversuch indiziert sein.

\begin{tabular}{|c|c|c|c|}
\hline Nr. & $\begin{array}{l}\text { Empfehlung: ACE-Hemmer und chronischer } \\
\text { Husten }\end{array}$ & $\begin{array}{l}\text { Empfeh- } \\
\text { lungsgrad }\end{array}$ & $\begin{array}{l}\text { Evidenz- } \\
\text { grad }\end{array}$ \\
\hline E20 & $\begin{array}{l}\text { ACE-Hemmer sind die häufigste medikamentöse } \\
\text { Ursache eines chronischen Hustens. }\end{array}$ & & $1 a$ \\
\hline E21 & $\begin{array}{l}\text { Der ACE-Hemmer-Husten setzt mehrere Tage bis } \\
\text { Monate nach Beginn der Medikation ein und } \\
\text { klingt nach } 2-3 \text { Wochen nach Absetzen ab. Falls } \\
\text { der Husten nach } 4 \text { Wochen noch persistiert, ist } \\
\text { die Diagnostik einzuleiten. }\end{array}$ & A & $2 a$ \\
\hline E21 & $\begin{array}{l}\text { Angiotensin-II-Rezeptor-Antagonisten verur- } \\
\text { sachen keinen Husten und sind als Ersatz für } \\
\text { ACE-Hemmer geeignet. }\end{array}$ & D & $3 a$ \\
\hline
\end{tabular}

\subsection{Bronchomalazie}

Wenn es infolge Bronchomalazie (idiopathisch, im Rahmen einer COPD, Tracheostomie, isolierte Erkrankungen der Trachea, s. Kapitel 6.6) in seltenen Fällen bereits bei der Spontanatmung oder bei leicht forcierter Exspiration zu einem Kontakt der Vorderwand und Hinterwand - am häufigsten im Bereich des Intermediärbronchus und/oder der Trachea - kommt, kann ein therapieresistenter chronischer Husten auftreten [156].

Anmerkungen zur Diagnostik: Bei zentraler Tracheomalazie treten eine homogene Obstruktion (S-förmige Deformierung) der spezifischen Resistanceschleife und eine rechteckförmige Veränderung der Fluss-Volumenkurve auf, die aber bei isolierter Bronchomalazie des Intermediärbronchus meistens fehlen. Die flexible Funktionsbronchoskopie in örtlicher Betäubung erlaubt bei entsprechender Erfahrung des Untersuchers die Prüfung der tracheobronchialen Wandstabilität unter Normalatmung, leicht und stark forcierter Exspiration oder Husten mit Quantifizierung der Folgen der Bronchomalazie.

Anmerkung zur Therapie: Operative Stabilisierung der bronchomalazischen Wand des Bronchus oder eine - bei benignen $\mathrm{Er}$ krankungen wegen der Langzeitfolgen und Schleimretention stets problematische - Stenteinlage können in Einzelfällen zu einer Besserung des ansonsten therapieresistenten Hustens führen.

\section{Nr. Empfehlung: Husten bei Bronchomalazie}

Empfeh- Evidenzlungsgrad grad E23 Operative Stabilisierung.
E24 Stenteinlage problematisch; für Einzelfälle kann
geeignet sein.

C

\subsection{Eosinophile Bronchitis}

In seltenen Fällen kann ein chronischer Husten mit Eosinophilie im Sputum ohne bronchiale Hyperreagibilität auftreten [157] (Evidenzgrad 1a). Es könnte sich hierbei um Symptome des Asthmas (vgl. auch Husten als Asthmaäquivalent 7.3) handeln, jedoch sind Bronchialobstruktion oder bronchiale Hyperreagibilität nicht nachweisbar [158]. Die Diagnose wird durch Sputumeosinophilie $(\geq 5 \%)$ ggf. im induzierten Sputum oder in der bronchoalveolären Lavage, Nachweis einer normalen Lungenfunktion und Ausschluss einer bronchialen Hyperreagibilität gestellt. Die eosinophile Bronchitis spricht sehr gut auf eine inhalative Kortisontherapie an.

\begin{tabular}{|lll}
\hline Nr. $\begin{array}{l}\text { Empfehlung: Therapie des Hustens bei eosino- } \\
\text { philer Bronchitis }\end{array}$ & $\begin{array}{l}\text { Empfeh- } \\
\text { lungsgrad }\end{array}$ & $\begin{array}{l}\text { Evidenz- } \\
\text { grad }\end{array}$ \\
\hline E25 Gutes Ansprechen auf inhalative Steroide. & A & $\mathbf{1 a}$ \\
\hline
\end{tabular}

\subsection{Zystische Fibrose}

Zystische Fibrose (CF) ist eine autosomal rezessiv vererbte $\mathrm{Er}$ krankung. Es handelt sich um Mutationen im Bereich des langen Armes des Chromosoms 7. Durch fehlerhafte Kodierung des „cystic fibrosis transmembrane conductance regulator" (CFTR), eines Ionenkanals, wird die Chloridsekretion und dadurch der Flüssigkeitsgehalt des Bronchialsekrets und je nach Genotyp auch des Pankreassekrets, der Galle, des Sperma reduziert. Die pulmonale Manifestation ist durch bronchiale Infekte, Bronchiektasen und Husten sowie reduzierten Ernährungszustand charakterisiert. In klassischen Fällen wird die Diagnose mit Hilfe des Schweißtests schon im frühen Kindesalter gestellt; somit kommt CF selten als differenzialdiagnostisches Problem beim Husten vor. Bei abortiven Formen der Erkrankung kann aber CF erst im Erwachsenenalter klinisch in Erscheinung treten [159] und diagnostische Schwierigkeiten bereiten: die Messung der Potenzialdifferenz an der Nasenschleimhaut kann bei negativem Schweißtest diagnostisch sein.

\section{Diagnostik beim Husten}

Husten ist das gemeinsame Symptom eines breiten Spektrums von Erkrankungen mit unterschiedlicher Diagnose, Therapie und Prognose. Einige konkrete diagnostische Maßnahmen wurden bei den einzelnen Krankheitsbildern aufgeführt. Hier soll nur auf allgemeine Prinzipien der Stufendiagnostik, die als Flussdiagramm dargestellt wird, eingegangen werden. Zweck der Stufendiagnostik ist die möglichst schnelle und rationelle Abklä- 
rung der Ursache des Hustens, um eine kausale Therapie einleiten zu können.

Wegen der Häufigkeit des Symptoms Husten empfiehlt sich als erster Schritt der Diagnostik die Klassifizierung anhand eines anamnestisch leicht zu erhebenden Merkmals: akut und chronisch (Definitionen s. Kapitel 4), wenngleich eine klare Trennung naturgemäß nicht immer möglich ist. Es wurden daher zwei diagnostische Algorithmen: für den akuten (Abb.2) und den chronischen (Abb. 3) Husten ausgearbeitet.

Der Algorithmus dient zur Abklärung zunächst unklar erscheinender Fälle. Falls eine durch die Anamnese begründete Verdachtsdiagnose gestellt wird, kann es sinnvoll sein, vom Algorithmus abzuweichen. Häufige und oft kostspielige Fehler treten in der Diagnostik bei unbegründetem Abweichen von der logischen Reihenfolge auf (Kapitel 9).
Durch Anwendung des Algorithmus kann öfters nur eine Verdachtsdiagnose gestellt und der entsprechende Therapieversuch eingeleitet werden. Die endgültige Diagnose wird in diesen Fällen erst aufgrund des Erfolges der Therapie festgelegt. Bei Misserfolg ist eine Überprüfung von möglichen diagnostischen und therapeutischen Fehlern, der Compliance des Patienten und ggf. die Fortsetzung der Diagnostik mit dem nächsten Schritt im Algorithmus erforderlich.

\subsection{Akuter Husten (Abb. 2)}

Der akute Virusinfekt ist die häufigste Ursache des Hustens, der nach Abklingen des Infektes bis zu 8 Wochen (und länger) persistieren kann, falls eine infektbedingte bronchiale Überempfindlichkeit auftritt (Kapitel 5.6).

Die Diagnose eines infektbedingten akuten Hustens erfordert in der Regel nur die Erhebung der Anamnese und eine körperliche

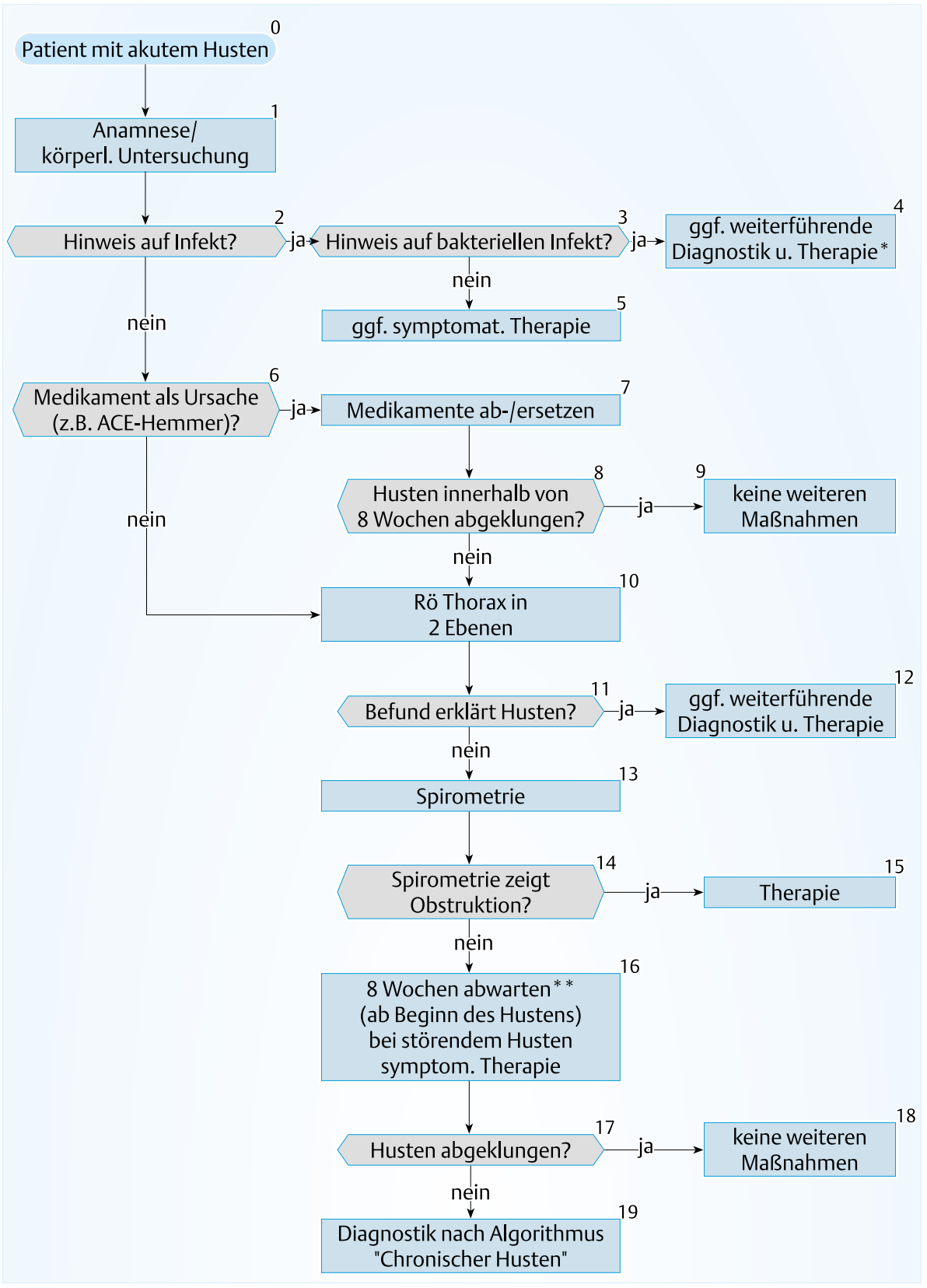

Abb. 2 Klinischer Algorithmus zur Diagnostik des akuten Hustens.

* Antibiotikum meist erforderlich bei eitrigem (grünem oder gelbem) Auswurf und Komorbidität, oft bei älteren Patienten.

** Cave rezidivierende kleine Lungenembolien mit Episoden von Husten, Palpitation, Atemnot, ggf. Hämoptoe 


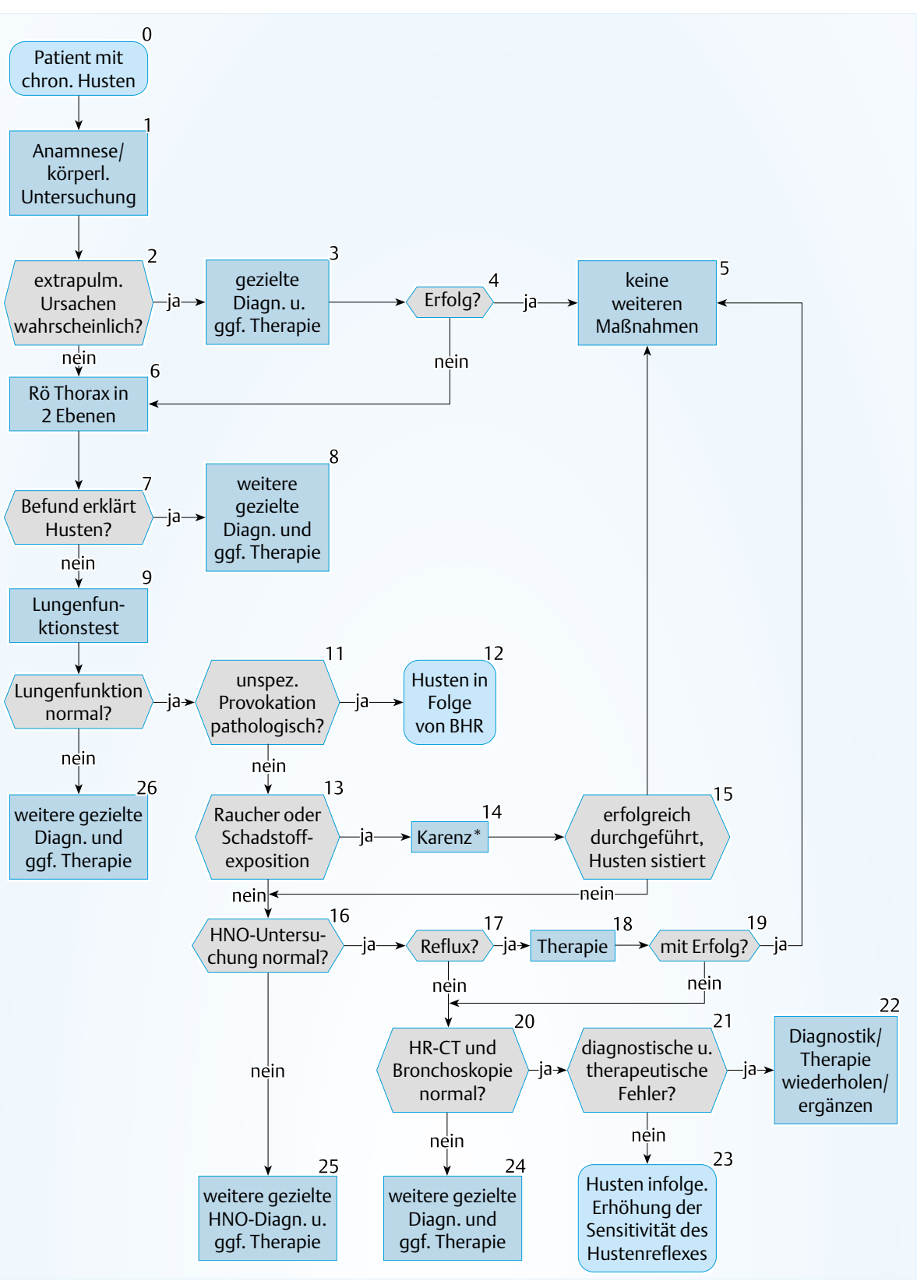

Abb. 3 Klinischer Algorithmus zur Diagnostik des chronischen Hustens.

*1. jeder Patient mit einem ungeklärten chronischen Husten muss spätestens am Ende des diagnostischen Algorithmus bronchoskopiert werden (Empfehlungsgrad A). 2. bei Änderung des Schweregrades und/ oder der Charakteristik des Hustens beim Raucher sollte bei klinischem Verdacht abweichend vom Algorithmus eine Bronchoskopie durchgeführt werden (Empfehlungsgrad D).

Untersuchung (Box 1) zum Ausschluss anderer Ursachen wie Pneumonie, akuter Linksherzinsuffizienz, inhalativer Intoxikation etc. (Box 2). Eine sichere Differenzierung zwischen einen viralen und bakteriellen Infekt aufgrund klinischer Merkmale ist nicht möglich [160]. Eine akute Infektion der Atemwege eines ansonsten gesunden Patienten stellt selbst bei bakterieller Infektion keine absolute Indikation für eine antibiotische Therapie dar [33]. Patienten mit eitrigem Auswurf und entweder gleichzeitiger Komorbidität (koronare Herzkrankheit, Diabetes mellitus, COPD, Immuninkompetenz bei Malignomen usw.) und/oder im hohen Alter profitieren jedoch von einer antibiotischen Therapie (Box 4) [161]. Eine Röntgenaufnahme der Thoraxorgane, Laboruntersuchungen einschließlich mikrobiologische und serologische Untersuchungen sind bei einem akuten Infekt bei ansonsten gesunden Personen in der Regel nicht erforderlich. Eine länger als eine Woche anhaltende Symptomatik mit CRP-Erhöhung, Leukozytose und gelb oder grün gefärbtes Sekret weisen auf einen bakteriellen Infekt hin, der auf eine kalkulierte antibiotische
Therapie anspricht. Akuter Husten mit negativem Röntgenbefund und oft mit restriktivem Lungenfunktionsmuster kann bei einer akuten Pleuritis oder bei kleinen rezidivierenden Lungenembolien gefunden werden, die häufig schwierig zu diagnostizieren sind, aber wichtige therapeutische Konsequenzen haben.

\begin{tabular}{|lll|}
\hline Nr. $\begin{array}{l}\text { Empfehlung: Therapie des Hustens bei akutem } \\
\text { Infekt der Atemwege }\end{array}$ & $\begin{array}{l}\text { Empfeh- } \\
\text { lungsgrad }\end{array}$ & $\begin{array}{l}\text { Evidenz- } \\
\text { grad }\end{array}$ \\
\hline E26 & $\begin{array}{l}\text { Selbst eine bakterielle Infektion stellt keine } \\
\text { absolute Indikation für eine antibiotische } \\
\text { Therapie dar. }\end{array}$ & B \\
\hline E27 $\begin{array}{l}\text { Ältere Patienten mit Komorbidität profitieren von } \\
\text { einer antibiotischen Therapie. }\end{array}$ & $\mathbf{4}$ \\
\hline E28 $\begin{array}{l}\text { Bei eitrigem Sekret, CRP-Erhöhung, verfärbtem } \\
\text { Sputum oder länger, als 1 Woche anhaltenden } \\
\text { Beschwerden Antibiotikum empfohlen. }\end{array}$ & D & $\mathbf{5}$ \\
\hline
\end{tabular}


Bei einem über 8 Wochen anhaltenden Husten ist die Diagnostik nach dem entsprechenden Algorithmus für den chronischen Husten weiterzuführen (Box 6 Abb. 3).

\subsection{Chronischer Husten}

Wenn ein Patient an chronischem, über 8 Wochen anhaltendem Husten leidet, sollte die diagnostische Abklärung sofort eingeleitet werden. Sie fängt mit der Erhebung der Anamnese und einer körperlichen Untersuchung an (Box 1). Wenn sich hierbei Hinweise auf eine ausschließliche oder vorwiegende extrapulmonale Ursache des Hustens ergeben, ist die gezielte Diagnostik einzuleiten (Box 3).

- Wenn ein blandes klinisches Bild vorliegt und die Medikamentenanamnese die Einnahme eines ACE-Hemmers ergibt, sollte vor weiteren Maßnahmen das Ergebnis einer 3-wöchigen Karenz abgewartet werden (Box 2, 3).

- Patienten mit Symptomen einer chronischen Sinusitis, blockierter Nasenatmung/Ausfluss aus der Nase, Halsschmerzen, sollten nach einer Röntgenuntersuchung der Thoraxorgane in 2 Ebenen hals-nasen-ohrenärztlich abgeklärt werden (Box 2,3).

- Patienten mit klinischen Zeichen einer Linksherzinsuffizienz, Herzrhythmusstörungen, Galopprhythmus, Hypertonie, Herzgeräuschen etc. sind neben einer Röntgenuntersuchung der Thoraxorgane in 2 Ebenen der gezielten kardialen Diagnostik zuzuführen (Box 2, 3).

- Patienten mit neurologischen Auffälligkeiten (z.B. bulbäre Sprache, Paresen, Parkinson-Symptomatik) könnten an Husten infolge rezidivierender Aspirationen leiden und sollten neben einer Röntgenuntersuchung der Thoraxorgane in 2 Ebenen neurologisch abgeklärt werden (Box 2).

- Bei Patienten mit Husten und Sodbrennen kann - nach einer Röntgenuntersuchung der Thoraxorgane in 2 Ebenen - die Verdachtsdiagnose eines gastroösophagealen Refluxes (Box 17) klinisch gestellt werden, um die (probatorische) Therapie mit PPI einzuleiten. Bei auffälliger gastroenterologischer Anamnese sollte nach den geltenden gastroenterologischen Empfehlungen verfahren werden.

Oft gibt in der Diagnostik des Hustens die Röntgenaufnahme der Thoraxorgane Hinweise auf die weiterführende gezielte Diagnostik (z. B. einer Pneumonie, einer diffusen Lungenparenchymerkrankung etc.). Diese Diagnostik ist nicht Gegenstand dieser Leitlinie. In vielen Fällen existieren evidenzbasierte separate Leitlinien (Box 7, 8).

Die Lungenfunktionsprüfung erlaubt einen weiteren wichtigen diagnostischen Schritt im Sinne der Abgrenzung von Erkrankungen, die Husten verursachen und mit einer obstruktiven Ventilationsstörung einhergehen. Am häufigsten handelt es sich hier um Asthma oder COPD. Die Messung der Diffusionskapazität (TLCO) erlaubt COPD-Patienten mit vorwiegendem Emphysem zu diagnostizieren (Box 26).

Bei einer restriktiven Ventilationsstörung ist an Thoraxwandund neuromuskuläre Erkrankungen zu denken. Wenn der Diffusionskoeffizient ebenfalls erniedrigt ist, könnte dieser ein Hinweis auf eine diffuse Lungenparenchymerkrankung sein (Box 26).
Die schwierigste Herausforderung stellt die Abklärung des chronischen Hustens dar, wenn weder die Röntgenaufnahme der Thoraxorgane noch die Lungenfunktion richtungweisend sind. Wenn in dieser Situation die unspezifische inhalative Provokationstestung (Box 11) auf eine bronchiale Hyperreagibilität hinweist, kann der Husten als Asthmaäquivalent (Kapitel 7.3) angesehen werden.

Bei Rauchern und (beruflich) schadstoffexponierten Patienten mit chronischem Husten (Box 13) kann die Ursache eine chronische (nicht obstruktive) Bronchitis im Sinne der WHO-Definition sein. Es ist darauf hinzuweisen, dass der Anteil der Raucher unter Patienten mit chronischem nicht geklärtem Husten viel niedriger ist, als etwa bei COPD-Patienten in Stadium 1-3 der Erkrankung (Kapitel 6.2). Bei Rauchern mit nicht richtungweisendem Röntgenbild und normaler Lungenfunktion ist jedoch das Rauchen die wahrscheinlichste Ursache des Hustens. Daher ist vor weiteren diagnostischen Maßnahmen eine Karenz (Box 14) angezeigt. Abweichend hiervon kann es aber bei Änderung der Intensität oder der Charakteristik des Hustens notwendig sein, die Diagnostik sofort weiterzuführen. Falls eine Raucherentwöhnung nicht gelingt oder durch Karenz die Symptomatik sich nach 4 Wochen nicht bessert, ist die Diagnostik ohnehin nach dem Algorithmus (Box 16) fortzusetzen.

Bei Patienten ohne anamnestischen Hinweis auf eine Refluxsymptomatik (Box 17) soll wie folgt verfahren werden: Eine Diagnostik (24 Stunden pH-Metrie, ggf. Endoskopie und Röntgendiagnostik des Ösophagus) ist zu empfehlen, es kann aber auch gleich die probatorische Therapie mit PPI - je nach der Verfügbarkeit der pH-Metrie und Akzeptanz der Untersuchung durchgeführt werden.

Falls die Ursache des chronischen Hustens am Ende des Algorithmus (Box 21) nicht evident ist und der Husten persistiert, sollten

Tab. 15 Die wichtigsten Empfehlungen und evidenzbasierten Empfehlungsgrade* zur Abklärung des Hustens

\section{Empfehlung und Empfehlungsgrad für die Untersuchung} Untersuchungsmethode Akuter Husten Chronischer Husten

\begin{tabular}{|lll|}
\hline Anamnese & ja (A) & ja (A) \\
\hline Raucheranamnese & ja (D) & ja (A) \\
\hline körperliche Untersuchung & ja (A) & ja (A) \\
\hline $\begin{array}{l}\text { Röntgen-Thorax-Aufnahme } \\
\text { Lungenfunktionsprüfung }\end{array}$ & nein (A) & jain (D) \\
$\begin{array}{l}\text { unspezifischer Provokationstest } \\
\text { hals-nasen-ohrenärztl. Unter- }\end{array}$ & nein (D) & ja (A) \\
suchung & ja (A) \\
CT der Nebenhöhlen & nein (D) & ja (A) \\
\hline 24 Stunden pH-Metrie & nein (D) & ja (C) \\
\hline HR-CT Thorax & nein (D) & ja (C) \\
\hline Bronchoskopie & nein (D) & ja (D) \\
\hline
\end{tabular}

*Anmerkung: die Empfehlungsgrade gelten nur, wenn die aufgeführte logische Reihenfolge der Untersuchungen eingehalten wird. Die Anamnese und die körperliche Untersuchung können Befunde ergeben, die eine Abweichung erforderlich machen: z. B. akute Hämoptoe. 
Tab. 16 Häufige diagnostische (und therapeutische) Fehler, welche die Abklärung des chronischen Hustens verhindern

\section{obere Atemwege}

sehr häufig angetroffene, relativ geringe entzündliche Veränderungen der Schleimhäute werden ignoriert und nicht behandelt

zu kurze Behandlungsdauer bei Rhinitis, Nasenpolypen

Asthma

unspezifische inhalative Provokation wird nicht durchgeführt

ein positiver Ausfall der Provokation wird mit Asthma gleichgesetzt, obwohl er auch in der gesunden Allgemeinbevölkerung vorkommt. Nur wenn der Husten auf die Asthmatherapie anspricht, kann die Diagnose „Husten als Asthmaäquivalent" gestellt werden

GÖR

Standarddosen von PPI (z. B. 40 mg Omeprazol) können unzureichend sein um eine volle Säuresuppression zu erreichen. Ggf. 24 Stunden pH-Metrie unter PPI erforderlich

zu kurze Behandlungsdauer

Linksherzinsuffizienz

wird übersehen

multiple Erkrankungen

wenn der CPH mehrere Ursachen hat (zum Beispiel Asthma und Rhinopathie), wird der Husten erst besser, wenn alle zugrundeliegenden Erkrankungen behandelt werden

unklar gebliebene Fälle

werden nicht bronchoskopiert

häufige diagnostische und therapeutische Fehler (Tab.16), eine beginnende, radiologisch noch wenig ausgeprägte diffuse Lungenparenchymerkrankung, ein (allerdings seltener) psychogener Husten oder andere sehr seltene Erkrankungen in Erwägung gezogen werden (Box 22). Bei einigen Patienten bleibt jedoch die Ursache des chronischen Hustens trotz Ausschöpfung der diagnostischen Möglichkeiten unklar: eine Erhöhung der Sensitivität des Hustenreflexes wird dann angenommen (Kapitel 7.7).

Es muss darauf hingewiesen werden, dass keine nach den Prinzipien der evidenzbasierten Medizin evaluierten Algorithmen vorliegen.

\subsection{Ambulante und stationäre Diagnostik}

Die Diagnostik des Hustens ist die Domäne der ambulanten Versorgung. Im Regelfall können alle aufgeführten Untersuchungsmethoden ambulant durchgeführt werden. Die Notwendigkeit einer stationären Untersuchung und Behandlung ist von dem Zustand des Patienten, Komorbidität und dem Husten zugrunde liegenden Erkrankung abhängig: Unter anderem erfordern beispielsweise eine massive Hämoptoe, eine akute Aspiration mit Zeichen der Asphyxie, eine akute Lungenembolie mit Kreislaufinstabilität, Risikobronchoskopien bei Komorbidität oder transbronchialen Lungenbiopsien unbedingt eine stationäre Behandlung.

\subsection{Nebenwirkungen, Komplikationen und Kosten der Diagnostik des Hustens}

Im Allgemeinen sind die zur Diagnostik des Hustens eingesetzten Untersuchungsmethoden risikoarm. Bei der unspezifischen inhalativen Provokationstestung kann eine schwere Obstruktion, bei der 24 Stunden pH-Metrie können Erbrechen, Übelkeit und Aspiration, bei der Bronchoskopie Hypoxie, Infektion, Blutung,

\begin{tabular}{|llll}
\hline Nr. & $\begin{array}{l}\text { Empfehlung: Ambulante oder stationäre } \\
\text { Diagnostik }\end{array}$ & $\begin{array}{l}\text { Empfeh- } \\
\text { lungsgrad }\end{array}$ & $\begin{array}{l}\text { Evidenz- } \\
\text { grad }\end{array}$ \\
\hline E29 & Im Regelfall ambulant. & D & kein \\
\hline E30 & $\begin{array}{l}\text { Bedrohliche Begleitsymptome (Asphyxie, } \\
\text { instabiler Kreislauf, massive Hämoptoe) } \\
\text { Komorbidität: stationär. }\end{array}$ & A & 1c \\
\hline
\end{tabular}

Pneumothorax (nur bei transbronchialen Biopsie) in seltenen Fällen auftreten. Das größte Risiko der Diagnostik liegt im Übersehen von schwerwiegenden Erkrankungen, deren Kardinalsymptom der Husten ist: zum Beispiel Lungenembolie, Bronchialkarzinom oder Tuberkulose. Die Stufendiagnostik der Leitlinie bietet Gewähr für einen nicht zu frühen aber rechtzeitigen Einsatz invasiver Untersuchungsmethoden und optimiert hierdurch das Nutzen/Risiko-Verhältnis. Die Einhaltung der logischen Reihenfolge der Untersuchungen trägt zudem dazu bei, den Kostenaufwand zu optimieren (s. auch Kapitel 9: Häufige Fehler).

\subsection{Zusammenfassung der wichtigsten Empfehlungen zur Diagnostik des Hustens (Tab. 15)}

\section{Häufige Fehler bei der Stufendiagnostik des Hustens}

Die außerordentliche Häufigkeit des Symptoms bzw. der Beschwerde Husten und potenzielle Folgen und Folgekosten einer verspäteten Diagnose bei ansteckender Tuberkulose oder bei Bronchialkarzinom und Lungenembolie unterstreichen die Notwendigkeit einer evidenzbasierten rationellen und rationalen Diagnostik.

\section{Hierbei sollte sowohl ein}

„zu viel“ an Diagnostik: (Computertomographie, Bronchoskopie bei einer banalen, protrahiert verlaufenden akuten Bronchitis), als auch

„zu wenig“(die Bagatellisierung des „Raucherhustens“, welcher Symptom eines Bronchialkarzinoms sein kann) - vermieden werden.

Die Reihenfolge der diagnostischen Schritte in beiden Algorithmen für den akuten und den chronischen Husten zeigt jeweils die zweckmäßigste, das heißt am schnellsten zum Ziele führende, dabei am wenigsten invasive und preiswerteste Untersuchung an. Wenn zwei diagnostische Verfahren in einer konkreten Situation gleichwertig sind, wurde primär das weniger invasive oder kostengünstigere Verfahren aufgeführt.

Bei einem von früher her bekannten Patienten, der zum Beispiel bereits eine Lungenresektion wegen Bronchialkarzinom gehabt hat, kann es sinnvoll und wirtschaftlich sein, bei anhaltendem Husten, abweichend vom Algorithmus, bereits nach wenigen Tagen eine Röntgendiagnostik und die Bronchoskopie einzuleiten. Die häufigsten Fehler treten jedoch bei ungerechtfertigtem Abweichen vom Algorithmus auf, um die am leichtesten verfügbaren - anstelle der zweckmäßigsten - Untersuchungen bei der Abklärung des Hustens durchzuführen. Nachfolgend werden die 
in der Praxis am häufigsten anzutreffenden Fehler der logischen Reihenfolge der Diagnostik aufgezählt. Durch Vermeidung solcher Fehler können erhebliche Kosten eingespart werden.

- Patienten mit massiv beeinträchtigter Nasenatmung als Ausdruck einer Rhinitis werden bronchoskopiert, bevor sie dem Hals-Nasen-Ohrenarzt vorgestellt werden.

- Häufig wird die Bronchoskopie in der Suche nach einer seltenen Ursache des Hustens - mit negativem Ergebnis - durchgeführt, bevor der Patient auf die sehr häufige Diagnose Husten als Asthmaäquivalent mittels unspezifischer bronchialer Provokation getestet wurde.

- Ein GÖR wird anhand der Ösophagoskopie oder Röntgenuntersuchung des Ösophagus „ausgeschlossen“, obwohl es GÖR ohne Ösophagitis geben kann, der Husten verursacht.

- Eine allergologische Diagnostik wird vorgezogen, obwohl einem IgE-vermittelten (atopisch-)allergischen Husten entweder ein („cough variant“) Asthma oder eine allergische Rhinitis zugrunde liegen. Wenn kein Asthma und keine Rhinitis vorliegen, ist die allergologische Diagnostik überflüssig.

- Serologische Untersuchungen auf Viren und Bakterien (z.B. Mycoplasma pneumoniae und Bordatella pertussis) werden ohne konkreten Verdacht (z. B. Kontaktperson) in einer zu frühen Phase der Diagnostik durchgeführt, obwohl sie nur selten einen CPH erklären. Sie haben ihren Platz am Ende der Stufendiagnostik.

- Die computertomographische Diagnostik der Nebenhöhlen wird vor einer HNO-ärztlichen Untersuchung veranlasst.

- Patienten mit Husten bei negativem Röntgen-Thoraxbefund und Karzinophobie werden mit CT untersucht.

\begin{tabular}{|lll|}
\hline Nr. Empfehlung: Diagnostische Algorithmen & $\begin{array}{l}\text { Empfeh- } \\
\text { lungsgrad }\end{array}$ & $\begin{array}{l}\text { Evidenz- } \\
\text { grad }\end{array}$ \\
\hline E31 Anwendung der diagnostischen Algorithmen. & D & $\mathbf{5}$ \\
\hline E32 & $\begin{array}{l}\text { Erhebliches Einsparpotenzial durch Anwendung } \\
\text { der Algorithmen. }\end{array}$ & $\mathbf{5}$ \\
\hline
\end{tabular}

\section{Therapie}

Vor der Einleitung einer Therapie sollte zunächst die Ursache des Hustens abgeklärt werden, um kausal behandeln zu können. Eine symptomatische Therapie des diagnostisch nicht abgeklärten chronischen Hustens ist der häufigste Fehler, der bei der Behandlung des Hustens in der Praxis vorkommt. Beim chronischen Husten kann neben der kausalen Behandlung des Grundleidens eine symptomatische Therapie zur sofortigen Linderung der Symptomatik mit Sekretolytika und/oder Antitussiva sinnvoll sein. Sie darf aber nicht zur Verzögerung der Diagnostik und zur verspäteten Einleitung der kausalen Therapie (z. B. Bronchialkarzinom) führen.

In den Kapiteln 5 und 6 wurden kausale Therapiemaßnahmen zu den einzelnen Krankheiten dargestellt oder auf existierende Leitlinien hingewiesen. Die nachfolgend aufgeführte symptomatische Therapie ist dann angezeigt, wenn
- die Ursache des Hustens nach der Diagnostik unklar bleibt (z.B. CPH infolge Erhöhung der Sensitivität des Hustenreflexes, Kapitel 7.7)

- die zugrunde liegende Erkrankung nicht kausal behandelt werden kann, z.B. Bronchialkarzinom (Kapitel 6.3), akute virale Laryngo-Tracheobronchitis (Kapitel 5.1).

- die Wirkung der kausalen Therapie verzögert einsetzt (Tuberkulose, Kapitel 6.9).

Jede Erfolg versprechende symptomatische Therapie des Hustens wirkt an einem oder mehreren der 5 Abschnitte des HustenReflexbogens (s. Kapitel 3.1): am Rezeptor, am afferenten oder am efferenten Schenkel, am Hustenzentrum oder am Erfolgsorgan (thorakale und abdominelle Muskulatur) (Tab. 17).

Tab. 17 Klassifikation der Hustentherapeutika nach Ort ihrer Wirkung

Hustentherapeutika mit vorwiegender Wirkung am Hustenrezeptor

Hustentherapeutika mit vorwiegender Wirkung am Reflexbogen (Herabsetzung der Sensitivität des Hustenreflexes)

zentral wirkende Hustentherapeutika

am Effektororgan wirkende Hustentherapeutika (Muskelrelaxanzien)

\section{Die Wirkung selbst kann}

- protussiv (husten- bzw. expektorationsfördernd) und

- antitussiv (hustendämpfend) sein.

Die Elimination von Sekret entlastet die Hustenrezeptoren und lindert hierdurch den Hustenreiz. Welches der Prinzipien zur Anwendung kommen sollte, hängt von der Grunderkrankung ab: - Die Förderung der Expektoration ist das zentrale Prinzip in der Therapie der chronischen hypersekretorischen Bronchitis und der Bronchiektasie. Antitussiva sind bei Bronchiektasen daher kontraindiziert. Dies gilt auch für einen Teil der COPDPatienten mit Retention von zähem Sekret in den Stadien II und III nach der Klassifikation der Deutschen Gesellschaft für Pneumologie und der Atemwegsliga [48].

- Die überwiegende Mehrzahl der Patienten, die wegen Husten den Arzt konsultieren, leidet an einem unproduktiven „Reizhusten“ wie bei Asthma oder Lungenparenchymerkrankungen bzw. an Husten mit geringen Sekretmengen, wie bei akuten oberen und unteren respiratorischen Infektionen. Es besteht kein Grund, auf die Vorteile einer effektiven hustenstillenden Therapie bei solchen Patienten zu verzichten.

- In Hinblick auf die bislang bekämpfte Kombination einer antitussiven und sekretolytischen Therapie findet heute ein Paradigmenwechsel statt [162]: die Wirkung kann eventuell durch die Kombination beider Prinzipien (tagsüber Sekretolyse, nachts Hustendämpfung) verstärkt werden.

\subsubsection{Physiotherapie bei produktivem Husten}

Sekretansammlungen im Bronchialsystem (oder aspirierte Fremdkörper) aktivieren den Hustenreflex. Bevor jedoch das Bronchialsekret abgehustet werden kann, muss es von der Bronchialwand abgelöst werden. Der einfachste Weg Sekrete aus dem Bronchialbaum zu lösen und zu entfernen, ist das Erzeugen von 
Kaliberschwankungen der Bronchien durch vermehrte Ein- und Ausatmung [163] und z. B. durch Atemtechniken wie die autogene Drainage auch in Verbindung mit Lageveränderungen und körperlicher Belastung. Verschiedene Atemtechniken wie active cycle breathing oder die autogene Drainage ebenso wie Lagerungsübungen (Seitenlage) nutzen oder kombinieren das physikalische Grundprinzip der Ablösung des Sekrets mit der Wirkung der Schwerekraft. Der Ablösung des Sekrets dienen auch der Brustwand manuell oder mit Hilfe von elektrischen Geräten aufgesetzte Vibrationen, die im Gewebe bis zur Bronchialwand weitergeleitet werden. Niederfrequente Klopfmassagen gelten hingegen als obsolet [164].

Der richtig durchgeführte Hustenstoß ist die effektivste Maßnahme zur Elimination des Sekrets. Bei instabilen Bronchien sind besondere Atemtechniken erforderlich, wie Huffing, ein Husten mit geöffneter Glottis. Nach Einatmen durch die Nase mit anschließender Atempause erfolgen unter Betätigung der Bauchmuskulatur 2-3 schnelle „Huffs“ (als wenn man eine Scheibe anhauchen wollte). Befindet sich das Sekret bereits in den zentralen Atemwegen, ist der Huff nur kurz, bei Sekretvorkommen in den peripheren Atemwegen wird der Huff länger durchgeführt. Die Tiefe der Inspiration vor dem Huff beeinflusst bei Instabilität der Bronchialwand (chronische Bronchitis), welcher Abschnitt gereinigt wird. Ein mittleres Atemzugvolumen vor der forcierten Exspiration lässt die vorwiegende Reinigung der 4.-6. Generation der Bronchien, ein tiefer Atemzug die der zentralen Bronchien zu (s. Kapitel 3.1).

Alle diese Techniken bedürfen zunächst der Anleitung durch einen in der Atemtherapie erfahrenen Physiotherapeuten und sollten dann zu Hause regelmäßig durchgeführt werden. Die Compliance ist jedoch niedrig [165].

Obwohl physiotherapeutische Maßnahmen in der Therapie von Bronchiektasen, der zystischen Fibrose und COPD zum Standard gehören [48] gibt es keine Evidenz aus randomisierten kontrollierten Studien für deren Effekte [166,167]. 3 Studien untersuchten insgesamt 27 Bronchiektasiepatienten mit verschiedenen Methoden der Physiotherapie und wiesen eine Zunahme der Expektoration bzw. der Radioaerosolclearance, aber keine Beeinflussung der Lungenfunktion nach [168-171]. Die meisten Studien liegen für die Behandlung der zystischen Fibrose mit verschiedenen Techniken, die miteinander verglichen werden, vor $[163,172,173]$.

Eine Physiotherapie ist in der Regel nur bei chronischem Husten mit oder ohne Bronchiektasen indiziert.

\subsubsection{Physiotherapie bei unproduktivem Husten}

Beim produktiven Husten wird ein Ausatemstoß provoziert, ein quälender unproduktiver Husten sollte hingegen unterdrückt werden. Dies ist für den Patienten die am schwersten erlernbare Hustentechnik, welche Hustendisziplin voraussetzt [174]. Der Patient wird aufgefordert zwischen den Hustenattacken die Luft in Inspirationsstellung anzuhalten, dann vorsichtig und oberflächlich weiter zu atmen. Muss dennoch gehustet werden, kann dies gegen die geschlossenen Lippen erfolgen. Es wird angenommen, dass hierdurch die Reizung der Dehnungsrezeptoren vermindert werden kann.
Hustenvermindernde Techniken sind in Einzelfällen indiziert.

\subsubsection{Atemphysiotherapie unter Zuhilfenahme von Geräten}

In den letzten Jahren haben Atemphysiotherapiegeräte wie Flutter (früher VRP1 Desitin) und RC-Cornet für die Sekretelimination erheblich an Bedeutung gewonnen.

Die Verwendung der Flutter (VRP1 Desitin), eines kleinen Physiotherapiegerätes mit einem PEP (positive exspiratory pressure) und Vibrationseffekt, bietet Vorteile neben und gegenüber der klassischen Physiotherapie, da die Sekretmobilisation patientenseitig mehrmals am Tag durchgeführt werden kann. In einer Studie bei COPD-Patienten konnten Vorteile in Hinblick auf den Husten, die Atemnot und die Lungenfunktion festgestellt werden [175]. Die vorhandene spärliche Literatur bestätigt keine Vorteile für den Flutter bei Bronchiektasie [176]. In einer Vergleichstudie mit Flutter konnte für das RC-Cornet, das der Exspiration ebenfalls PEP und Vibrationseffekt aufsetzt, nach einwöchiger zusätzlicher Therapie bei Patienten mit tracheobronchialer Instabilität nicht nur eine signifikante Besserung der Expektoration, sondern als einzige physiotherapeutische Maßnahme - auch eine klinische Besserung des Hustens nachgewiesen werden [177]. Statistisch signifikante Effekte fanden sich auch auf die Lungenfunktion, die Notwendigkeit von Krankenhausbehandlungen und den Antibiotikumbedarf. Diese Geräte sind bei gesicherter Compliance in Einzelfällen indiziert.

\begin{tabular}{|llll}
\hline Nr. & Empfehlung: Physiotherapie beim Husten & $\begin{array}{l}\text { Empfeh- } \\
\text { lungsgrad }\end{array}$ & $\begin{array}{l}\text { Evidenz- } \\
\text { grad }\end{array}$ \\
\hline E33 & $\begin{array}{l}\text { Bei chronischem produktiven Husten. } \\
\text { E34 }\end{array}$ & Cei trockenem Husten: hustenvermindernde & kein \\
Techniken. & $\mathbf{5}$ & \\
\hline E35 & $\begin{array}{l}\text { Physiotherapiegeräte (RC Cornet). } \\
\text { Flutter }\end{array}$ & C & $\begin{array}{l}\text { 3b } \\
\text { kein }\end{array}$ \\
\hline
\end{tabular}

Medikamentöse Therapie

\subsection{Hustentherapeutika mit vorwiegender Wirkung am Hustenrezeptor}

(Manche Medikamente haben kombinierte Effekte und wirken auch auf den afferenten und efferenten Schenkel des Reflexbogens und auf das Hustenzentrum). Tab. 18 zeigt die möglichen pharmakologischen Effekte, die den Hustenrezeptor entlasten.

Tab. 18 Lokale Effekte an den Hustenrezeptoren

\begin{tabular}{ll}
\hline Effekt & Wirkstoffklasse \\
\hline $\begin{array}{l}\text { Erhöhung des Sekretvolumens } \\
\text { Herabsetzung der Viskosität }\end{array}$ & $\begin{array}{l}\text { Sekretolytika } \\
\text { Mukolytika }\end{array}$ \\
\hline $\begin{array}{l}\text { Verringerung der Sekretproduktion } \\
\text { Steigerung der mukoziliären Clearance }\end{array}$ & Anticholinergika \\
\hline $\begin{array}{l}\text { Reduktion physikalischer und chemi- } \\
\text { scher Irritation (Schleimhautabschwel- }\end{array}$ & $\boldsymbol{\beta}_{2}$-Adrenergika, Theophyllin \\
\hline lung, entzündliche Mediatoren) & Antibiotika, Kortikosteroide \\
\hline
\end{tabular}




\subsubsection{Expektoranzien}

Durch Erhöhung des Sekretvolumens (Sekretolytika) und Herabsetzung der Viskosität (Mukolytika) werden die bronchiale Reinigung erleichtert, visköser Schleim und mit dem Schleim auch inhalierte Fremdpartikel entfernt. Die Reizung der Hustenrezeptoren wird hierdurch gemindert, der Husten soll durch „Abhusten“ erleichtert werden. Dieses Prinzip kann dann wirken, wenn der Hustenreiz durch eine Sekretretention ausgelöst wird. Am häufigsten werden Expektoranzien jedoch bei der akuten viralen Bronchitis eingesetzt, obwohl meist keine Sekretretention vorliegt. Dennoch stellt diese Substanzengruppe die am häufigsten verordneten Arzneimittel für Erkrankungen des respiratorischen Systems dar [178]. Ihre Wirkung ist schwer objektivierbar [179]. Die in Deutschland gebräuchlichsten Substanzen sind Ambroxol und N-Acetylcystein, in englischsprachigen Ländern Guaifenesin und Kalium jodatum. Betreffend die Wirksamkeit von verschiedenen Expektoranzien gibt es widersprüchliche Evidenz in der Literatur, auf entsprechende Übersichten $[180,181]$ wird hingewiesen. Die Erhöhung der Flüssigkeitszufuhr in normalem Hydratationszustand führt nicht zur Vermehrung des Sekretvolumens. Viele Patienten geben eine günstige subjektive Wirksamkeit bei Selbstmedikation auch bei der akuten Bronchitis an. Es gibt aber derzeit keine methodisch einwandfreien Studien zur Bewertung der Wirksamkeit verschiedener, meist frei verkäuflicher Sekretolytika speziell in Hinblick auf die Linderung des akuten Hustens [182]. Zur Frage der Therapie des Symptoms Husten mit Sekretolytika, Phytopharmaka oder Hausmittel (Honig) gibt es keine evidenzbasierte Empfehlung. Die fehlende Evidenz darf aber nicht unbedingt mit fehlender Wirkung gleichgesetzt werden. Zentral wirksame Opioide (Alkaloide aus der Mohnpflanze Papaver somniferum) und peripher wirksames Ephedrin bzw. Pseudoephedrin (aus dem chinesischen Kraut Ephedra sinica) sind wissenschaftlich geprüft. Dennoch kann im Allgemeinen die zum Teil jahrhundertelange Anwendung von Phytopharmaka in den westlichen Ländern, aber auch in der traditionellen chinesischen Medizin, in Indien (Ayurveda Medizin) oder Japan mit Ausnahme der genannten Opioide und Ephedrin nicht auf valide Studien gestützt werden, die modernen methodologischen Anforderungen der evidenzbasierten Medizin entsprächen. Solche Studien sind auch nicht zu erwarten, da ihre Kosten durch eine bessere Vermarktung des Phytopharmakons nicht eingefahren werden könnten [183].

In Tab. 19 und Tab. 20 werden die gebräuchlichsten Sekretolytika aufgeführt.

Anmerkung: Bei den pflanzlichen Wirkstoffen gibt es nicht immer eine klare Trennung der Indikation Hustenblocker oder Schleimlöser. So wird Spitzwegerich unter verschiedenen Handelsnamen sowohl als Antitussivum, als auch als Sekretolytikum geführt. Viele pflanzliche Präparate enthalten Kombinationen der Phytopharmaka.

\subsubsection{Medikamente zur Verringerung der Schleimproduktion}

Inhalative Anticholinergika verringern die oft pathologisch vermehrte (entzündliche) Sekretproduktion - auch bei nicht obstruktiven Patienten [188]. Sie wirken auch auf den efferenten Schenkel des Reflexbogens, möglicherweise ist der verschluckte Anteil für diese Wirkung verantwortlich [189]. Eine zusätzliche Wirkung durch die Verringerung des bronchialen Muskeltonus
Tab. 19 Pflanzliche Sekretolytika

\begin{tabular}{|c|c|c|}
\hline Phytopharmakon & Wirksubstanz & Nebenwirkung \\
\hline $\begin{array}{l}\text { Ätherische Öle: in Form von } \\
\text { Kapsel, Tablette, Lösung, } \\
\text { Sirup, Einreibung, Bade- } \\
\text { zusatz, Teeaufguss, Inhala- } \\
\text { tion }\end{array}$ & $\begin{array}{l}\text { Anis } \\
\text { Myrtol } \\
\text { Pfefferminz } \\
\text { Eukalyptus } \\
\text { Thymian }\end{array}$ & $\begin{array}{l}\text { Allergien } \\
\text { Hautreaktionen } \\
\text { Magen-Darm-Beschwerden } \\
\text { Alkoholgehalt }\end{array}$ \\
\hline Saponine & Efeublätter & \\
\hline Glykoside & Primelwurzel & \\
\hline
\end{tabular}

Tab. 20 Chemisch definierte Sekretolytika

\begin{tabular}{|ll}
\hline Wirkstoff & Nebenwirkung \\
\hline Bromhexin & Übelkeit, Allergie \\
\hline Ambroxol & Übelkeit, Allergie \\
\hline N-Acetylcystein & Übelkeit, Erbrechen, Allergie \\
\hline Guaifenesin & Übelkeit \\
\hline Cineol & Magendruck, Allergie \\
\hline Dornase alfa* & Heiserkeit, Bronchospasmus \\
\hline Kaliumjodid & Hyperthyreose \\
\hline isotone oder hypertone (3\%) Koch- & Bronchospasmus \\
salzlösung zur Inhalation [184] & \\
\hline Emser Sole zur Inhalation [185] & Bronchospasmus \\
\hline
\end{tabular}

*Dornase alfa, eine mit rekombinanter Technik hergestellte DNAse, depolimerisiert den pathologischen Mucin-Polymer-Komplex. Bei CF-Patienten konnten hierdurch Besserungen der Lungenfunktion und eine Senkung der Infektexazerbationen nachgewiesen werden [186, 187]. Bei der chronischen Bronchitis und Bronchiektasen anderer Ursache fand sich hingegen kein Effekt.

\begin{tabular}{|llll}
\hline Nr. Empfehlung: Sekretolytika & $\begin{array}{l}\text { Empfeh- } \\
\text { lungsgrad }\end{array}$ & $\begin{array}{l}\text { Evidenz- } \\
\text { grad }\end{array}$ \\
\hline E36 & $\begin{array}{l}\text { Husten mit Sekretretention (Bronchiektasie, } \\
\text { COPD). }\end{array}$ & $\mathbf{C}$ & $\mathbf{4}$ \\
\hline E37 & Akuter Husten. & kein & kein \\
\hline E38 & Bei zystischer Fibrose: Dornase alpha. & B & $3 b$ \\
\hline
\end{tabular}

[190] und Entlastung der langsam adaptierenden Rezeptoren ist anzunehmen [191]. Nasales Ipratropium (in Deutschland nicht zugelassen) beeinflusst den durch eine vasomotorische Rhinopathie ausgelösten Husten günstig [192]. In den Studien wurden relativ hohe Dosen (bis zu $360 \mu \mathrm{g} /$ die) verwendet.

\subsubsection{Medikamente zur Steigerung der mukoziliären Clearance}

Neben Expektoranzien (s. 10.2.1) könnten Theophyllin [14,62] und $\beta_{2}$-Adrenergika durch Steigerung der mukoziliären Clearance $[193,194]$ und bei obstruktiven Patienten auch durch Bronchodilatation beim Husten erleichternd wirken. Es gibt Berichte, dass diese Substanzen auch bei nicht obstruktiven Patienten mit akutem Husten eingesetzt werden können [195], eine neuere Metaanalyse ergab jedoch keinen Hinweis auf ihre hustenstillende Wirksamkeit [196]. 


\subsubsection{Medikamente zur Reduktion der Reizung} der Hustenrezeptoren

Demulzentia wirken durch „Einhüllung“ der im Rachen befindlichen Hustenrezeptoren antitussiv. Sirups, Hustensäfte, Gurgellösungen, Lutschtabletten, Honig, Hustenbonbons enthalten als gemeinsamen Bestandteil Zuckersirup. Die Wirkungsdauer beschränkt sich auf die Verweildauer des Zuckers am Rezeptor, meist auf 20-30 Minuten. Häufige weitere wirksame Bestandteile sind Lokalanästhetika und zentral wirkende (pflanzliche) Antitussiva und Sekretolytika. Tab. 21 stellt eine kleine Auswahl von Hustensirups dar.

Tab. 21 Hustensirups

\section{Phytopharmakon Wirkstoff}

\section{Spitzwegerich}

Isländisch Moos

Eibischblätter

Zucker in Sirups und Bonbons

\section{Nebenwirkungen, Kontraindikation}

Allergie

Magen-Darm-Beschwerden

Alkoholgehalt

Diabetes

\subsubsection{Schleimhautabschwellende Substanzen}

Die Hustenrezeptoren im Bereich der oberen Atemwege können auch durch Schleimhautschwellung (Hyperämie, Ödem) gereizt werden. Abschwellend wirkende Substanzen wie topische oder systemische $\alpha$-Adrenergika - ggf. in Kombination mit älteren, anticholinerg wirksamen Antihistaminika - wirken hustenstillend, wenn der Hustenreiz tatsächlich im Bereich der oberen Atemwege entsteht. Die Anwendung als Kombinationspräparat in systemischer Form ist in Nordamerika sehr populär. Solche Kombinationspräparate werden als geeignet betrachtet, die $\mathrm{Di}$ agnose des Hustens als Folge von Affektionen der oberen Atemwege (Rhinopathie, Sinusitis, Pharyngitis) ex iuvantibus zu stellen. Dies gilt sowohl für den akuten [197] als auch für den chronischen Husten $[28,198,199]$. Der Patient ist auf die sedierende Nebenwirkung (Verkehrstüchtigkeit!) des Antihistamins und auf die adrenerge Nebenwirkungen des Pseudoephedrins hinzuweisen, zumal die Präparate rezeptfrei sind. Die in Deutschland erhältlichen Kombinationspräparate enthalten als $\alpha$-Adrenergikum Pseudoephedrin; als Antihistaminikum Triprolidin bzw. das nicht sedierende Anthistaminikum Cetirizin.

\subsubsection{Antibiotika}

- Bakterielle Infekte der oberen Atemwege, insbesondere die akute (Rhino)Sinusitis, akute eitrige Tonsillitis, akute Pharyngitis und eventuell die Otitis media verursachen durch Produktion von bakteriellen und körpereigenen Entzündungsmediatoren und Sekreten akuten und chronischen Husten. Hier ist eine kalkulierte antibiotische Therapie unter Berücksichtigung der am häufigsten verursachenden Keime (S. pneumoniae, S. aureus, H. influenzae) und der örtlichen Resistenzlage indiziert und führt rasch zur Besserung. Auf die entsprechende Leitlinie der Deutschen Gesellschaft für Hals-Nasen- und Ohrenheilkunde wird hingewiesen [103]. Chronische Sinusitiden, die oft chronischen Husten verursachen, bedürfen in erster Linie einer hals-nasen-ohrenärztlichen chirurgischen Intervention.
- Akute Bronchitiden bei ansonsten gesunden Personen sind in der überwiegenden Mehrzahl der Fälle primär viraler Natur. Antibiotika sind nur wirksam aber nicht obligat für die Behandlung eines manchmal auftretenden sekundären bakteriellen Infektes (s. E26-28). Die Verordnung eines Antibiotikums für die akute virale Bronchitis ist ein häufiger Fehler, der in der Praxis bei der Behandlung des Hustens auftritt. Durch die Verordnung entstehen nicht nur überflüssige Kosten, sondern auch eine Zunahme der Antibiotikaresistenz. Die akute Exazerbation der COPD, die stets mit vermehrtem Husten einhergeht, ist hingegen in der Hälfte der Fälle (dann, wenn purulentes Sputum expektoriert wird) bakterieller $\mathrm{Na}$ tur und spricht dann auf Antibiotika an. Empfohlen wird in der Regel eine kalkulierte antibiotische Therapie. Auf die entsprechende Empfehlung der Deutschen Atemwegsliga wird hingewiesen [38].

Bronchiektasen mit und ohne zystische Fibrose: Erweiterte Bronchien mit Sekretstau bieten infolge verminderter Clearance einen optimalen Nährboden für die mikrobielle Besiedlung. Häufig sind $\mathrm{H}$. influenzae, S. pneumoniae, S. aureus und bei der zystischen Fibrose insbesondere P. aeruginosa zu finden. M. tuberculosis, nicht tuberkulöse Mykobakterien, Aspergillus, gramnegative Bakterien und Anaerobier kommen ebenfalls vor. Bronchiektasen können steril, kolonisiert oder infiziert sein. Die akute Exazerbation bleibt meist eine in der Bronchialwand und der peribronchialen Lungengewebe lokalisierte Infektion ohne wesentliche systemische Entzündungsreaktion [200]. Wegen der Vielfalt der infrage kommenden und nach wiederholten antibiotischen Behandlungen häufig resistenten Keime sollte bei bekannter Bronchiektasen-Krankheit - im Gegensatz zur Behandlung einer akuten Exazerbation der COPD - keine kalkulierte, sondern eine gezielte (nach Kultur und Resistenztestung festgesetzte) antibiotische Therapie durchgeführt werden. Akute Exazerbationen können zwar mit Allgemeinsymptomen wie Nachtschweiß, Abgeschlagenheit und auch Fieber einhergehen. In vielen Fällen verläuft aber die Infektion okkult und führt zu therapieresistentem Husten, dessen Ursache nicht auf den ersten Blick zu erkennen ist. Trotz invasiver Diagnostik (Bronchiallavage, geschützte Bürste) gelingt es oft nicht, den Keim zu identifizieren. Selbst eine gezielte orale antibiotische Therapie bleibt in vielen Fällen erfolglos. Eine aggressive breite intravenöse antibiotische Therapie über 14-21 Tage Dauer kann dann erforderlich sein, um den Infekt zu sanieren bzw. eine Reduktion der Keimzahl zu erreichen und den Husten zu lindern [201]. In einigen Fällen sind wiederholte intravenöse antibiotische Behandlungen erforderlich. Für Pseudomonas-infizierte Bronchiektasen ist auch eine inhalative Therapie mit Tobramycin wirksam [202 - 204]. Für das inhalative Colistin (Heilversuch, keine Zulassung) liegen positive Daten in der Behandlung des zystischen Fibrose vor [205].

\begin{tabular}{|llll}
\hline Nr. & $\begin{array}{l}\text { Empfehlung: antibiotische Therapie bei } \\
\text { Bronchiektasie }\end{array}$ & $\begin{array}{l}\text { Empfeh- } \\
\text { lungsgrad }\end{array}$ & $\begin{array}{l}\text { Evidenz- } \\
\text { grad }\end{array}$ \\
\hline E39 $\begin{array}{l}\text { Bei persistierendem Husten nach oralem Anti- } \\
\text { biotikum: intravenöse antibiotische Therapie. }\end{array}$ & C & $\mathbf{4}$ \\
\hline E40 & $\begin{array}{l}\text { Inhalatives Tobramycin bei Pseudomonas- } \\
\text { Infektion. }\end{array}$ & B & $\mathbf{2 b}$ \\
\hline E41 Inhalatives Colistin bei zystischer Fibrose. & kein & $\mathbf{2 b}$ \\
\hline
\end{tabular}


10.2.7 Entzündungshemmende Substanzen

Der antitussive Wirkungsmechanismus der inhalativen Kortikosteroide besteht darin, dass sie zur Erneuerung einer durch Infekte oder Asthma zerstörten Schleimhaut beitragen, wie in bioptischen Studien nachgewiesen wurde [206]. Durch ein intaktes Epithel werden die Hustenrezeptoren geschützt [207]. Durch ihre antientzündliche Wirkung wird die Konzentration von Entzündungsmediatoren in der Schleimhaut reduziert.

Wenn der Husten durch eine intermittierende oder persistierende allergische oder nichtallergische Rhinitis ausgelöst wird, helfen nasale Kortikosteroide. Weitere topische antientzündliche Substanzen mit potenzieller Wirkung am Hustenrezeptor sind: Nedocromil und Dinatrium Cromoglykat [208-210] sowie das systemisch wirksame Zafirlukast [211] und Montelukast, letztere allerdings ausschließlich beim Husten als Asthmaäquivalent. Für die Anwendung entzündungshemmender Substanzen beim Asthma und somit beim asthmatischen Husten gibt es den Evidenzgrad 1a und Empfehlungsgrad A. http://www.nih.gov/

\subsection{Hustentherapeutika mit vorwiegender Wirkung am Reflexbogen}

Lokalanästhetika heben die elektrophysiologische Aktivität der Rezeptoren und der afferenten Nervenfasern auf und wirken so als potente Antitussiva $[212,213]$. Die Nutzung von Lokalanästhetika bei der Bronchoskopie ist tägliche Routine. Ihre Verwendung in der Therapie des Hustens ist schwierig: Sie haben eine kurze Wirkungsdauer (bis zu 30 Minuten), und es gibt keine geeignete inhalative Applikationsform; es sei denn die Verneblung mit einem elektrischen Vernebler. Es gibt kein Lokalanästhetikum auf dem Markt mit Zulassung für die antitussive Indikation. Als so genannter Heilversuch („off label use“) können $4 \mathrm{ml}$ $2 \%$-iges Prilocain oder Lidocain tgl. 2-3× mit dem elektrischen Vernebler bei Patienten mit therapieresistentem Husten meist unbekannter Ursache (idiopathische Erhöhung der Sensitivität des Hustenreflexes, Kapitel 7.7) appliziert werden (s. E19).

Lokalanästhetika in Lutschtabletten und Gurgellösungen wirken im Pharynx und verfehlen dann die beabsichtigte antitussive Wirkung, wenn der Husten durch Reizung von Rezeptoren im Kehlkopf verursacht wird.

\subsection{Zentral wirkende Hustentherapeutika (Antitussiva)}

Sie haben zwar auch einen peripheren Wirkmechanismus, die Hauptwirkung wird jedoch durch Bindung an die Opioid- $(\mu)$-Rezeptoren im Hustenzentrum im Hirnstamm erzielt [214]. Ihre Wirksamkeit ist durch die periphere Wirkung alleine nicht zu erklären, da den Capsaicin induzierten Husten nur systemisch appliziertes Morphin oder Kodein antagonisieren kann [215]. Weitere natürliche und synthetische Opiate (Dihydrocodein, Dextromethorphan und Noscapin) sowie einige synthetische und pflanzliche Arzneimittel ohne Suchtpotenz haben eine zentrale antitussive Wirkung (Tab. 22 und Tab. 23). Bei den Opiaten müssen neben der Suchtpotenz die atemdepressive Wirkung (bei bestehender respiratorischer Globalinsuffizienz, z.B. bei COPD wichtig), die Obstipation und die Sedierung berücksichtigt werden. Bei produktivem Husten sind sie kontraindiziert. Opiate stellen den Goldstandard der antitussiven Wirkung dar. Beim Husten im Rahmen akuter Infekte der oberen Atemwege (Kapitel 5.1) und beim postinfektiösem Husten (Kapitel 5.6) sind jedoch
Tab. 22 Pflanzliche Antitussiva

\begin{tabular}{ll}
\hline Phytopharmakon Wirkstoff & Nebenwirkungen \\
\hline $\begin{array}{l}\text { Thymian } \\
\text { Spitzwegerich }\end{array}$ & Allergie \\
Drosera & Magen-Darm \\
Wollblumen & Alkoholgehalt beachten \\
\hline
\end{tabular}

Tab. 23 Synthetisch hergestellte Antitussiva

\begin{tabular}{|ll}
\hline Wirkstoff & Nebenwirkung \\
\hline Codein & Suchtpotenz, Atemdepression \\
Dihydrocodein & Obstipation, Übelkeit \\
\hline Dextrometorphan & Obstipation, Übelkeit \\
\hline Clobutinol & Übelkeit \\
\hline Pentoxyverin & Übelkeit, Müdigkeit \\
\hline Noscapin & Kopfschmerzen, Übelkeit \\
\hline
\end{tabular}

Dexometorphan oder Standarddosen bis zu $120 \mathrm{mg}$ Codein/die nicht wirksamer als Plazebo [216-218]. Allerdings hat Plazebo gegenüber „Nichtbehandlung“ beim Husten einen starken Effekt, der auf die zentrale Hustenregulation über endogene Opioide zurückgeführt wird [216]. Zu weiteren, chemisch definierten (Tab. 23) und pflanzlichen (Tab. 22) Antitussiva gibt es nur wenig ältere, methodisch den heutigen Anforderungen nicht entsprechende Literatur. Eine Übersicht zu den teils widersprüchlichen Ergebnissen in Hinblick auf die klinische Wirksamkeit der Antitussiva ist bei [180] zu finden..

\begin{tabular}{|lll}
\hline Nr. Empfehlung: Antitussiva & $\begin{array}{l}\text { Empfeh- } \\
\text { lungsgrad }\end{array}$ & $\begin{array}{l}\text { Evidenz- } \\
\text { grad }\end{array}$ \\
\hline E42 Therapie des akuten Reizhustens mit Antitussiva. & B & $3 a$ \\
\hline
\end{tabular}

\subsection{Hustentherapeutika mit Wirkung am Effektororgan (Muskelrelaxanzien)}

Muskelrelaxanzien des Curaretyps reduzieren bei beatmeten Patienten den Ventilator-induzierten Husten. Über therapeutische Anwendungen von Muskelrelaxanzien liegen nur Angaben über das zentrale Muskelrelaxans Baclofen von einer Arbeitsgruppe vor $[219,220]$. Baclofen ist wirksam in Dosen von $3 \times 10 \mathrm{mg} / \mathrm{die}$, allerdings sind zahlreiche Nebenwirkungen zu beachten, und es liegt keine Zulassung für diese Indikation vor.

\section{Komplikationen des Hustens}

In der Expulsionsphase des Hustens entstehen intrathorakale Drücke bis zu $300 \mathrm{kPa}$. Hierdurch können in den verschiedenen Organsystemen Komplikationen (Tab. 24) auftreten. Die häufigsten Komplikationen eines chronischen Hustens sind alltäglich: 
Tab. 24 Komplikationen des Hustens

Harninkontinenz (bei Frauen)
Heiserkeit
Stechende Brustschmerzen
Auslösung von Asthmaanfällen bei Asthma bronchiale
Konjunktivale Einblutungen
Epistaxis
Gastroösophagealer Reflux
Petechiale Blutungen
Rippenfraktur*
Mediastinalemphysem
Hustensynkope**
Epileptischer Anfall ausgelöst durch Husten**
Ruptur des Zwerchfells [222]
Kopfschmerzen
Leistenhernie
Rectus abdominis Ruptur

* „Spontane“ Rippenfrakturen können Folge von schweren Hustenanfällen sein [223 - 224]; sie treten meist bei Patienten unter systemischer Kortisontherapie auf, oft an der Knochen/Knorpelgrenze. Im letzteren Fall verursachen sie einen lokalen Druckschmerz, sind aber im Röntgenbild nicht sichtbar. Zur Diagnose ist die Knochenszintigraphie geeignet.

Es sollte stets eine pathologische Fraktur (z. B. Knochenmetastasen eines Prostatakarzinoms) ausgeschlossen werden.

** Klinisch problematisch erscheint manchmal die Differenzialdiagnose der Hustensynkope von epileptischen Anfällen, die mit Husten eingeleitet werden (Aura) [226]. Der Patient mit Hustensynkope ist meist adipös-muskulös, leidet an COPD und verliert das Bewusstsein in Rahmen eines Hustenanfalles infolge der intrathorakalen Drucksteigerung, welche den venösen Rückfluss zum Herzen für die Dauer des Hustenstoßes unterbindet und den arteriellen Zufluss zum Gehirn verringert. Die Erhöhung des zentralen Venendruckes pflanzt sich auch intrazerebral fort, es kommt zusätzlich zu einer Stase [225]. Durch Husten kann auch ein atrioventrikulärer Block und dadurch bedingt die Synkope provoziert werden $[44,46]$. Husten als Aura eines epileptischen Anfalles kann hingegen bei jedem Patienten mit zerebralem Krampfleiden (häufig bereits anamnestisch bekannt) auftreten und geht eher mit Hüsteln, denn mit kräftigem Husten, oft bei respiratorisch gesunden Patienten, einher.

Erschöpfung, Schlaflosigkeit, stechende Thoraxschmerzen, Stressinkontinenz der Frau, Heiserkeit, psychische Störungen [221]. Die in der Tab. 24 aufgeführten seltenen Komplikationen basieren auf Kasuistiken und haben den.

\section{Anhang 1}

Teilnehmer des ersten Konsensustreffens am 12. 12. 2002 im Maingau Krankenhaus, Frankfurt am Main:

Dr. Helmut Sitter, Marburg, Leiter der Diskussion (AWMF)

Prof. Dr. Adrian Gillissen, Ko-Autor (Pneumologe, Krankenhausarzt), Leipzig

Dr. Peter Kardos, federführend (niedergelassener Internist und Belegarzt), Frankfurt

Dr. Jens Kleinschmidt, eingeladener Vertreter der Pharmaindustrie (Zambon) Kerpen

Prof. Dr. Ludger Klimek, HNO-ärztlicher Berater (niedergelassener HNO-Arzt), Wiesbaden

Frau Marianne Krohn (Hausfrau, eingeladener Vertreter der Patientenliga e.V.) Frankfurt
Dr. Harald Mitfessel, Ko-Autor (niedergelassener Pneumologe), Remscheid

Prof. Dr. Harald Morr, Ko-Autor (Pneumologe, Krankenhausarzt), Greifenstein

Prof. Dr. Gerhard Schultze-Werninghaus, Ko-Autor (Pneumologe, Krankenhausarzt), Bochum

Dr. Thomas Voshaar, Ko-Autor (Pneumologe, Krankenhausarzt), Moers

Prof. Dr. Heinrich Worth, Ko-Autor, Vertreter der Leitlinienkommission der DGP (Pneumologe, Krankenhausarzt), Fürth

Entschuldigt:

Prof. Dr. V. F. Eckardt, Berater in Gastroenterologie (Gastroenterologe, Deutsche Klinik für Diagnostik, Wiesbaden

Prof. Dr. Detlef Kirsten, Ko-Autor (Pneumologe, Krankenhausarzt), Großhansdorf

Prof. Dr. Claus Vogelmeier, Ko-Autor (Pneumologe, Krankenhausarzt), Marburg

Prof. Dr. Ulrich Cegla, Ko-Autor, (niedergelassener Pneumologe), Dernbach

Teilnehmer des zweiten Konsensustreffens am 20.02.2003 im Maingau Krankenhaus, Frankfurt am Main:

Dr. Helmut Sitter, Marburg

Dr. Hering, Thomas, Vertreter des Berufsverbandes der Pneumologen (niedergelassener Pneumologe), Berlin

Prof. Dr. Adrian Gillissen, Leipzig

Dr. Peter Kardos, Frankfurt

Petra Kirchner (Vertreter des Verbandes der Physiotherapeuten), Frankfurt

Prof. Dr. Detlef Kirsten (Koautor und Vertreter der Leitlinienkommission der DGP), Großhansdorf

Prof. Dr. Ludger Klimek, Wiesbaden

Frau Marianne Krohn, Frankfurt

Dr. Harald Mitfessel, Remscheid

Prof. Dr. Harald Morr, Greifenstein

Prof. Dr. Claus Vogelmeier, Marburg

Dr. Thomas Voshaar, Moers

Prof. Dr. Heinrich Worth, Fürth

Entschuldigt:

Prof. Dr. V. F. Eckardt, Wiesbaden

Prof. Dr. G. Schultze-Werninghaus, Bochum

Prof. Dr. Ulrich Cegla, Dernbach

\section{Anhang 2}

Ableitung von Qualitätsindikatoren aus der Leitlinie Husten

Die vorliegende systematisch entwickelte Leitlinie erfüllt die geforderten formalen und inhaltlichen Anforderungen hinsichtlich ihrer systematischen Entwicklung (Konsensusfindung, Algorithmen, Evidenz). Auch die diagnostischen und therapeutischen Wahrscheinlichkeiten und die Kosteneffektivität sind bei den Empfehlungen berücksichtigt worden. In diesem Anhang 2 werden Vorschläge für mögliche Qualitätskriterien- und -indikatoren genannt, die es erlauben könnten aufgrund einer OutcomeAnalyse Hinweise auf die Qualität der Versorgung in einer medizinischen Einrichtung zu erhalten [227]. 
Husten ist keine eigenständige Krankheit sondern das Symptom der meisten pulmonalen und einiger extrapulmonalen Erkrankungen, die in ihrem subjektiven und objektiven Krankheitswert und in ihrer Prognose stark differieren. Im Gegensatz zu definierten Erkrankungen wie Asthma oder Mammakarzinom lassen sich einheitliche klinische Messgrößen, wie Überlebensrate, Lebensqualität etc. als Qualitätsindikator nicht definieren, da sie in erster Linie von der Grundkrankheit wie Bronchialkarzinom oder Rhinitis abhängig sind. Folgende integrierte klinische Messgrößen sind für die Qualität der Versorgung in einer medizinischen Einrichtung von Patienten mit dem Symptom Husten geeignet:

\section{Zur Überprïfung der Prozessqualität der medizinischen Einrichtung}

- Die Prüfung der Adhärenz zu der Leitlinie gibt Aufschluss über die Prozessqualität der Einrichtung. Dies beinhaltet die Einhaltung der auf Wahrscheinlichkeit, Invasivität der Methode und Kosten/Nutzenanalyse ruhenden vorgeschlagenen Reihenfolge der Untersuchungen für den Regelfall im Rahmen der Diagnostik des Hustens. Begründete Abweichungen hiervon sind zu akzeptieren.

- Die volle Ausschöpfung der diagnostischen Möglichkeiten für ungeklärte Fälle ist im Rahmen der Prüfung der Strukturqualität ebenfalls zu untersuchen (Tab. 25).

Tab. 25 Beispiele für Qualitätsmerkmale für die Beurteilung der Prozessqualität bei Diagnostik des Hustens in einer Einrichtung

\begin{tabular}{|c|c|}
\hline $\begin{array}{l}\text { Stufendiagnostik laut Empfehlung } \\
\text { der Leitlinie }\end{array}$ & Qualitätsmerkmal \\
\hline $\begin{array}{l}\text { bei } C P H \text { vor Einleitung der technischen } \\
\text { Diagnostik ACE-Hemmer absetzen und } \\
\text { Effekt abwarten }\end{array}$ & $\begin{array}{l}\text { \% Anteil der Patienten unter ACE- } \\
\text { Hemmer Medikation, die eine techni- } \\
\text { sche Diagnostik durchliefen }\end{array}$ \\
\hline $\begin{array}{l}\text { bei chronischem Husten ist in beinahe } \\
100 \% \text { eine Thorax-Röntgenaufnahme } \\
\text { erforderlich }\end{array}$ & $\begin{array}{l}\text { \% Anteil der Patienten mit chroni- } \\
\text { schem Husten ohne Röntgen-Thorax }\end{array}$ \\
\hline $\begin{array}{l}\text { Erkrankungen der oberen Atemwege } \\
\text { sind häufig für CPH verantwortlich, ihr } \\
\text { Ausschluss ggf. durch HNO-Untersu- } \\
\text { chung steht am Anfang der Diagnostik }\end{array}$ & $\begin{array}{l}\text { \% Anteil der CPH Patienten mit nega- } \\
\text { tivem Röntgen-Thoraxbild und CT des } \\
\text { Thorax ohne vorherige HNO Unter- } \\
\text { suchung }\end{array}$ \\
\hline $\begin{array}{l}\text { bei } \mathrm{CPH} \text { ist die unspezifische bronchiale } \\
\text { Provokation vor Bronchoskopie emp- } \\
\text { fohlen }\end{array}$ & $\begin{array}{l}\text { \% Anteil der Patienten mit CPH und } \\
\text { Bronchoskopie, ohne vorherige } \\
\text { Provokation }\end{array}$ \\
\hline $\begin{array}{l}\text { bei unklarem chronischen Husten ist } \\
\text { am Ende der Diagnostik immer eine } \\
\text { Bronchoskopie indiziert }\end{array}$ & $\begin{array}{l}\text { \% Anteil der Patienten mit nicht } \\
\text { abgeklärtem chronischem Husten } \\
\text { ohne Bronchoskopie }\end{array}$ \\
\hline
\end{tabular}

\section{Zur Überprïfung der Outcome}

Anmerkung: Die Ergebnisqualität kann nur bei $\mathrm{CPH}$ als homogene Diagnosegruppe erfasst werden. Bei Bronchialkarzinom, Tuberkulose, Pneumonie etc. erfolgt die Outcome-Analyse nicht für den Husten, sondern für die Grunderkrankung.

- Analyse des Therapieerfolges bei CPH (chronisch persistierendem Husten) in \% der diagnostizierten CPH Patienten (Besserung oder Sistieren des Hustens) (Tab. 26).
Tab. 26 Beispiele für Qualitätsmerkmale für die Beurteilung der Ergebnisqualität bei Diagnostik des Hustens in einer Einrichtung

\begin{tabular}{ll}
\hline Outcome-Merkmal & Qualitätsmerkmal \\
\hline $\begin{array}{l}\text { bei adäquater Therapie und Compli- } \\
\text { ance ist ein Therapieerfolg bei CPH } \\
\text { in }>80 \% \text { der Fälle zu erwarten }\end{array}$ & $\begin{array}{l}\text { \% Anteil der Patienten ohne Therapie- } \\
\text { erfolg }\end{array}$ \\
\hline
\end{tabular}

Anhang 3

\section{Zusammenfassung (Abstract) der Leitlinie Husten}

Ziele: Evidenzbasierte Empfehlungen für Ärzte zur Verbesserung der Diagnostik und Therapie des Hustens zu geben.

Erstellung: nach elektronischer Literaturrecherche wurde vom federführenden Autor ein erster Entwurf erstellt und an die von der Leitlinienkommission der Deutschen Gesellschaft für Pneumologie benannten Koautoren (Ärzte verschiedener Fachrichtungen, Vertreter der Fachgesellschaften, Patientenvertreter, Industrievertreter, Physiotherapeutenverband) geschickt. In 2 Konsensustreffen und in Delphi Verfahren sowie nach Begutachtung durch zwei unabhängige Pneumologen entstand die endgültige Version und eine Kurzversion. Eine weitere Version für Patienten liegt vor.

Ergebnisse: Das Symptom Husten wurde als akut oder chronisch klassifiziert und verschiedenen Krankheitsbildern zugeordnet. Diagnostische Algorithmen für die Abklärung des akuten und chronischen Hustens wurden entwickelt, auf die häufigsten Fehler in der Diagnostik und auf Kostengesichtspunkte hingewiesen. Falls eine kausale Therapie nicht möglich oder nicht ausreichend ist, sollte die symptomatische Therapie eingeleitet werden. Therapeutische Maßnahmen wurden nach Wirkungsmechanismus aufgeführt. Komplikationen des Hustens und Vorschläge für das Qualitätsmanagement werden genannt.

Evidenz: Empfehlungsgrad und Nachweisstärke der Effektivität wurden entsprechend dem Centre of Evidence Based Medicine, Oxford, 1999 nach Empfehlungsgraden A, B, C und D sowie Evidenzgraden 1a-c, 2a-c, 3a-b, 4 und 5 zugeordnet.

Nutzen: Die Leitlinie hilft mit ihrer Systematik auch schwer zu diagnostizierende Patienten mit Husten zielgerichtet, beschleunigt und kostensparend abzuklären. Hierdurch wird die Symptomatik und Lebensqualität der betroffenen Patienten zweifelsfrei gebessert, wenngleich hierfür keine evidenzbasierten Daten vorliegen.

Kosten: Kostengesichtspunkte wurden weitestgehend berücksichtigt. Es konnte evidenzbasiert angegeben werden, ab welchem Zeitpunkt nach Auftreten des Hustens eine intensive Diagnostik erforderlich ist und welche Reihenfolge der Untersuchungen aufgrund der Symptome und der Häufigkeit der Ursache am zweckmäßigsten und kostengünstigsten ist. 
Wirksamkeit der Empfehlungen: es ist mit höchster Evidenzgrad belegt, dass die überwältigende Mehrheit der Patienten mit Husten abgeklärt und einer wirksamen Therapie zugeführt werden kann.

Implementierungsplan: Publikationen in Fachzeitschriften für Pneumologen, Internisten HNO- und Allgemeinärzte sowie auf der Internetseite der AWMF, der Fachgesellschaften und der Deutschen Atemwegsliga.

Gültigkeitsdauer: Aktualisierung spätestens nach 3 Jahren.

Fortschreibung: In Verantwortung der Deutschen Gesellschaft für Pneumologie.

Sponsoren: Die Kosten für die Konsensustreffen wurden von der Deutschen Gesellschaft für Pneumologie getragen. Sonstige Kosten (Honorare) wurden nicht gezahlt.

Zusammenfassende Empfehlung: beim akuten Husten genügen in der Regel die Erhebung der Anamnese und die körperliche Untersuchung. Wenn der Husten nach 8 Wochen persistiert, sind eine Röntgenaufnahme der Thoraxorgane und eine Lungenfunktionsuntersuchung indiziert. Hierdurch ergeben sich in der Mehrzahl der Fälle Hinweise für das weitere Vorgehen. Ist dies nicht der Fall, ist eine gezielte weitere Diagnostik der häufigsten drei infrage kommenden Erkrankungen erforderlich: Husten als Asthmaäquivalent, Erkrankungen im Bereich der oberen Atemwege und Husten infolge von gastroösophagealem Reflux.

\section{Literatur}

${ }^{1}$ Gesellschaft für Pädiatrische Pneumologie. Leitlinie der Gesellschaft für Pädiatrische Pneumologie. Husten. Hofmann D http://www. awmf-online.de/, 1998

2 Dt. Ges. f. Hals-Nasen-Ohren-Heilkunde KuH-C. Leitlinie Reizhusten/ Räusperzwang Kinder (Klinischer Algorithmus). HNO-Mitteilungen 1997; 45 (3): 7S - 7S

${ }^{3}$ Irwin RS, Boulet LP, Cloutier MM et al. Managing cough as a defense mechanism and as a symptom. A consensus panel report of the American College of Chest Physicians. Chest 1998; 114 (2): 133S- 181

${ }^{4}$ Society for Medical Decision Making. Committee on standardization of clinical algorithms Proposals for clinical algorithm standards. Med Decis Making 1992; 12: 49-154

${ }^{5}$ Schappert SM. National ambulatory medical care survey: 1991 . Summary 1993; 230: 1-20

${ }^{6}$ Anon Y. Office Visits to Internists: The National Ambulatory Medical Care Survey 1975. Vital and Health Statistics Series 13. 1978; 36: 29

${ }^{7}$ Roche N, Huchon G. Du symptome au diagnostic: toux. Pneumologie 1997; 6- 090 (A-15): 6-6

${ }^{8}$ Kirsten D. Die Top-ten der Pneumologie. Hamburg: Kongress der Deutschen Gesellschaft für Pneumologie 2000

${ }^{9}$ Kanzow G, Kirsten D, Magnussen H. Stufendiagnostik in der Pneumologie am Beispiel der Leitsymptome: Husten, Hämoptysen, Dyspnoe. Internist 1996; 37: $132-139$

${ }^{10}$ Widdicombe JG. Neurophysiology of the cough reflex. Eur Respir J 1995; 8 (7): 1193-1202

${ }^{11}$ Braman SS, Corrao WM. Cough: differential diagnosis and treatment. Clin Chest Med 1987; 8 (2): 177- 188

12 Kardos P. Chronisch persistierender Husten (CHP). Pneumologie 1995; $49(1): 2-13$

${ }^{13}$ Irwin R. Cough. In: Irwin R, Curley F, Grossmann R. Symptoms of the Respiratory Tract. USA: Futura Publishing Company Inc., Armonk, N.Y, 1997; (1): $1-54$
${ }^{14}$ Kohler D, Vastag E. Bronchiale Clearance. Pneumologie 1991; 45 (5): 314-332

${ }^{15}$ Salem H, Aviado D. Antitussive Drugs. Am J Med Sci 1964; 247: $585-600$

${ }^{16}$ Pomerantz M, Braman S. Cough Reflexes in Asthma. Am Rev Respir Dis 1992; A12: 89

17 Sheppard D, Rizk NW, Boushey HA et al. Mechanism of cough and bronchoconstriction induced by distilled water aerosol. Am Rev Respir Dis 1983; 127 (6): 691 -694

${ }^{18}$ Lalloo UG, Barnes PJ, Chung KF. Pathophysiology and clinical presentations of cough. J Allergy Clin Immunol 1996; 98 (5 Pt 2): S91 - S96

${ }^{19}$ Chang AB, Gibson PG. Relationship between cough, cough receptor sensitivity and asthma in children. Pulm Pharmacol Ther 2002; 15 (3): $287-291$

20 Smyrnios NA, Irwin RS, Curley FJ. Chronic Cough with a history of excessive sputum production. The spectrum and frequency of causes, key components of the diagnostic evaluation, and outcome of specific therapy. Chest 1995; 108 (4): $991-997$

${ }^{21}$ Corren J. The Impact of allergic rhinitis on bronchial asthma. J Allergy Clin Immunol 1998; 101 (2 PT 2): S352-S356

22 Poe RH, Israel RH, Utell MJ et al. Chronic Cough: Bronchoscopy or pulmonary function testing? Am Rev Respir Dis 1982; 126 (1): 160-162

${ }^{23}$ Poe RH, Harder RV, Israel RH et al. Chronic Persistent Cough. Experience in Diagnosis and outcome using an anatomic diagnostic protocol. Chest 1989; 95 (4): $723-728$

${ }^{24}$ Holinger LD, Sanders AD. Chronic Cough in infants and children: an update. Laryngoscope 1991; 101 (6 PT 1): 596-605

${ }^{25}$ Mello CJ, Irwin RS, Curley FJ. Predictive Values of the character, timing, and complications of chronic cough in diagnosing its cause. Arch Intern Med 1996; 156 (9): $997-1003$

${ }^{26}$ Kardos P, Gebhardt T. Chronisch persistierender Husten (CPH) in der Praxis: Diagnostik und Therapie bei 329 Patienten in 2 Jahren. Pneumologie 1996; 50 (6): $437-441$

27 Palombini BC, Villanova CA, Araújo E et al. A pathogenic triad in chronic cough: asthma, postnasal drip syndrome, and gastroesophageal reflux disease. Chest 1999; 116 (2): 279-284

${ }^{28}$ Irwin RS, Corrao WM, Pratter MR. Chronic Persistent Cough in the adult: the spectrum and frequency of causes and successful outcome of specific therapy. Am Rev Respir Dis 1981; 123 (4 PT 1): 413 - 417

${ }^{29}$ McGarvey LP, Heaney LG, Lawson JT et al. Evaluation and outcome of patients with chronic non-productive cough using a comprehensive diagnostic protocol. Thorax 1998; 53 (9): $738-743$

${ }^{30}$ Irwin RS, Madison JM. Review Articles Primary Care: The Diagnosis and Treatment of Cough. The New England Journal of Medicine 2000; 343 (23): $1715-1721$

${ }^{31}$ Irwin RS, Madison JM. The Persistently Troublesome Cough. American Journal of Respiratory and Critical Care Medicine 2002; 165 (11): $1469-1474$

32 Macfarlane JT, Colville A, Guion A et al. Prospective study of aetiology and outcome of adult lower-respiratory-tract infections in the community. Lancet 1993; 341 (8844): $511-514$

${ }^{33}$ Arroll B, Kenealy T. Antibiotics for acute bronchitis. BMJ 2001; 322 (7292): 939-940

${ }^{34}$ Heikkinen T, Järvinen A. The common cold. Lancet 2003; 361 (9351): $51-59$

${ }^{35}$ Interdisziplinäre Arbeitsgruppe „Allergische Rhinitis“ der Sektion HNO Allergische Rhinokonjunktivitis. Leitlinie der Deutschen Gesellschaft für Allergologie und klinische Immunologie. Allergo J 2003; 12 (4): $182-194$

36 Wettengel R, Berdel D, Hofmann D et al. Empfehlungen für Asthmatherapie bei Kindern und Erwachsenen. Pneumologie 1998; 52 (11): $591-601$

37 Barber CM, Curran AD, Fishwick D et al. Impaired cough reflex in patients with recurrent pneumonia. Thorax 2003; 58 (7): 645-646

${ }^{38}$ Worth H, Adam D, Handrick W et al. Prevention und Therapie von bronchialen Infektionen. Empfehlungen der Deutschen Atemwegsliga und der Deutschen Gesellschaft für Pneumologie. Pneumologie 1998; 52 (4): 232-237

${ }^{39}$ Stein PD, Willis PW, DeMets DL. History and physical examination in acute pulmonary embolism in patients without preexisting cardiac or pulmonary disease. Am J Cardiol 1981; 47 (2): 218-223

${ }^{40}$ Meissner E, Niedermeyer J, Worth $\mathrm{H}$ et al. Diagnose der akuten Lungenembolie. Empfehlungen der Deutschen Gesellschaft für Pneumologie. Pneumologie 2000; 54 (12): 587-591 
${ }^{41}$ Brunnee T, Graf K, Kastens B et al. Bronchial hyperreactivity in patients with moderate pulmonary circulation overload. Chest 1993; 103 (5): $1477-1481$

42 Pison C, Malo JL, Rouleau JL et al. Bronchial hyperresponsiveness to inhaled methacholine in subjects with chronic left heart failure at a time of exacerbation and after increasing diuretic therapy. Chest 1989; 96 (2): $230-235$

${ }^{43}$ Lee D, Beldner S, Pollaro F et al. Cough-induced heart block. Pacing Clin Electrophysiol 1999; 22 (8): 1270-1271

${ }^{44}$ Baron SB, Huang SK. Cough syncope presenting as Mobitz type Il atrioventricular block - an electrophysiologic correlation. Pacing Clin Electrophysiol 1987; 10 (1 Pt 1): 65-69

45 Saito D, Matsuno S, Matsushita K et al. Cough syncope due to atrioventricular conduction block. Jpn Heart J 1982; 23 (6): 1015-1020

${ }^{46}$ Hart G, Oldershaw PJ, Cull RE et al. Syncope caused by cough-induced complete atrioventricular block. Pacing Clin Electrophysiol 1982; 5 (4): $564-566$

${ }^{47}$ Mitton M. Paroxysmal atrioventricular block in a healthy patient receiving spinal anesthesia: a case report. AANA J 1993; 61 (6): 605-609

${ }^{48}$ Worth H, Buhl R, Cegla U et al. Leitlinie der Deutschen Atemwegsliga und der Deutschen Gesellschaft für Pneumologie zur Diagnostik und Therapie von Patienten mit chronisch obstruktiver Lungenerkrankung (COPD). Pneumologie 2002; 56 (11): $704-738$

${ }^{49}$ Lee JJ, Lin RL, Chen CH et al. Clinical manifestations of bronchogenic carcinoma. J Formos Med Assoc 1992; 91 (2): 146-151

${ }^{50}$ Hyde L, Hyde CI. Clinical manifestations of lung cancer. Chest 1974; 65 (3): 299-306

${ }^{51}$ Saito Y, Nagamoto N, Ota S et al. Results of surgical treatment for roentgenographically occult bronchogenic squamous cell carcinoma. J Thorac Cardiovasc Surg 1992; 104 (2): 401 - 407

52 Thomas M, Gatzemeier U, Goerg R et al. Empfehlungen zur Diagnostik des Bronchialkarzinoms. Pneumologie 2000; 54 (8): 361 - 371

53 Thomas M, Baumann M, Deppermann $\mathrm{M}$ et al. Empfehlungen zur Therapie des Bronchialkarzinoms. Pneumologie 2002; 56 (2): $113-131$

54 Fontana GA, Lavorini F, Pistolesi M. Water aerosols and cough. Pulm Pharmacol Ther 2002; 15 (3): 205-211

55 Ebihara S, Saito H, Kanda A et al. Impaired Efficacy of Cough in Patients With Parkinson Disease. Chest 2003; 124 (3): 1009-1015

${ }^{56}$ Lalloo UG, Lim S, DuBois R et al. Increased sensitivity of the cough reflex in progressive systemic sclerosis patients with interstitial lung disease. Eur Respir J 1998; 11 (3): 702 - 705

57 Spira A, Grossman R, Balter M. Large airway disease associated with inflammatory bowel disease. Chest 1998; 113 (6): 1723-1726

${ }^{58}$ Lengyel C, Boros I, Varkonyi T et al. (Amiodarone-induced pulmonary fibrosis). Orv Hetil 1996; 137 (32): 1759-1762

${ }^{59}$ Imokawa S, Colby TV, Leslie KO et al. Methotrexate pneumonitis: review of the literature and histopathological findings in nine patients. Eur Respir J 2000; 15 (2): 373-381

${ }^{60}$ Strimlan CV, Rosenow EC, Divertie MB et al. Pulmonary manifestations of Sjoegren's syndrome. Chest 1976; 70 (03): 354 - 361

${ }^{61}$ Cain HC, Noble PW, Matthay RA. Pulmonary manifestations of Sjoegren's syndrome. Clin Chest Med 1998; 19 (4): 687 -99, viii

62 Ukena D, Harnest U, Sakalauskas R et al. Comparison of addition of theophylline to inhaled steroid with doubling of the dose of inhaled steroid in asthma. Eur Respir J 1997; 10 (12): 2754-2460

${ }^{63}$ Larson TS, Hall S, Hepper NG et al. Respiratory tract symptoms as a clue to giant cell arteritis. Ann Intern Med 1984; 101 (5): 594-597

${ }^{64}$ Olopade CO, Sekosan M, Schraufnagel DE. Giant Cell Arteritis Manifesting as chronic cough and fever of unknown origin. Mayo Clin Proc 1997; 72 (11): $1048-1050$

${ }^{65}$ Breton JL, Ranfaing E, Depierre A et al. (Bronchial involvement disclosing Wegener's granulomatosis). Rev Mal Respir 1986; 3 (3): $153-155$

${ }^{66}$ Daum TE, Specks U, Colby TV et al. Tracheobronchial involvement in Wegener's granulomatosis. Am J Respir Crit Care Med 1995; 151 (2 Pt 1): $522-526$

${ }^{67}$ Camus P, Piard F, Ashcroft T et al. The lung in inflammatory bowel disease. Medicine (Baltimore) 1993; 72 (3): 151-183

${ }^{68}$ Bargon J, Rust M, Kardos P et al. Salazosulfapyridine-induzierte eosinophile Pneumonie mit pulmonaler und kutaner epitheloidzelliger Granulomatose bei Sjögren syndrome. Pneumologie 1990; 44 (4): $744-750$
${ }^{69}$ Shub C, Alexander BB. Persistent cough - the presenting feature in unsuspected sarcoidosis: a case report. Mil Med 1971; 136 (9): $757-758$

${ }^{70}$ Baughman RP, Iannuzzi MC, Lower EE et al. Use of fluticasone in acute symptomatic pulmonary sarcoidosis. Sarcoidosis Vasc Diffuse Lung Dis 2002; 19 (3): $198-204$

${ }^{71}$ Usalan C, Emri S. Exertional dyspnoea and nonproductive cough in a 22-year-old man. Postgrad Med J 2000; 76 (892): 115-117

72 Kirsten D. Deutsche Gesellschaft für Pneumologie: Empfehlungen für Diagnosis und Therapie der Sarkoidose. Pneumologie 1998; 52 (1): $26-30$

${ }^{73}$ Fink JB. Metered-dose inhalers, dry powder inhalers, and transitions. Respir Care 2000; 45 (6): 623-635

${ }^{74}$ Rapti A, Drossos C, Tzavelas D et al. Mounier-Kuhn syndrome (tracheobronchomegaly). Monaldi Arch Chest Dis 1995; 50 (3): $195-198$

${ }^{75}$ Schwartz M, Rossoff L. Tracheobronchomegaly. Chest 1994; 106 (5): $1589-1590$

${ }^{76}$ Kirchner J, Jacobi V, Kardos P et al. CT findings in extensive tracheobronchial amyloidosis. Eur Radiol 1998; 8 (3): 352 - 354

${ }^{77}$ Molina JF, Espinoza LR. Relapsing polychondritis. Baillieres Best Pract Res Clin Rheumatol 2000; 14 (1): $97-109$

${ }^{78}$ Leske V, Lazor R, Coetmeur D et al. Tracheobronchopathia osteochondroplastica: a study of 41 patients. Medicine (Baltimore) 2001; 80 (6): $378-390$

79 Sutor GC, Glaab T, Eschenbruch C et al. Tracheobronchopathia osteochondroplastica: eine ungewöhnliche Ursache einer Retentionspneumonie. Pneumologie 2001; 55 (12): $563-567$

${ }^{80}$ Sen RP, Walsh TE. Fiberoptic bronchoscopy for refractory cough. Chest 1991; 99 (1): 33-35

81 Walther EK, Herberhold C. Die Behandlung der laryngotrachealen Papillomatose mit kombinierter Laserchirurgie und localer Administration von $\alpha$-Interferon (Roferon). Laryngorhinootologie 1993; 72 (10): $485-491$

82 Guillou L, Sahli R, Chaubert P et al. Squamous cell carcinoma of the lung in a nonsmoking, nonirradiated patient with juvenile laryngotracheal papillomatosis. Evidence of human papillomavirus-11 DNA in both carcinoma and papillomas. Am J Surg Pathol 1991; 15 (9): $891-898$

83 Sweriduk ST, DeLuca SA. Juvenile laryngotracheal papillomatosis. Am Fam Physician 1986; 33 (4): 155-156

${ }^{84}$ Schonhofer B, Voshaar T, Kohler D. Long-term lung sequelae following accidental chlorine gas exposure. Respiration 1996; 63 (3): $155-159$

${ }^{85}$ Brooks SM, Weiss MA, Bernstein IL. Reactive airways dysfunction syndrome (RADS). Persistent asthma syndrome after high level irritant exposures. Chest 1985; 88 (3): 376-384

${ }^{86}$ Brooks SM, Hammad Y, Richards I et al. The spectrum of irritant-induced asthma: sudden and not-so-sudden onset and the role of allergy. Chest 1998; 113 (1): $42-49$

${ }^{87}$ Christopher KL, Wood RP, Eckert RC et al. Vocal-cord dysfunction presenting as asthma. N Engl J Med 1983; 308 (26): 1566-1570

${ }^{88}$ Newman KB, Mason UG, Schmaling KB. Clinical features of vocal cord dysfunction. Am J Respir Crit Care Med 1995; 152 (4 Pt 1): $1382-1386$

${ }^{89}$ Thomas PS, Geddes DM, Barnes PJ. Pseudo-steroid resistant asthma. Thorax 1999; 54 (4): 352-356

${ }^{90}$ Kenn K, Schmitz M. Vocal cord dysfunction, eine wichtige Differenzialdaignose des schweren Asthma bronchiale. Pneumologie 1997; 51 (1): $14-18$

${ }^{91}$ Ip MS, So SY, Lam WK et al. Endobronchial tuberculosis revisited. Chest 1986; 89 (5): 727-730

${ }^{92}$ Lee JH, Park SS, Lee DH et al. Endobronchial tuberculosis. Clinical and bronchoscopic features in 121 cases (published erratum appears in Chest 1993; 103 (5): 1640). Chest 1992; 102 (4): 990-994

93 Pierson DJ, Lakshminarayan S, Petty TL. Endobronchial tuberculosis. Chest 1973; 64 (4): 537-539

${ }^{94}$ Schaberg T, Forssbohm M, Hauer B et al. Richtlinien zur medikamentösen Behandlung der Tuberkulose im Erwachsenen- und Kindesalter. Pneumologie 2001; 55 (11): 494-511

${ }^{95}$ Wright SW, Edwards KM, Decker MD et al. Pertussis infection in adults with persistent cough. JAMA 1995; 273 (13): 1044-1046

${ }^{96}$ Birkebaek NH, Kristiansen M, Seefeldt T et al. Bordetella pertussis and chronic cough in adults. Clin Infect Dis 1999; 29 (5): 1239-1242 
${ }^{97}$ Jackson LA, Cherry JD, Wang SP et al. Frequency of serological evidence of Bordetella infections and mixed infections with other respiratory pathogens in university students with cough illnesses. Clin Infect Dis 2000; 31 (1): 3-6

${ }^{98}$ Vincent JM, Cherry JD, Nauschuetz WF et al. Prolonged afebrile nonproductive cough illnesses in American soldiers in Korea: a serological search for causation. Clin Infect Dis 2000; 30 (3): 534-539

${ }^{99}$ Martin L, Gustaferro C. Chronic Cough Associated With Subacute Bacterial endocarditis. Mayo Clin Proc 1995; 70 (7): 662 - 664

${ }^{100}$ Irwin RS, Rosen MJ, Braman SS. Cough. A comprehensive review. Arch Intern Med 1977; 137 (9): 1186-1191

101 Irwin RS, Curley FJ, French CL. Chronic Cough. The Spectrum And Frequency of causes, key components of the diagnostic evaluation, and outcome of specific therapy. Am Rev Respir Dis 1990; 141 (3): 640-647

${ }^{102}$ Holinger LD. Chronic Cough In Infants And Children. Laryngoscope 1986; 96 (3): 316 - 322

${ }^{103}$ Federspil P. Antibiotische Therapie von Infektionen im Bereich von Kopf und Hals. Deutsche Gesellschaft für Hals-, Nasen-, Ohrenheilkunde, Kopf- und Halschirurgie. Laryngorhinootologie 2000; 79 (6): 366-377

${ }^{104}$ Dt. Ges. f. Hals-Nasen-Ohren-Heilkunde KuH-C. Leitlinie Reizhusten/ Räusperzwang Erwachsene (Klinischer Algorithmus). HNO-Mitteilungen 1997; 47 (3): $6 S-6 S$

105 Berg P, Wehrli R, Medici TC. Asthmahusten. Das monosymptomatische Bronchialasthma in Form von chronischem Husten. Dtsch Med Wochenschr 1986; 111 (45): 1730-1731

106 Connell EJ, Rojas AR, Sachs MI. Cough-type asthma: a review. Ann Allergy 1991; 66 (4): 278-282, 285

107 Corrao WM, Braman SS, Irwin RS. Chronic Cough as the sole presenting manifestation of bronchial asthma. N Engl J Med 1979; 300 (12): 633-637

${ }^{108}$ Frans A, Eeckhaut J Van Den. Cough as the sole manifestation of airway hyperreactivity. J Laryngol Otol 1989; 103 (7): 680-682

109 Johnson D, Osborn LM. Cough Variant Asthma: A review of the clinical literature. J Asthma 1991; 28 (2): 85-90

110 Nowak D, Heinrich J, Jorres R et al. Prevalence of respiratory symptoms, bronchial hyperresponsiveness and atopy among adults: west and east Germany. Eur Respir J 1996; 9 (12): 2541 - 2552

111 Sears MR, Jones DT, Holdaway MD et al. Prevalence of bronchial reactivity to inhaled methacholine in New Zealand children. Thorax 1986; 41 (4): 283-289

112 Dicpinigaitis P. Zafirlukast in cough-variant asthma. J Asthma 2002; 39: $291-297$

113 Fujimura M, Ogawa H, Nishizawa Y et al. Comparison of atopic cough with cough variant asthma: is atopic cough a precursor of asthma? Thorax 2003; 58 (1): $14-18$

${ }^{114}$ Hollenz M, Stolte M, Labenz J. Prevalänz des gastro-ösophagealen Refluxes in der Allgemeinpraxis. Dtsch Med Wochenschr 2002; 127 (19): $1007-1012$

115 Peterson W. Improving the Management of GERD. Evidence-based therapeutic strategies. American Gastroenterological Association Consensus Development Panel. AGA Edition, 2002

${ }^{116}$ Marchesani F, Cecarini L, Pela R et al. Causes of chronic persistent cough in adult patients: the results of a systematic management protocol. Monaldi Arch Chest Dis 1998; 53 (5): 510-514

117 Schnatz PF, Castell JA, Castell DO. Pulmonary symptoms associated with gastroesophageal reflux: use of ambulatory $\mathrm{pH}$ monitoring to diagnose and to direct therapy. Am J Gastroenterol 1996; 91 (9): $1715-1718$

118 Paterson WG, Murat BW. Combined ambulatory esophageal manometry and dual-probe $\mathrm{pH}$-metry in evaluation of patients with chronic unexplained cough. Dig Dis Sci 1994; 39 (5): 1117- 1125

119 Ing AJ, Ngu MC, Breslin AB. Chronic Persistent Cough And Gastro-oesophageal Reflux. Thorax 1991; 46 (7): 479-483

${ }^{120}$ Koufman JA. The otolaryngologic manifestations of gastroesophageal reflux disease (GERD): a clinical investigation of 225 patients using ambulatory 24-hour pH monitoring and an experimental investigation of the role of acid and pepsin in the development of laryngeal injury. Laryngoscope 1991; 101 (4 Pt 2 Suppl 53): 1-78

${ }^{121}$ Poe RH, Kallay MC. Chronic Cough and Gastroesophageal Reflux Disease: Experience With Specific Therapy for Diagnosis and Treatment. Chest 2003; 123 (3): 679-684
122 Schmidt D, Jorres RA, Magnussen H. Citric acid-induced cough thresholds in normal subjects, patients with bronchial asthma, and smokers. Eur J Med Res 1997; 2 (9): 384 - 388

${ }^{123}$ Avidan B, Sonnenberg A, Schnell TG et al. Temporal associations between coughing or wheezing and acid reflux in asthmatics. Gut 2001; 49 (6): $767-772$

${ }^{124}$ Harding SM, Guzzo MR, Richter JE. 24-h esophageal pH-testing in asthmatics: respiratory symptom correlation with esophageal acid events. Chest 1999; 115 (3): 654-659

${ }^{125}$ Irwin RS, French CL, Curley FJ et al. Chronic Cough Due To Gastroesophageal Reflux. Clinical, diagnostic, and pathogenetic aspects (see comments). Chest 1993; 104 (5): $1511-1517$

126 Ours TM, Kavuru MS, Schilz RJ et al. A prospective evaluation of esophageal testing and a double-blind, randomized study of omeprazole in a diagnostic and therapeutic algorithm for chronic cough. Am J Gastroenterol 1999; 94 (11): 3131 - 3138

127 Jaspersen D, Diehl KL, Weber R. Diagnostischer Omeprazoltest be Verdacht auf refluxassoziierten chronisch persistierenden Husten. Pneumologie 1999; 53 (3): S64-S64

128 Vaezi MF, Richter JE. Twenty-four-hour Ambulatory Esophageal PH Monitoring In the diagnosis of acid reflux-related chronic cough. South Med J 1997; 90 (3): 305-311

129 Lazenby JP, Harding SM. Chronic cough, asthma, and gastroesophageal reflux. Curr Gastroenterol Rep 2000; 2 (3): 217-223

${ }^{130}$ Fraser AG, Morton RP, Gillibrand J. Presumed laryngo-pharyngeal reflux: investigate or treat? J Laryngol Otol 2000; 114 (6): 441 - 447

131 Leite LP, Johnston BT, Just RJ et al. Persistent acid secretion during omeprazole therapy: a study of gastric acid profiles in patients demonstrating failure of omeprazole therapy. Am J Gastroenterol 1996; 91 (8): $1527-1531$

132 Katzka DA, Paoletti V, Leite L et al. Prolonged ambulatory pH monitoring in patients with persistent gastroesophageal reflux disease symptoms: testing while on therapy identifies the need for more aggressive anti-reflux therapy. Am J Gastroenterol 1996; 91 (10): $2110-2113$

${ }^{133}$ Johnston BT, Gideon RM, Castell DO. Excluding gastroesophageal reflux disease as the cause of chronic cough. J Clin Gastroenterol 1996; 22 (3): $168-169$

134 Irwin RS. Silencing chronic cough. Hosp Pract (Off Ed) 1999; 34 (1): $53-30$

${ }^{135}$ Irwin RS, Zawacki JK, Wilson MM et al. Chronic cough due to gastroesophageal reflux disease: failure to resolve despite total/near-total elimination of esophageal acid. Chest 2002; 121 (4): $1132-1140$

${ }^{136}$ Novitsky YW, Zawacki JK, Irwin RS et al. Chronic cough due to gastroesophageal reflux disease: efficacy of antireflux surgery. Surg Endosc 2002; 16 (4): 567-571

${ }^{137}$ McGarvey LP, Forsythe P, Heaney LG et al. Bronchoalveolar lavage findings in patients with chronic nonproductive cough. Eur Respir J 1999; 13 (1): 59-65

138 Lee SY, Cho JY, Shim JJ et al. Airway inflammation as an assessment of chronic nonproductive cough. Chest 2001; 120 (4): 1114-1120

139 Nelson S, Summer WR, Mason CM. The role of the inflammatory response in chronic bronchitis: therapeutic implications. Semin Respir Infect 2000; 15 (1): 24-31

${ }^{140}$ Kanner RE, Connett JE, Williams DE et al. Effects of randomized assignment to a smoking cessation intervention and changes in smoking habits on respiratory symptoms in smokers with early chronic obstructive pulmonary disease: the Lung Health Study. Am J Med 1999; 106 (4): 410-416

${ }^{141}$ Krzyzanowski M, Robbins DR, Lebowitz MD. Smoking cessation and changes in respiratory symptoms in two populations followed for 13 years. Int J Epidemiol 1993; 22 (4): 666-673

142 Tashkin DP, Clark VA, Coulson AH et al. The UCLA population studies of chronic obstructive respiratory disease. VIII. Effects of smoking cessation on lung function: a prospective study of a free-living population. Am Rev Respir Dis 1984; 130 (5): 707 - 715

${ }^{143}$ Kastelik JA, Jackson W, Davies TW et al. Measurement of Gastric Emptying in Gastroesophageal Reflux-Related Chronic Cough. Chest 2002; 122 (6): 2038-2041

${ }^{144}$ Fujimoto T, Hillejan L, Stamatis G. Current strategy for surgical management of bronchiectasis. The Annals of Thoracic Surgery 2001; 72 (5): $1711-1715$

145 Kutlay H, Cangir AK, Enon S et al. Surgical treatment in bronchiectasis: analysis of 166 patients. European Journal of Cardio-Thoracic Surgery $2002 ; 21$ (4): $634-637$ 
${ }^{146}$ Agasthian T, Deschamps C, Trastek VF et al. Surgical Management of Bronchiectasis. The Annals of Thoracic Surgery 1996; 62 (4): 976-978

147 Prieto D, Bernardo J, Matos MJ et al. Surgery for bronchiectasis. European Journal of Cardio-Thoracic Surgery 2001; 20 (1): 19-24

148 Morice AH, Lowry R, Brown MJ et al. Angiotensin-converting enzyme and the cough reflex. Lancet 1987; 2 (8568): 1116-1118

${ }^{149}$ Fuller RW. Cough provocation tests: their clinical value. Pulm Pharmacol Ther 2002; 15 (3): 273-276

150 Birring SS, Brightling C, Symon F et al. Idiopathic chronic cough: association with organ specific autoimmune disease and bronchoalveolar lymphocytosis. Thorax 2003; 58: 1066-1070

151 Lee PC, Cotterill J, Eccles R. Voluntary control of cough. Pulm Pharmacol Ther 2002; 15 (3): 317-320

152 French C, Irwin RS, Curley FG et al. Impact of chronic cough on quality of life. Arch Intern Med 1998; 158 (15): 1657- 1661

${ }^{153}$ Choudry NO, Fuller RW, Pride NB. Sensitivity of the human cough reflex: effect of inflammatory mediators prostaglandin E2, bradykinin, and histamine. Am Rev Respir Dis 1989; 140 (1): 137-141

${ }^{154}$ Israili ZH, Hall WD. Cough and angioneurotic edema associated with angiotensin-converting enzyme inhibitor therapy. A review of the literature and pathophysiology. Ann Intern Med 1992; 117 (3): $234-242$

155 Lacourciere Y, Brunner H, Irwin R et al. Effects of modulators of the renin-angiotensin-aldosterone system on cough. Losartan Cough Study Group. J Hypertens 1994; 12 (12): 1387-1393

${ }^{156}$ Imaizumi H, Kaneko M, Mori K et al. Reversible acquired tracheobronchomalacia of a combined crescent type and saber-sheath type. J Emerg Med 1995; 13 (1): 43-49

157 Gibson PG, Dolovich J, Denburg J et al. Chronic Cough: Eosinophilic Bronchitis Without Asthma. Lancet 1989; 1 (8651): 1346-1348

158 Kardos P. Eosinophile Bronchitis ohne Asthma: eine weitere seltene Ursache für chronisch persistierenden Husten? Pneumologie 2001; 55 (5): $249-252$

${ }^{159}$ Kujat A, Gillissen A, Zuber MA. Genetische Diagnose und Beratung bei Bronchiektasie. Erstdiagnose der zystischen Fibrose bei Erwachsenen. Dtsch Med Wochenschr 2002; 127 (10): $501-502$

${ }^{160}$ Macfarlane J, Holmes W, Gard P et al. Prospective study of the incidence, aetiology and outcome of adult lower respiratory tract illness in the community. Thorax 2001; 56: 109-104

161 Verheij TJ, Hermans J, Mulder JD. Effects of doxycycline in patients with acute cough and purulent sputum: a double blind placebo controlled trial. Br J Gen Pract 1994; 44 (386): 400 - 404

162 Morice AH, Widdicombe J, Dicpinigaitis P et al. Understanding cough. Eur Respir J 2002; 19 (1): 6 - 7

163 Mortensen J, Falk M, Groth S et al. The effects of postural drainage and positive expiratory pressure physiotherapy on tracheobronchial clearance in cystic fibrosis. Chest 1991; 100 (5): 1350-1357

164 Gosselink R. Therapie, Training, Tests. van den Berg F. Angewandte Physiologie 2001; (3): 275-276

165 Hardy KA, Anderson BD. Noninvasive clearance of airway secretions. Respir Care Clin N Am 1996; 2 (2): 323 - 345

166 Jones A, Rowe B. Bronchopulmonary hygiene physical therapy for chronic obstructive pulmonary disease and bronchiectasis. The Cochrane Library 2002; 2: Letzte update 01.2003

${ }^{167}$ Rubin BK. The pharmacologic approach to airway clearance: mucoactive agents. Respir Care 2002; 47 (7): 818-822

168 Mazzocco MC, Owens GR, Kirilloff LH et al. Chest percussion and postural drainage in patients with bronchiectasis. Chest 1985; 88 (3): $360-363$

169 Gallon A. Evaluation of chest percussion in the treatment of patients with copious sputum production. Respir Med 1991; 85 (1): 45 - 51

170 Sutton PP, Lopez V, Pavia D et al. Assessment of percussion, vibratoryshaking and breathing exercises in chest physiotherapy. Eur J Respir Dis 1985; 66 (2): 147-152

171 Sutton PP, Parker RA, Webber BA et al. Assessment of the forced expiration technique, postural drainage and directed coughing in chest physiotherapy. Eur J Respir Dis 1983; 64 (1): $62-68$

172 Lannefors L, Wollmer P. Mucus clearance with three chest physiotherapy regimes in cystic fibrosis: a comparison between postural drainage, PEP and physical exercise. Eur Respir J 1992; 5 (6): $748-753$

173 Miller S, Hall DO, Clayton CB et al. Chest physiotherapy in cystic fibrosis: a comparative study of autogenic drainage and the active cycle of breathing techniques with postural drainage. Thorax 1995; 50 (2): $165-169$

${ }^{174}$ Lauber B, Lauber J. Krankengymnastische Atemtherapie. Nolte D Manuale Pneumologicum 1992; (IV-12): 7

175 Cegla UH, Retzow A. Physiotherapy mit VRP1 bei chronisch obstruktiven Atemwegserkrankungen. Ergebnisse einer multizentrischen Vergleichsstudie. Pneumologie 1993; 47 (11): 636-639

176 Thompson CS, Harrison S, Ashley J et al. Randomised crossover study of the Flutter device and the active cycle of breathing technique in non-cystic fibrosis bronchiectasis. Thorax 2002; 57 (5): 446 - 448

177 Cegla UH, Bautz M, Frode G et al. Physiotherapie bei Patienten mt COPD und tracheobronchialer Instabilität. Vergleich von zwei oszillierenden PEP Systemen (RC-Cornet, VRP1 Desitin). Ergebnisse einer randomisierten, prospektiven Studie mit 90 Patienten. Pneumologie 1997; 51 (2): 129-136

${ }^{178}$ Hausen T. Therapie von obstruktiven Atemwegserkrankungen. MMW-Fortschr Med 1991; 46: 700-703

${ }^{179}$ Lurie A, Mestiri M, Huchon G et al. Methods for clinical assessment of expectorants: a critical review. Int J Clin Pharmacol Res 1992; 12 (1): 47-52

180 Gillissen A, Tasci S, Ewig S et al. Sinn und Unsinn von Antitussiva. Internist (Berl) 2001; 42 (1): 134 - 142

${ }^{181}$ Rubin BK. The pharmacologic approach to airway clearance: mucoactive agents. Respir Care 2002; 47 (7): 818-822

182 Schroeder K, Fahey T. Systematic review of randomised controlled trials of over the counter cough medicines for acute cough in adults. BMJ 2002; 324 (7333): 329

183 Ziment I. Herbal antitussives. Pulm Pharmacol Ther 2002; 15 (3): $327-333$

${ }^{184}$ Köhler D. Inhalationstherapie bei chronischer Schleimretention. Pneumologie 1990; 44 (10): 1166 - 1170

${ }^{185}$ Haidl P, Schonhofer B, Siemon K et al. Inhaled isotonic alkaline versus saline solution and radioaerosol clearance in chronic cough. Eur Respir J 2000; 16 (6): $1102-1108$

186 Laube BL, Auci RM, Shields DE et al. Effect of rhDNase on airflow obstruction and mucociliary clearance in cystic fibrosis. Am J Respir Crit Care Med 1996; 153 (2): 752 - 760

187 Robinson PJ. Dornase alfa in early cystic fibrosis lung disease. Pediatr Pulmonol 2002; 34 (3): 237-241

188 Ghafouri MA, Patil KD, Kass I. Sputum changes associated with the use of ipratropium bromide. Chest 1984; 86 (3): 387-393

${ }^{189}$ Holmes PW, Barter CE, Pierce RJ. Chronic persistent cough: use of ipratropium bromide in undiagnosed cases following upper respiratory tract infection. Respir Med 1992; 86 (5): 425-429

${ }^{190}$ Lowry R, Wood A, Johnson T et al. Antitussive properties of inhaled bronchodilators on induced cough. Chest 1988; 93 (6): 1186-1189

${ }^{191}$ Higenbottam TW. Anticholinergics and cough. Postgrad Med J 1987; 63 Suppl 1: $75-78$

192 Shore SC, Weinberg EG. Ipratropium bromide inhalation for allergic rhinitis and chronic cough. S Afr Med J 1981; 59 (8): 252 - 252

193 Tay HL, Armoogum N, Tan LK. Nasal mucociliary clearance and salmeterol. Clin Otolaryngol 1997; 22 (1): 68 - 70

194 Mortensen J, Lange P, Nyboe J et al. Lung mucociliary clearance. Eur J Nucl Med 1994; 21 (9): 953 -961

195 Hueston W. A comparison of albuterol and erythromycin for the treatment of acute bronchitis. J Fam Pract 1991; 33 (5): 476 - 480

${ }^{196}$ Smucny JJ, Flynn CA, Becker LA et al. Are $\beta_{2}$-agonists effective treatment for acute bronchitis or acute cough in patients without underlying pulmonary disease? A systematic review. J Fam Pract 2001; 50 (11): $945-951$

197 Curley FJ, Irwin RS, Pratter MR et al. Cough and the common cold. Am Rev Respir Dis 1988; 138 (2): 305-311

198 Corrao WM. Chronic Persistent Cough: Diagnosis and treatment update. Pediatr Ann 1996; 25 (3): 162 - 168

199 Pratter MR, Bartter T, Akers S et al. An Algorithmic approach to chronic cough. Ann Intern Med 1993; 119 (10): 977-983

${ }^{200}$ Angrill J, Agusti C, De Celis R et al. Bronchial Inflammation and Colonization in Patients with Clinically Stable Bronchiectasis. American Journal of Respiratory and Critical Care Medicine 2001; 164 (9): $1628-1632$

${ }^{201}$ Schaefer O, Irwin R. Chronic cough due to clinically silent suppurative disease of the airways: a new clinical entity (abstract). Am J Respir Crit Care Med 1999; 159 (Part 2): A830

202 Barker AF, Couch LESL, Fiel SB et al. Tobramycin Solution for Inhalation Reduces Sputum Pseudomonas aeruginosa Density in Bron- 
chiectasis. American Journal of Respiratory and Critical Care Medicine 2000; 162 (2): 481 - 485

${ }^{203}$ Ramsey BW, Pepe MS, Quan JM et al. Intermittent administration of inhaled tobramycin in patients with cystic fibrosis. Cystic Fibrosis Inhaled Tobramycin Study Group. The New England Journal of Medicine 1999; 340 (1): $23-30$

${ }^{204}$ Kalliomaki M, Salminen S, Arvilommi $\mathrm{H}$ et al. Probiotics in primary prevention of atopic disease: a randomised placebo-controlled trial. Lancet 2001; 357 (9262): 1076-1079

205 Tamm M, Eich C, Frei R et al. Inhalierbares Colistin bei zystischer Fibrose. Schweiz Med Wochenschr 2000; 130 (39): 1366-1372

${ }^{206}$ Laitinen LA, Laitinen A, Haahtela T. A comparative study of the effects of an inhaled corticosteroid, budesonide, and a $\beta_{2}$-agonist, terbutaline, on airway inflammation in newly diagnosed asthma: a randomized, double-blind, parallel-group controlled trial. J Allergy Clin Immunol 1992; 90 (1): $32-42$

${ }^{207}$ Higenbottam T. Cough induced by changes of ionic composition of airway surface liquid. Bull Eur Physiopathol Respir 1984; 20 (6): $553-562$

${ }^{208}$ Chan PW, Debruyne JA. Inhaled nedocromil sodium for persistent cough in children. Med J Malaysia 2001; 56 (4): 408 - 413

209 Young IH. Nedocromil sodium (Tilade) metered aerosol in the treatment of chronic cough. Med J Aust 1996; 164 (12): 755-755

${ }^{210}$ Moroni M, Porta C, Gualtieri G et al. Inhaled sodium cromoglycate to treat cough in advanced lung cancer patients. Br J Cancer 1996; 74 (2): 309-311

211 Dicpinigaitis PV, Dobkin JB, Reichel J. Antitussive effect of the leukotriene receptor antagonist zafirlukast in subjects with cough-variant asthma. J Asthma 2002; 39 (4): $291-297$

212 Hansson L, Midgren B, Karlsson JA. Effects of inhaled lignocaine and adrenaline on capsaicin-induced cough in humans. Thorax 1994; 49 (11): $1166-1168$

213 Karlsson JA. Airway anaesthesia and the cough reflex. Bull Eur Physiopathol Respir 1987; 23 Suppl 10: 29s - 36s
${ }^{214}$ Fuller RW, Jackson DM. Physiology and treatment of cough. Thorax 1990; 45 (6): $425-430$

${ }^{215}$ Fuller RW, Karlsson JA, Choudry NB et al. Effect of inhaled and systemic opiates on responses to inhaled capsaicin in humans. J Appl Physiol 1988; 65 (3): 1125-1130

${ }^{216}$ Eccles R. The powerful placebo in cough studies? Pulm Pharmacol Ther 2002; 15 (3): $303-308$

217 Taylor JA, Novack AH, Almquist JR et al. Efficacy of cough suppressants in children. J Pediatr 1993; 122 (5 Pt 1): 799-802

${ }^{218}$ Eccles R, Morris S, Jawad M. Lack of effect of codeine in the treatment of cough associated with acute upper respiratory tract infection. J Clin Pharm Ther 1992; 17 (3): 175 - 180

${ }^{219}$ Dicpinigaitis PV, Rauf K. Treatment of chronic, refractory cough with baclofen. Respiration 1998; 65 (1): 86-88

${ }^{220}$ Dicpinigaitis PV, Dobkin JB. Antitussive effect of the GABA-agonist baclofen. Chest 1997; 111 (4): $996-999$

${ }^{221}$ Irwin RS, Curley FJ. The treatment of cough. A comprehensive review. Chest 1991; 99 (6): 1477

${ }^{222}$ George L, Rehman SU, Khan FA. Diaphragmatic rupture: A complication of violent cough. Chest 2000; 117 (4): 1200-1201

${ }^{223}$ Prasad S, Baur LA. Fracture of the first rib as a consequence of pertussis infection. J Paediatr Child Health 2001; 37 (1): 91 -93

${ }^{224}$ De Maeseneer M, De Mey J, Debaere C et al. Rib fractures induced by coughing: an unusual cause of acute chest pain. Am J Emerg Med 2000; 18 (2): $194-197$

225 Mattle HP, Nirkko AC, Baumgartner RW et al. Transient cerebral circulatory arrest coincides with fainting in cough syncope. Neurology 1995; 45 (3 Pt 1): $498-501$

${ }^{226}$ Tanaka T, Inoue $\mathrm{H}$, Aizawa $\mathrm{H}$ et al. Case of cough syncope with seizure. Respiration 1994; 61 (1): 48-50

${ }^{227}$ Kopp I, Müller W, Lorenz W. Die zentrale Rolle von Outcome in Leitlinien und Disease-Management Programmen. 8. Rundbrief. AWMF online, 2003: 1 - 10 